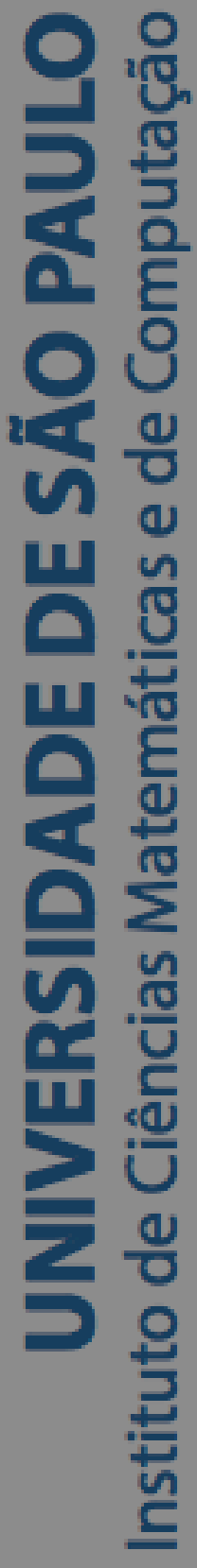

\title{
Avaliação de qualidade em aplicativos educacionais móveis
}

\section{Gustavo Willians Soad}

Dissertação de Mestrado do Programa de Pós-Graduação em Ciências de Computação e Matemática Computacional (PPG-CCMC) 

SERVIÇO DE PÓS-GRADUAÇÃO DO ICMC-USP

Data de Depósito:

Assinatura:

\section{Gustavo Willians Soad}

\section{Avaliação de qualidade em aplicativos educacionais móveis}

Dissertação apresentada ao Instituto de Ciências Matemáticas e de Computação - ICMC-USP, como parte dos requisitos para obtenção do título de Mestre em Ciências - Ciências de Computação e Matemática Computacional. VERSÃO REVISADA

Área de Concentração: Ciências de Computação e Matemática Computacional

Orientadora: Profa. Dra. Ellen Francine Barbosa 
Ficha catalográfica elaborada pela Biblioteca Prof. Achille Bassi e Seção Técnica de Informática, ICMC/USP, com os dados fornecidos pelo(a) autor(a)

\begin{tabular}{|c|c|}
\hline \multirow[t]{3}{*}{ s676a } & $\begin{array}{l}\text { Soad, Gustavo Willians } \\
\quad \text { Avaliação de qualidade em aplicativos } \\
\text { educacionais móveis / Gustavo Willians Soad; } \\
\text { orientadora Ellen Francine Barbosa. -- São Carlos, } \\
2017 \text {. } \\
\quad 147 \text { p. }\end{array}$ \\
\hline & $\begin{array}{l}\text { Dissertação (Mestrado - Programa de Pós-Graduação } \\
\text { em Ciências de Computação e Matemática } \\
\text { Computacional) -- Instituto de Ciências Matemáticas } \\
\text { e de Computação, Universidade de São Paulo, } 2017 \text {. }\end{array}$ \\
\hline & $\begin{array}{l}\text { 1. Aprendizagem Móvel. 2. Aplicativos } \\
\text { Educacionais Móveis. 3. Avaliação de Qualidade. } 4 . \\
\text { Qualidade de Software. I. Barbosa, Ellen Francine, } \\
\text { orient. II. Título. }\end{array}$ \\
\hline
\end{tabular}




\section{Gustavo Willians Soad}

\section{Quality evaluation of mobile learning applications}

Master dissertation submitted to the Instituto de Ciências Matemáticas e de Computação - ICMCUSP, in partial fulfillment of the requirements for the degree of the Master Program in Computer Science and Computational Mathematics. FINAL VERSION

Concentration Area: Computer Science and Computational Mathematics

Advisor: Profa. Dra. Ellen Francine Barbosa 

Aos meus pais, meu irmão, amigos e toda a minha família pelo apoio durante toda a vida.

Também dedico a minha noiva que sempre me incentivou a seguir os meus sonhos. 

A Deus, por ter me acompanhado em todos os momentos de minha vida.

Aos meus pais, José e Angela, meu irmão Bruno e toda minha família pelo apoio que me deram durante os estudos.

A minha noiva Nathalie, por sempre me incentivar a seguir os meus sonhos.

A Walter Franco de Souza, por compartilhar comigo sua sabedoria.

Aos todos os amigos da pós-graduação, que estiveram comigo durante o período do mestrado.

A minha orientadora Profa. Dra. Ellen Francine Barbosa, por seus conselhos e ensinamentos e principalmente por ter acreditado no meu potencial para conclusão deste trabalho.

Por fim, agradeço também aos demais professores do ICMC/USP, que contribuíram para minha formação. 



\section{RESUMO}

SOAD, G. W. Avaliação de qualidade em aplicativos educacionais móveis. 2017. 147 p. Dissertação (Mestrado em Ciências - Ciências de Computação e Matemática Computacional) - Instituto de Ciências Matemáticas e de Computação, Universidade de São Paulo, São Carlos - SP, 2017.

Estudos indicam que a utilização de aplicativos educacionais móveis vêm crescendo continuamente, possibilitando a alunos e professores maior flexibilidade e comodidade na execução de atividades e práticas educacionais. Embora várias instituições já tenham aderido à modalidade de aprendizagem móvel (m-learning), sua adoção ainda traz problemas e desafios organizacionais, culturais e tecnológicos. Um destes problemas consiste em como avaliar adequadamente a qualidade dos aplicativos educacionais desenvolvidos. De fato, os métodos existentes para avaliação da qualidade de software ainda são muito genéricos, não contemplando aspectos específicos aos contextos pedagógico e móvel. Nesse cenário, o presente trabalho apresenta o método MoLEva, desenvolvido para avaliar a qualidade de aplicativos educacionais móveis. O método tem como base a norma ISO/IEC 25000, sendo composto por: (i) modelo de qualidade; (ii) métricas; e (iii) critérios de julgamento. Para validar o método, foram realizados dois estudos de caso; o primeiro consistiu na aplicação do MoLEva para avaliar o aplicativo do ENEM; o segundo consistiu na aplicação do método para avaliação de aplicativos para o ensino de idiomas. A partir dos resultados obtidos, foi possível identificar problemas e pontos de melhoria nos aplicativos avaliados. Além disso, os estudos de caso conduzidos forneceram bons indicativos a respeito da viabilidade de uso do método MoLEva na avaliação de aplicativos educacionais móveis.

Palavras-chave: Aprendizagem Móvel, Aplicativos Educacionais Móveis, Avaliação de Qualidade, Qualidade de Software. 



\section{ABSTRACT}

SOAD, G. W. Quality evaluation of mobile learning applications. 2017. 147 p. Dissertação (Mestrado em Ciências - Ciências de Computação e Matemática Computacional) - Instituto de Ciências Matemáticas e de Computação, Universidade de São Paulo, São Carlos - SP, 2017.

Studies indicate that the use of mobile learning applications has grown continuously, allowing students and teachers greater flexibility and convenience in the execution of educational activities and practices. Although several institutions have already adhered to the mobile learning (m-learning) modality, their adoption still brings organizational, cultural and technological problems and challenges. One of these problems is how to adequately evaluated the quality of the mobile learning applications developed. In fact, existing methods for evaluating software quality are still very generic, not considering aspects specific to the pedagogical and mobile contexts. In this scenario, the present work presents the MoLEva method, developed to evaluate the quality of mobile learning applications. The method is based on the ISO / IEC 25000 standard, being composed of: (i) quality model; (ii) metrics; and (iii) criteria of judgment. To validate the method, two case studies were performed; the first consisted of applying MoLEva to evaluate the ENEM application; the second consisted of applying the method for evaluating applications for language teaching. From the obtained results, it was possible to identify problems and improvement points in the evaluated applications. In addition, the case studies conducted provided good indications regarding the feasibility of using the MoLEva method in evaluating mobile learning applications.

Keywords: Mobile Learning, Mobile Learning Applications, Quality Evaluation, Software Quality. 



\section{LISTA DE ILUSTRAÇÕES}

Figura 1 - Backboard Mobile Learn . . . . . . . . . . . . . . . 36

Figura $2-$ GeoTouch . . . . . . . . . . . . . . 36

Figura 3 - Duolingo . . . . . . . . . . . . . . 37

Figura 4 - Learning Birds . . . . . . . . . . . . . . . . 38

Figura 5 - Relacionamento entre a ISO/IEC 9126 e ISO/IEC 14598. Fonte: (ROCHA; MALDONADO; WEBER, 2001) . . . . . . . . . . . . . 40

Figura 6 - Hierarquia do Modelo de McCall (CAVANO; MCCALL, 1978) . . . . . 41

Figura 7 - Fatores da Qualidade de Software (CAVANO; MCCALL, 1978) . . . . 42

Figura 8 - Divisões da Norma ISO/IEC 25000. Fonte: (ISO/IEC 25000, 2005) . 44

Figura 9 - Modelo de Qualidade TUP. Adaptado de Bednarik (2002) . . . . . . . 51

Figura 10 - Estudos sobre Qualidade Publicados no Período de 2003 - 2014 . . . . 61

Figura 11 - Etapas do Processo de Desenvolvimento do Método de Avaliação de Qualidade para Aplicativos Educacionais Móveis. Adaptado de DuarteFilho e Barbosa (2013a) . . . . . . . . . . . . . . . . . 74

Figura 12 - Componentes do Método de Avaliação de Qualidade MoLEva . . . . . 76

Figura 13 - Modelo de Qualidade do MoLEva . . . . . . . . . . . . . . . . 78

Figura 14 - Ferramenta Desenvolvida para Utilização do Método MoLEva (http://molevagustavosoad.rhcloud.com) . . . . . . . . . . . . . . 87

Figura 15 - Aplicativos Educacionais Móveis Selecionados . . . . . . . . . . . . 89

Figura 16 - Resultado da Avaliação do Duolingo . . . . . . . . . . . . . . . . . . . 90

Figura 17 - Resultado Final da Avaliação dos Aplicativos . . . . . . . . . . . . . . 92

Figura 18 - Aplicativo ENEM . . . . . . . . . . . . . . . . . . . . 96

Figura 19 - Aplicativo ENEM: Resultado por Critério de Qualidade . . . . . . . . 97

Figura 20 - Resultado Final da Avaliação de Qualidade do Aplicativo ENEM . . 99

Figura 21 - Etapas de Execução do Estudo de Caso 2 . . . . . . . . . . . . . . . 102

Figura 22 - Relacionamento entre os Aspectos de Qualidade do TUP com o MoLEva103

Figura 23 - Comparação dos Problemas Encontrados nos Métodos MoLEva e TUP 108

Figura 24 - Respostas sobre "O Quão Confortável" o Avaliador sentiu-se ao Aplicar o Método . . . . . . . . . . . . . . . . . . . 110

Figura 25 - Respostas sobre o Método ser Adequado ou não para o Contexto de Aplicativos Educacionais Móveis . . . . . . . . . . . . . . . 111

Figura 26 - Respostas sobre o Método ser Abrangente e Contemplar as Principais Características Relacionadas aos Aplicativos Educacionais Móveis . . . 111 
Figura 27 - Respostas sobre a Compreensão das Perguntas Contidas no Checklist . 111

Figura 28 - Respostas sobre a Adequação das Perguntas Contidas no Checklist . . 112

Figura 29 - Resultado da Avaliação de Qualidade dos Aplicativos por Critério de Qualidade: Avaliadores Experientes . . . . . . . . . . . . . . . . 113

Figura 30 - Resultado da Avaliação de Qualidade dos Aplicativos por Categoria Avaliadores Experientes . . . . . . . . . . . . . . . . . . 114

Figura 31 - Resultado da Avaliação de Qualidade dos Aplicativos por Critério de Qualidade ... . . . . . . . . . . . . . . . 115

Figura 32 - Resultado da Avaliação de Qualidade dos Aplicativos por Categoria . . 115

Figura 33 - Níveis de Qualidade dos Aplicativos Duolingo e Wlingua . . . . . . . . 116 
Tabela 1 - Vendas de Smartphones no Mundo por Sistema Operacional. Fonte: (GARTNER, 2017) . . . . . . . . . . . . . 26 26

Tabela 2 - Resultado da Seleção Preliminar . . . . . . . . . . . . . . . 60

Tabela 3 - Resultado da Seleção dos Estudos . . . . . . . . . . . . . . . . . 61

Tabela 4 - Características dos Dispositivos Móveis que Podem Afetar a Qualidade de Aplicativos m-learning . . . . . . . . . . . . . . . . . 62

Tabela 5 - Características Relacionadas à Adequação Funcional . . . . . . . . . . 63

Tabela 6 - Características Relacionadas à Eficiência do Desempenho . . . . . . . . 64

Tabela 7 - Características Relacionadas à Compatibilidade . . . . . . . . . . . . . 64

Tabela 8 - Características Relacionadas à Usabilidade . . . . . . . . . . . . 65

Tabela 9 - Características Relacionadas à Confiabilidade . . . . . . . . . . . 66

Tabela 10 - Características Relacionadas à Segurança . . . . . . . . . . . . . 66

Tabela 11 - Características Relacionadas à Portabilidade . . . . . . . . . . . . . . 66

Tabela 12 - Métricas relacionadas às características técnicas . . . . . . . . . . . 68

Tabela 13 - Características Relacionadas à Interatividade . . . . . . . . . . . . . 69

Tabela 14 - Características Relacionadas à Aprendizagem . . . . . . . . . . . . . . 69

Tabela 15 - Características Relacionadas ao Conteúdo . . . . . . . . . . . . . . 70

Tabela 16 - Características Relacionadas à Aplicação . . . . . . . . . . . . . . . . . 70

Tabela 17 - Métricas Relacionadas às Características Pedagógicas . . . . . . . . . . 70

Tabela 18 - Características Socioeconômicas Identificadas . . . . . . . . . . . . 71

Tabela 19 - Características Socioculturais Identificadas . . . . . . . . . . . . . 71

Tabela 20 - Características de Qualidade Relacionadas ao Critério Aprendizagem . 77

Tabela 21 - Características de Qualidade Relacionadas ao Critério Conteúdo . . . . 79

Tabela 22 - Características de Qualidade Relacionadas ao Critério Interatividade . 79

Tabela 23 - Características de Qualidade Relacionadas ao Critério Socioeconômico 79

Tabela 24 - Características de Qualidade Relacionadas ao Critério Sociocultural . . 80

Tabela 25 - Características de Qualidade Relacionadas ao Critério Adequação Funcional . . . . . . . . . . . . . . . . . . 8 80

Tabela 26 - Características de Qualidade Relacionadas ao Critério Eficiência do Desempenho . . . . . . . . . . . . . . . . 8 80

Tabela 27 - Características de Qualidade Relacionadas ao Critério Compatibilidade 81

Tabela 28 - Características de Qualidade Relacionadas ao Critério Usabilidade . . 81

Tabela 29 - Características de Qualidade Relacionadas ao Critério Confiabilidade . 82 
Tabela 30 - Características de Qualidade Relacionadas ao Critério Segurança . . . 82

Tabela 31 - Características de Qualidade Relacionadas ao Critério Portabilidade . 82

Tabela 32 - Pontuações Definidas para as Respostas Binárias . . . . . . . . . . . . 84

Tabela 33 - Pontuações Definidas para as Respostas por Grau de Concordância . . 84

Tabela 34 - Critérios de Qualidade e seus Principais Objetivos . . . . . . . . . . . 89

Tabela 35 - Pontuações Obtidas na Avaliação de Usabilidade do Duolingo . . . . . 90

Tabela 36 - Pontos Positivos e Negativos Identificados para o Aplicativo Duolingo . 91

Tabela 37 - Principais Vantagens e Desvantagens dos Aplicativos Avaliadas . . . . 92

Tabela 38 - Problemas Relacionados à Tecnologia, Resultantes da Aplicação do Método TUP . . . . . . . . . . . . . . . . . . . . . . . . 104

Tabela 39 - Problemas Relacionados à Tecnologia, Resultantes da Aplicação do Método MoLEva . . . . . . . . . . . . . . . . . . . . . . . . . . . . . 104

Tabela 40 - Problemas Relacionados à Usabilidade, Resultantes da Aplicação do Método TUP . . . . . . . . . . . . . . . . . . . . . . 105

Tabela 41 - Problemas Relacionados à Usabilidade, Resultantes da Aplicação do Método MoLEva . . . . . . . . . . . . . . . . 106

Tabela 42 - Problemas Relacionados à Pedagogia, Resultantes da Aplicação do Método TUP . . . . . . . . . . . . . . . . . . . 106

Tabela 43 - Problemas Relacionados à Pedagogia, Resultantes da Aplicação do Método MoLEva . . . . . . . . . . . . . . . . . . . . 107

Tabela 44 - Problemas Relacionados ao Contexto Social, Resultantes da Aplicação do Método MoLEva . . . . . . . . . . . . . . . . . . . . . . . . . 108

Tabela 45 - Pontos Positivos e Negativos Identificados na Aplicação do Método TUP109

Tabela 46 - Pontos Positivos e Negativos Identificados na Aplicação do Método MoLEva . . . . . . . . . . . . . . . . . . . . . . 109 


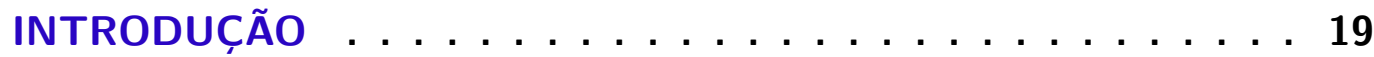

1.1 Contexto e Motivação . . . . . . . . . . . . . . . . . 19

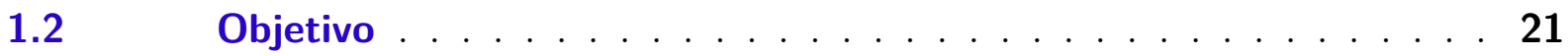

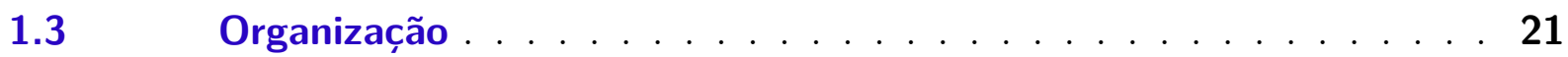

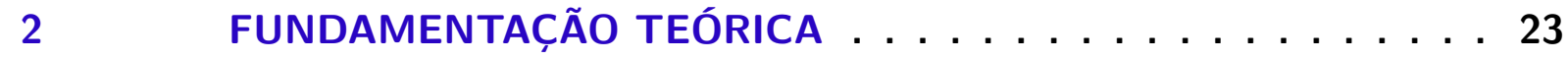

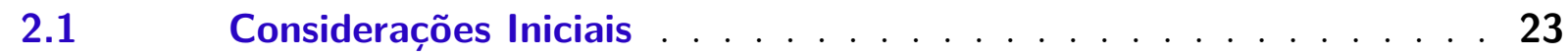

$2.2 \quad$ Aprendizagem Móvel _. . . . . . . . . . . . . . . . . 24

2.2.1 Tipos de Dispositivos Móveis . . . . . . . . . . . . . . . . . 25

2.2.2 Características dos Dispositivos Móveis . . . . . . . . . . . . . 27

2.2.3 Características da Aprendizagem Móvel . . . . . . . . . . . . . 28

2.2.4 Benefícios e Limitações da Aprendizagem Móvel . . . . . . . . . . . 34

2.2.5 Exemplos de Aplicativos de Aprendizagem Móvel . . . . . . . . . 35

$2.3 \quad$ Qualidade de Software . . . . . . . . . . . . . . . . . 38

2.3.1 Modelos de Qualidade . . . . . . . . . . . . . . . . . . 40

2.3.1.1 Modelo de McCall . . . . . . . . . . . . . . . . . . . . . . . . 41

2.3.1.2 Modelo de Boehm . . . . . . . . . . . . . . . . . . . . . 42

2.3.1.3 Norma de Qualidade ISO/IEC 25000 (Modelo SQuaRE) . . . . . . . . 43

2.3.1.4 Modelo de Qualidade TUP . . . . . . . . . . . . . . . . . . . . 50

$2.4 \quad$ Considerações Finais . . . . . . . . . . . . . . . 53

3 CARACTERÍSTICAS DE QUALIDADE DE APLICATIVOS EDUCACIONAIS MÓVEIS: UM MAPEAMENTO SISTEMÁTICO . . . 55

$3.1 \quad$ Considerações Iniciais . . . . . . . . . . . . . . . 55

$3.2 \quad$ Planejamento do Mapeamento Sistemático . . . . . . . . . . 56

3.2.1 Questões de Pesquisa . . . . . . . . . . . . . . . . . 56

3.2.2 Estratégia de Busca . . . . . . . . . . . . . . . . 57

3.2.3 Seleção de Estudos . . . . . . . . . . . . . . . . . . 58

3.3 Condução do Mapeamento Sistemático . . . . . . . . . . . . . . 59

3.3.1 Construção da String de Busca . . . . . . . . . . . . . . . . 59

3.3.2 Seleção Preliminar dos Estudos . . . . . . . . . . . . . . 59

3.3.3 Seleção dos Estudos . . . . . . . . . . . . . . . . . . 59

$3.4 \quad$ Resultados e Análise . . . . . . . . . . . . . 60 
4 MOLEVA: UM MÉTODO DE AVALIAÇÃO DE QUALIDADE PARA APLICATIVOS EDUCACIONAIS MÓVEIS . . . . . . . . 73

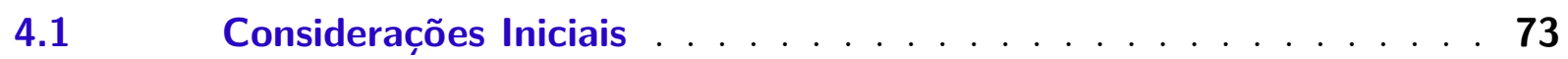

4.2 Definição do Método MoLEva . . . . . . . . . . . . . . 74

4.2.1 Modelo de Qualidade . . . . . . . . . . . . . . . 76

4.2.2 Métricas . . . . . . . . . . . . . . . . . . . 82

4.2.3 Critérios de Julgamento . . . . . . . . . . . . . . . 83

$4.3 \quad$ Ferramenta Web MoLEva . . . . . . . . . . . . . . 86

4.4 MoLEva: Uma Aplicação Prática Durante o Desenvolvimento . . 88

4.4.1 Avaliação do Duolingo . . . . . . . . . . . . . . . . . . 89

4.4.2 Resultados da Avaliação de Qualidade dos Aplicativos . . . . . . . 91

$4.5 \quad$ Considerações Finais . . . . . . . . . . . . . . . . 93

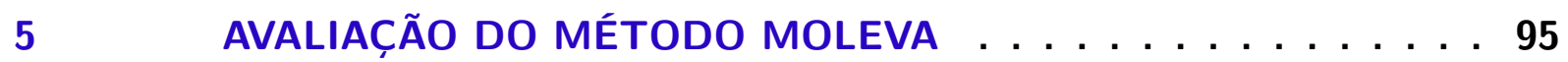

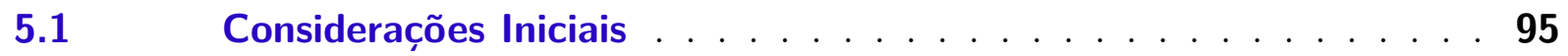

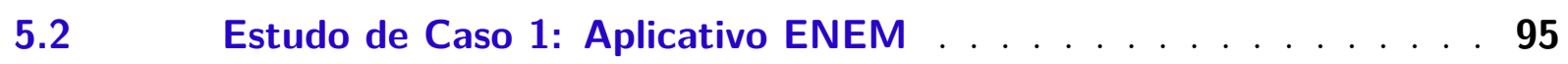

5.2.1 Análise dos Resultados . . . . . . . . . . . . . . . . 97

5.3 Estudo de Caso 2: Aplicativos Duolingo e Wlingua . . . . . . . . . 99

5.3.1 Planejamento do Estudo de Caso . . . . . . . . . . . . . . 100

5.3.2 Execução do Estudo de Caso . . . . . . . . . . . . . . . . 101

5.3.3 Análise dos Resultados . . . . . . . . . . . . . . . . . 103

5.3.4 Ameaças à Validade . . . . . . . . . . . . . . . . . . 116

$5.4 \quad$ Considerações Finais . . . . . . . . . . . . . . . . 117

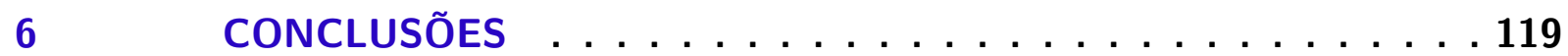

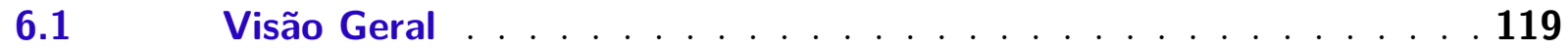

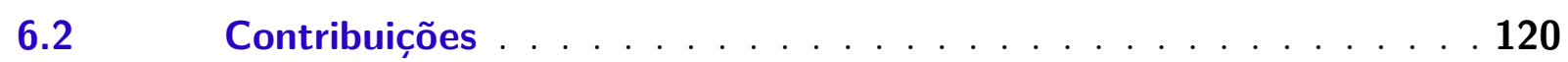

6.2.1 Produção Científica . . . . . . . . . . . . . . . 120

6.3 Dificuldades e Limitações . . . . . . . . . . . . . . . . 121

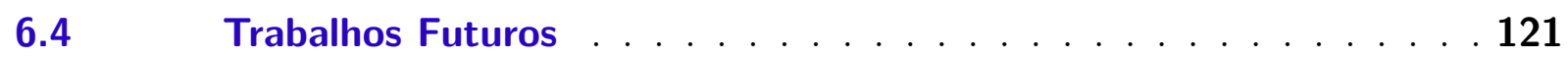

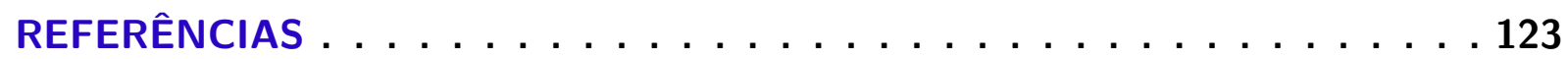

APÊNDICE A LISTA DE VERIFICAÇÃO DO MÉTODO MOLEVA . 131 


\section{1}

INTRODUÇÃO

\subsection{Contexto e Motivação}

Nos últimos anos, temas relacionados ao ensino e aprendizagem têm sido amplamente discutidos e estudados pela comunidade científica. Em especial, aplicações computacionais têm apresentado uma crescente importância, desempenhando um papel fundamental em atividades de ensino e aprendizagem, sendo relevantes não apenas no âmbito acadêmico como também no meio industrial (BARBOSA, 2004; SVETLANA et al., 2009; CRAIG et al., 2012; RUBENS; KAPLAN; OKAMOTO, 2014).

Tais aplicações proporcionaram, entre várias práticas educacionais inovadoras, uma nova modalidade de ensino - a aprendizagem móvel ou mobile learning (m-learning) (KINSHUK; SUTINEN; GOH, 2003; NAH; WHITE; SUSSEX, 2008; GUY, 2009; WEXLER et al., 2008; KEARNEY et al., 2012). Em linhas gerais, o m-learning caracteriza-se pela capacidade de proporcionar uma forte interação entre os aprendizes e instrutores, possibilitando a eles contribuir, participar e acessar o ambiente de ensino por meio de dispositivos móveis (celulares, tablets, laptops, rádio, tv, entre outros) a qualquer momento e em qualquer lugar.

Além dos benefícios citados, os dispositivos móveis dispõem de muitas tecnologias que podem apoiar o m-learning, por exemplo, a presença de sensores, GPS (Global Positioning System), acelerômetro, câmera e tela sensível ao toque (LANE et al., 2010). A presença dessas tecnologias contribui para que os aplicativos de aprendizagem móvel explorem esses recursos, favorecendo o interesse do aluno e estimulando a interação entre tutores e aprendizes (HUANG; LIN; CHENG, 2010; MISHRA; CHAVHAN, 2012; PICEK; GRCIC, 2013; FAZLINA; MANAP; RIAS, 2013; AL-ANI; HAMEED; FAISAL, 2013).

Apesar dos benefícios proporcionados no contexto de ensino e aprendizagem, por se tratar de um conceito novo e ainda incipiente, o m-learning apresenta problemas e 
desafios organizacionais, culturais e tecnológicos em sua utilização (SARRAB; AL-SHIHI; REHMAN, 2013; ECONOMIDES, 2008; SHARPLES, 2013). Um destes problemas é que os métodos existentes para avaliação da qualidade de software ainda são muito genéricos, não contemplando aspectos específicos dos aplicativos educacionais móveis.

De fato, aspectos de qualidade, em particular, representam uma questão importante a ser abordada, principalmente em virtude da crescente popularidade dos aplicativos móveis em diferentes setores da sociedade. Neste cenário emergente, a qualidade não é apenas relacionada a aspectos técnicos. Há também a necessidade de lidar com questões intrínsecas (por exemplo, educacionais, socioculturais e socioeconômicas) relacionadas com as atividades diárias de aprendizes, professores e tutores (ECONOMIDES, 2008; KEARNEY et al., 2012; ABDURRAHMAN; BEER; CROWTHER, 2015).

Apesar de sua relevância, poucos estudos sobre as diretrizes de qualidade para aplicativos móveis são encontrados na literatura. Como consequência, torna-se difícil identificar mecanismos bem definidos e amplamente utilizados para apoiar a avaliação da qualidade de aplicativos educacionais móveis.

Vários modelos de qualidade já foram propostos, como o modelo de McCall (CAVANO; MCCALL, 1978), o modelo de Boehm (BOEHM; BROWN; LIPOW, 1976), a norma ISO/IEC 9126 (ISO/IEC 9126, 2001), a norma ISO/IEC 25010 (ISO/IEC 25010, 2010) e o modelo TUP (Technology Usability Pedagogy) (BEDNARIK et al., 2004). No entanto, tais modelos, além de outros existentes na literatura, possuem deficiências ao lidar com aplicativos educacionais móveis.

O modelo TUP proposto em Bednarik et al. (2004) e Bednarik (2002), por exemplo, compreende aspectos pedagógicos. Observa-se, entretanto, que o modelo foi desenvolvido para softwares educacionais, não considerando os aspectos técnicos relacionados aos aplicativos móveis. Dessa maneira, a sua utilização no contexto móvel apresenta limitações. Já os outros modelos citados são genéricos, não contemplando todas as características relacionadas ao contexto de m-learning.

Apesar de alguns estudos investigarem a avaliação de qualidade de aplicativos m-learning (PARSONS; RYU, 2006; ACHARYA; SINHA, 2013), tais estudos não contemplam todos os aspectos citados por Economides (2008). Dessa maneira, a avaliação de qualidade é feita de forma incompleta, ignorando aspectos que podem influenciar na avaliação da qualidade do aplicativo.

Dentro do contexto apresentado, o presente trabalho de mestrado visa a proposição de um método para avaliar a qualidade de aplicativos educacionais móveis. O objetivo é apresentado a seguir. 


\subsection{Objetivo}

Considerando o contexto e as motivações apresentadas, este trabalho tem como principal objetivo desenvolver um método para avaliar a qualidade de aplicativos educacionais móveis. Em linhas gerais, o método denominado MoLEva (Mobile Learning Evaluation) é composto por um modelo de qualidade, métricas, níveis de pontuação e critérios de julgamento, tendo principalmente como base a norma ISO/IEC 25000 (ISO/IEC 25000, 2005).

O modelo de qualidade, em especial, deve estabelecer um conjunto bem definido de critérios e requisitos para avaliação de aplicativos educacionais móveis, contemplando aspectos técnicos, pedagógicos, socioeconômicos e socioculturais. Além disso, também devem ser identificadas métricas de qualidade. Estas métricas devem ser definidas a partir da identificação de atributos mensuráveis, os quais podem receber valores tanto quantitativos quanto qualitativos.

A partir da definição das métricas, deve ser criado um checklist a fim de coletar informações referentes aos aplicativos. Por meio das respostas do checklist, devem ser utilizados critérios de julgamento para classificar o nível de qualidade no qual o aplicativo se encontra.

Por fim, ainda como parte do trabalho, devem ser feitos estudos de casos com o MoLEva na avaliação de qualidade de aplicativos educacionais móveis, permitindo assim a avaliação do método proposto.

\subsection{Organização}

Neste capítulo foram apresentados o contexto no qual este trabalho se insere, as motivações relacionadas a sua realização e seus principais objetivos. O restante deste documento está organizado da seguinte forma.

No Capítulo 2 é apresentada uma visão geral sobre aprendizagem móvel. Ainda neste capítulo são apresentados conceitos sobre qualidade de software, além de serem descritos alguns dos principais modelos de qualidade existentes.

No Capítulo 3 é apresentado um mapeamento sistemático sobre as características de qualidade dos aplicativos de aprendizagem móvel.

No Capítulo 4 é apresentado o método MoLEva e a ferramenta desenvolvida para facilitar a sua utilização.

No Capítulo 5 são apresentados os estudos de casos e seus resultados utilizados para a avaliação do método MoLEva.

Por fim, no Capítulo 6 são apresentadas as conclusões sobre o trabalho. 



\section{FUNDAMENTAÇÃO TEÓRICA}

\subsection{Considerações Iniciais}

A aprendizagem móvel oferece várias vantagens em relação a outras modalidades de ensino e aprendizagem como, por exemplo, a ubiquidade e utilização do tempo ocioso (ACHARYA; SINHA, 2013).

Apesar dos benefícios que essa modalidade de ensino e aprendizagem oferece, caso a qualidade do aplicativo seja baixa, tais benefícios acabam tornando-se irrelevantes e ineficazes. Por esse motivo, obter um alto nível de qualidade é um objetivo importante para qualquer aplicativo, pois a qualidade produz um forte impacto sobre a sua utilização ou não pelo usuário (VISOIU; BATAGAN; BOJA, 2009).

Para se desenvolver um método de avaliação de qualidade para aplicativos educacionais móveis, é preciso conhecer os fundamentos básicos sobre aprendizagem móvel e qualidade de software, que constituem a base de conhecimento para atingir os objetivos do trabalho. Tais fundamentos são apresentados nas seções a seguir.

Este capítulo está organizado da seguinte maneira: na Seção 2.2 são apresentados os conceitos relacionados à aprendizagem móvel, descrevendo seus conceitos básicos, os tipos de dispositivos móveis existentes e suas características, benefícios e limitações. Já na Seção 2.3 são apresentados os fundamentos de qualidade de software, apresentando alguns dos principais modelos de qualidade existentes. Além disso, também é apresentado um modelo de qualidade específico para softwares educacionais, que será utilizado em um dos estudos de caso conduzidos como parte do presente trabalho. Por fim, na Seção 2.4 são apresentadas as considerações finais. 


\subsection{Aprendizagem Móvel}

Aprendizagem móvel (do inglês, mobile learning), também conhecida pelo termo m-learning, é uma modalidade de ensino e aprendizagem que, por meio de dispositivos móveis, permite o ensino e a aprendizagem sem limitações de tempo e espaço.

Há diversas definições de m-learning na literatura. Em Guy (2009) m-learning é definido como qualquer tipo de ensino ou aprendizagem que ocorre quando o aluno não está em algum lugar predeterminado ou fixo, ou quando o indivíduo aproveita-se de oportunidades de aprendizagem disponibilizadas pelas tecnologias móveis, associando assim os conceitos tecnológicos e de mobilidade.

Já Wexler et al. (2008) abordam m-learning como uma atividade que permite aos indivíduos serem mais produtivos quando consomem, criam ou interagem com as informações, mediados por dispositivos digitais móveis e portáteis, que acompanham o indivíduo de forma regular, desde o início ao fim das tarefas.

Em outra perspectiva relacionada, Nah, White e Sussex (2008) consideram que o m-learning se refere ao uso de celular e computador de mão, como PDAs, telefones celulares, laptops e tablets no ensino e aprendizagem, enquanto Crompton (2013) define m-learning como a aprendizagem em múltiplos contextos, por meio de interações sociais e de conteúdo, utilizando dispositivos eletrônicos de uso pessoal. Por fim, Oyelere e Suhonen (2016) definem m-learning como a capacidade do uso de dispositivos portáteis para acesso a recursos de aprendizagem, colaboração, comunicação e compartilhamento de experiências de aprendizado.

A partir das diversas definições em relação ao m-learning, Kinshuk, Sutinen e Goh (2003) e Traxler e Leach (2006) definem categorias de aprendizagem móvel que podem ser instanciadas na prática:

- Aprendizagem portátil em escala reduzida: adaptação de soluções do ensino a distância convencional para dispositivos portáteis com conexões sem fio;

- Aprendizagem em sala de aula: tecnologias sem fio e móveis são utilizadas como apoio à aprendizagem colaborativa, ligadas a outras tecnologias em sala de aula;

- Treinamento móvel e feedback: tecnologias são utilizadas para melhorar a produtividade, oferecendo informações e apoio na hora certa e no contexto de suas prioridades imediatas, funções e deveres;

- Desenvolvimento em grande escala: são implantadas tecnologias de comunicações móveis em nível institucional ou departamental para apresentar questões organizacionais; 
- Inclusão e diversidade assistida: tecnologias móveis e sem fio, utilizadas para aumentar a participação e envolvimento dos alunos no processo de ensino e aprendizagem;

- Ensino a distância, desenvolvimento rural e móvel: tecnologias utilizadas onde obstáculos ambientais e de infraestrutura não permitem a utilização das tecnologias de educação a distância convencionais.

Alguns dos principais benefícios dos dispositivos móveis vão muito além de disponibilidade, comodidade e comunicação (SCHEPMAN et al., 2012). Com dispositivos móveis os aprendizes podem utilizar aplicativos (processamento de texto, fotos), ambientes específicos de aprendizagem, acesso a $W e b$, ferramentas de colaboração, redes sociais, e-books, entre outros (DUARTE-FILHO; BARBOSA, 2012).

Com a evolução da tecnologia e da inclusão digital, fica clara a relevância de m-learning para a sociedade atual. Apesar disso, vários desafios também podem ser identificados. Aspectos de qualidade, em particular, representam um problema importante a ser abordado, principalmente por causa da crescente popularidade dos aplicativos educacionais móveis. Neste cenário emergente, a qualidade não está relacionada apenas a aspectos técnicos. Há também a necessidade de lidar com questões intrínsecas (por exemplo, educacionais, socioculturais e econômicas) relacionadas com as atividades diárias de aprendizes e tutores (ECONOMIDES, 2008; KEARNEY et al., 2012; ABDURRAHMAN; BEER; CROWTHER, 2015).

\subsubsection{Tipos de Dispositivos Móveis}

Atualmente existem diversos tipos de dispositivos móveis, como os tablets, celulares, smartphones e os chamados dispositivos wearables, que são conhecidos como dispositivos vestíveis. Com a evolução da tecnologia, estes dispositivos possuem um poder computacional cada vez maior, que possibilita adicionar a eles diversos recursos. Entretanto, esta diversidade de dispositivos pode trazer dificuldades no desenvolvimento de aplicativos, vindo a afetar sua qualidade.

Devido à diversidade de dispositivos móveis, Keegan (2005) define as principais características que tais dispositivos devem possuir para suprir as necessidades de um aplicativo m-learning: (i) são baratos e fáceis de utilizar; (ii) devem ser amigáveis e pessoais; (iii) podem ser utilizados constantemente para diferentes objetivos e não apenas com a finalidade de ensino e aprendizagem; e (iv) podem ser utilizados e transportados para qualquer lugar.

Além das diferenças entre os dispositivos, também se observa uma variedade de sistemas operacionais associados. Isto faz com que o desenvolvimento de aplicativos para tais dispositivos demande mais tempo, principalmente se for necessária a portabilidade 
Tabela 1 - Vendas de Smartphones no Mundo por Sistema Operacional. Fonte: (GARTNER, 2017)

\begin{tabular}{l|l|l}
\hline Sistema Operacional & $\mathbf{4}^{\mathbf{o}}$ Quadrimestre 2015 & $\mathbf{4}^{\mathbf{o}}$ Quadrimestre 2016 \\
\hline Android & 325.394 .400 & 352.669 .900 \\
\hline iOS & 71.525 .900 & 77.038 .900 \\
\hline Windows & 4.395 .000 & 1.092 .200 \\
\hline BlackBerry & 906.900 & 207.900 \\
\hline Outros & 887.300 & 530.400 \\
\hline Total & $\mathbf{4 0 3 . 1 0 9 . 4 0 0}$ & $\mathbf{4 3 1 . 5 3 9 . 3 0 0}$ \\
\hline
\end{tabular}

para os diferentes sistemas operacionais. A Tabela 1, apresentada pela Gartner ${ }^{1}$, mostra que dentre os sistemas operacionais atuais, as vendas de smartphones com o sistema operacional Android têm dominado o mercado, seguido dos dispositivos com iOS.

Embora a diferença entre sistemas operacionais dificulte o desenvolvimento, atualmente existem frameworks que auxiliam o desenvolvimento para multiplataformas. Um desses frameworks é o PhoneGap ${ }^{2}$, que permite a criação de aplicativos móveis utilizando padrões Web (HTML5, CSS e JavaScript), além de poder acessar os recursos nativos dos dispositivos como GPS e acelerômetro.

De fato, o processo torna-se mais ágil ao se utilizar este tipo de framework, porém a solução não fica otimizada para o sistema operacional utilizado. Um experimento realizado por Corral, Sillitti e Succi (2012) compara um aplicativo desenvolvido para o sistema operacional Android utilizando o PhoneGap, com outro utilizando Java, sua linguagem nativa. Pela análise dos resultados, observa-se que quando o foco do desenvolvimento é desempenho, a linguagem nativa é recomendada, já que se consegue otimizar as funcionalidades de acordo com o sistema operacional. Por outro lado, se o foco for produtividade, a utilização de frameworks como PhoneGap é mais viável, já que é possível o desenvolvimento para diferentes tipos de sistemas operacionais simultaneamente.

Por fim, é importante ressaltar que os tipos de dispositivos vão além dos sistemas operacionais. Os desenvolvedores precisam preocupar-se, por exemplo, com os diversos tipos de telas, pois isso pode afetar a saída dos dados, e também com os tipos de teclados utilizados, já que alguns são próprios do dispositivo e outros possuem o teclado do próprio sistema operacional. Além disso, a preocupação com os diversos tipos de processadores, memórias e baterias também deve ser considerada, já que todas estas características podem afetar a qualidade de um aplicativo de aprendizagem móvel.

1 Gartner: http://www.gartner.com

2 PhoneGap: http://phonegap.com 


\subsubsection{Características dos Dispositivos Móveis}

Dispositivos móveis estão rapidamente se tornando os dispositivos de comunicação mais presentes na vida das pessoas. Com sua evolução, eles vêm ganhando cada vez mais recursos como: acelerômetro, bússola digital, giroscópio, microfone, câmera, entre outros (LANE et al., 2010).

Apesar da variedade dos tipos de dispositivos móveis e seus diversos modelos existentes, várias características são compartilhadas entre eles. Estas características são:

- Tamanho do dispositivo: os dispositivos possuem tamanhos variados, porém para que sejam considerados dispositivos móveis devem possuir um tamanho que seja fácil de carregar (BOJA; BATAGAN, 2009).

- Tamanho da tela: com a diversidade de dispositivos existentes, o tamanho da tela também é variável, o que caracteriza um problema para os desenvolvedores. Para garantir o funcionamento dos aplicativos nesses diversos dispositivos, torna-se necessário realizar testes em diferentes tamanhos de tela (ACHARYA; SINHA, 2013; GAFNI, 2009; SPRIESTERSBACH; SPRINGER, 2004; PARSONS; RYU, 2006; DUARTE-FILHO; BARBOSA, 2013b; TAYLOR, 2004).

- Tamanho do teclado: esta característica pode variar de acordo com o dispositivo. No caso dos teclados virtuais dos atuais dispositivos sensíveis ao toque, o tamanho é adequado ao tipo de dispositivo, ou seja, dispositivos com uma tela maior têm um teclado maior, facilitando assim a entrada de dados (ACHARYA; SINHA, 2013; GAFNI, 2009; SPRIESTERSBACH; SPRINGER, 2004; TAYLOR, 2004).

- Processamento: os dispositivos móveis mais atuais estão cada vez mais potentes, possuindo processadores de quatro núcleos e processadores gráficos dedicados. Porém, o seu custo ainda é alto, sendo os modelos mais simples, os mais acessíveis atualmente (ACHARYA; SINHA, 2013; GAFNI, 2009; SPRIESTERSBACH; SPRINGER, 2004; DUARTE-FILHO; BARBOSA, 2013b).

- Capacidade de armazenamento: atualmente, a capacidade de armazenamento dos dispositivos vem aumentando consideravelmente, porém em muitos dispositivos ainda é pequena, o que limita a quantidade de informações e aplicativos disponibilizados (ACHARYA; SINHA, 2013; GAFNI, 2009; PARSONS; RYU, 2006; DUARTEFILHO; BARBOSA, 2013b).

- Autonomia da bateria: apesar da autonomia da bateria estar aumentando, este é um dos maiores desafios ao se desenvolver um dispositivo móvel. O aumento da sua capacidade exige aumento no tamanho, fazendo com que o dispositivo móvel fique 
maior e mais pesado (ACHARYA; SINHA, 2013; GAFNI, 2009; DUARTE-FILHO; BARBOSA, 2013b).

- Conectividade: a inclusão da conectividade com a Internet nos dispositivos móveis fez com que as possibilidades de utilização do dispositivo aumentassem. Apesar de ser um recurso importante e muito utilizado pelos dispositivos, o seu alto custo e os problemas de velocidade e cobertura fazem essa característica ter restrições durante a sua utilização (ACHARYA; SINHA, 2013; GAFNI, 2009; SPRIESTERSBACH; SPRINGER, 2004; PARSONS; RYU, 2006).

- Câmera: muitos desses dispositivos possuem câmeras (alguns possuem até duas câmeras, sendo uma delas frontal) que permitem tirar fotos e gravar vídeos. Muitas delas não possuem uma qualidade adequada, o que, entretanto, não inviabiliza o seu uso (BOJA; BATAGAN, 2009; LANE et al., 2010).

- Sensores: os dispositivos móveis possuem muitos sensores. Dentre os sensores utilizados pode-se citar (LANE et al., 2010):

- Giroscópio: responsável por identificar os movimentos realizados com o dispositivos.

- Acelerômetro: mede a intensidade da aceleração sofrida pelo dispositivo.

- Bússola: identifica a posição em relação ao polo norte e o polo sul da Terra.

\subsubsection{Características da Aprendizagem Móvel}

As características da aprendizagem móvel podem ser representadas em quatro dimensões (ECONOMIDES, 2008): técnica, pedagógica, sociocultural e socioeconômica.

O conjunto de características técnicas está relacionado às tecnologias de hardware e software envolvidas em um aplicativo de aprendizagem móvel. Já as características pedagógicas estão relacionadas às questões educacionais, e as socioculturais aos aspectos culturais que envolvem os utilizadores desse tipo de aplicativo. Por fim, as características socioeconômicas envolvem os impactos econômicos e sociais.

Economides (2008) baseia-se nas seis características de qualidade da ISO/IEC 9126 (2001) (funcionalidade, confiabilidade, usabilidade, eficiência, manutenibilidade e portabilidade) para definir oito áreas técnicas relacionadas à aprendizagem móvel que, por sua vez, possuem subáreas. As características técnicas definidas são:

- Interface de Usuário

- Usabilidade: o aplicativo deve ser fácil de ser entendido, aprendido, operado, fácil de lembrar como utilizar suas funções, além de não possuir elementos de distração ou sobrecarga cognitiva. 
- Layout e Organização: os componentes utilizados no aplicativo devem ser consistentes e uniformes, além de utilizar um menu de opções por níveis adequados e também ser esteticamente atraente e agradável de ser utilizada.

- Mídia: o aplicativo deve apoiar diversos tipos de mídias como áudio, texto e vídeo.

- Navegação e Orientação: a navegação deve ser simples, fácil e intuitiva, além de possuir alternativas e prover facilidades, tais como índice, botão de voltar, imprimir, entre outros.

- Eficácia: o aplicativo deve disponibilizar meios para aumentar significativamente a produtividade do usuário.

- Acessibilidade: o aplicativo deve ser acessível à maior quantidade de pessoas possível, independentemente da idade, habilidade ou presença de necessidades especiais.

- Ajuda: o aplicativo deve oferecer diversos modos de apoio ao usuário, por exemplo, dicionários, índices de ajuda, FAQ (Frequently Asked Questions), entre outros.

- Personalização: o aplicativo deve ser personalizável para cada usuário individualmente (por exemplo, em um ambiente com pouca luminosidade a tela pode ficar mais clara para o usuário).

- Funcionalidade

- Variedade: o aplicativo deve oferecer recursos para lidar com diversos tipos de situação, como, por exemplo, apoiar a mobilidade auxiliando a utilização do aplicativo em qualquer lugar e a qualquer hora.

- Qualidade: o aplicativo deve fornecer funcionalidades úteis e adequadas para os objetivos educacionais, ao aluno e à situação, além de fornecer flexibilidade e conveniência no momento certo. Seu funcionamento deve ser transparente, antecipando as necessidades ou ações futuras do aluno, apoiando-o.

- Interatividade, Comunicação e Colaboração: o aplicativo deve oferecer vários modos de comunicação, além de sincronização e coordenação entre dispositivos, aplicativos e redes.

- Consciência

- Estado do Aluno: o aplicativo deve conhecer os estados cognitivo, social, afetivo e físico do aluno. Deve-se reconhecer o máximo possível de informações referentes ao aluno, podendo utilizar essas informações para saber suas habilidades, preferências, vontades, entre outras. 
- Dispositivo: o aplicativo deve ter informações a todo momento sobre o dispositivo, como memória livre, autonomia da bateria, processamento, entre outros.

- Atividades: deve-se conhecer os estados dos aplicativos ativos e atividades, seus objetivos, duração, recursos consumidos, entre outros. Além disso, deve-se estar ciente do monitoramento e coleta de informações do aluno, e ter consciência do tempo, a fim de saber a sua disponibilidade.

- Equipes: o aplicativo deve conhecer as informações sobre as equipes como número de membros, papéis de cada membro, interação entre os membros e entre equipes, atividades da equipe, entre outras.

- Ambiente: o aplicativo deve estar ciente sobre o ambiente no qual está inserido, como terreno, clima, infraestrutura, recursos disponíveis e área de cobertura de rede.

- Adaptação

- Variedade de adaptação: relaciona-se com a adaptação para a variedade de parâmetros do contexto técnico, pedagógico, sociocultural, socioeconômico (por exemplo, a adaptação no envio de um vídeo com uma conexão ruim pela redução de sua qualidade ou um conteúdo educacional que deve se adaptar às características do aluno).

- Parâmetros de Consciência: o aplicativo deve se adaptar aos vários parâmetros de sensibilização, como emoções e expressões.

- Utilidade: a adaptação deve ser apropriada de acordo com cada situação.

- Transparência: a adaptação deve ser transparente para o aluno.

- Precisão: as adaptações devem ser exatas, corretas e precisas.

- Consistência: estados de consciência similar devem produzir adaptações semelhantes.

- Flexibilidade: a adaptação deve ser flexível e ajustável. Por exemplo, se não existir uma correspondência exata para a adaptação, deve-se encontrar a melhor possível através de aproximação.

- Velocidade: quanto mais rápidas as adaptações, melhor será o seu funcionamento.

- Confiabilidade e Manutenibilidade

- Livre de Erros: o aplicativo deve ser correto e exato, ficando livre de erros.

- Erros de Reconhecimento e Prevenção: o aplicativo deve sempre monitorar o seu estado, além de ser rápido de ser analisado e testado. Também deve evitar erros que possam ocorrer. 
- Tolerância e Recuperação de Falhas: quando um erro não pode ser evitado, o aplicativo deve se recuperar dele automaticamente, além de recuperar o seu estado de maneira transparente para o aluno.

- Disponibilidade: o aplicativo deve estar sempre disponível em qualquer ambiente.

- Facilidade de Instalação: o aplicativo deve ser fácil de instalar.

- Facilidade de Manutenção: a manutenção do aplicativo deve ser fácil e demandar o mínimo de esforço possível, mantendo o seu funcionamento de maneira eficiente.

- Facilidade de Reconfiguração: o aplicativo deve ser fácil de ser reconfigurado ou ter partes substituídas, preferencialmente de maneira automática.

- Facilidade de Atualização: a atualização deve ser fácil e rápida.

- Eficiência e Performance

- Capacidade de Resposta: o tempo de resposta das ações efetuadas no aplicativo deve ser rápido e apropriado.

- Largura da Banda de Comunicação: deve-se utilizar uma banda de comunicação suficiente para o aplicativo. Caso contrário, deve adaptar-se automaticamente a fim de ajustar o seu funcionamento a uma banda de comunicação mais estreita.

- Memória de Armazenamento: a memória deve ser utilizada de forma eficiente, utilizando técnicas para que esse objetivo possa ser atingido.

- Consumo de Energia: o aplicativo não deve consumir muita energia. Os desperdícios devem ser evitados por meio de técnicas utilizadas para otimizar o uso de energia do dispositivo.

- Entrada: o aplicativo deve prover eficiência na entrada de dados. Quando fizer uso da rede, deve-se adaptar a entrada de dados de acordo com a velocidade da rede.

- Saída: as saídas do aplicativo devem ser utilizadas de maneira eficiente, ajustando a qualidade das mídias de acordo com a velocidade da rede.

- Conectividade

- Abertura: é aconselhável utilizar arquiteturas abertas.

- Padrões de Conformidade: deve estar em conformidade com os padrões internacionais, possibilitando o trabalho em conjunto com outros aplicativos, dispositivos, plataformas, entre outros. 
- Portabilidade: a importação e exportação para outros sistemas de dados e serviços devem ser fáceis, além de seus módulos poderem ser utilizados facilmente por outros aplicativos.

- Transparência: as operações devem ser transparentes para os alunos, além de operar simultaneamente com outros aplicativos sem gerar interferências.

- Escalabilidade: deve ser fácil de aumentar o número de alunos, dados, serviços, entre outros, permitindo que o aplicativo seja escalável.

- Variedade de Conectividade: deve apoiar a maior variedade de dados e sistemas possível.

- Autonomia: deve-se exigir o mínimo possível de hardware e software.

- Segurança

- Integridade da Segurança: deve incorporar tecnologias atuais com a segurança atualizada, protegendo assim o acesso, armazenamento, comunicação, entre outras operações vulneráveis que são necessárias para o funcionamento do aplicativo.

- Níveis de Segurança: deve apoiar vários níveis de segurança de acordo com o recurso e o usuário, garantindo a legitimidade das ações e permitindo apenas serem executadas por pessoas autorizadas.

- Privacidade: deve preservar a privacidade do usuário, provendo confidencialidade, anonimato, privacidade e confiança.

- Controle de Segurança: o usuário deve ter controle sobre seus dados, aplicativos e recursos, determinando quais informações podem ficar disponíveis para o acesso de outros usuários.

Além das características técnicas, Economides (2008) define mais três áreas e suas respectivas características:

- Pedagógicas

- Teorias de Aprendizagem: o aplicativo deve possuir vários métodos de aprendizagem e teorias didáticas.

- Modelos de Projeto Instrucional: o aplicativo deve possuir vários modelos de projeto instrucional, como analisar, projetar, desenvolver e avaliar.

- Qualidade de Conteúdo: os conteúdos disponíveis devem ser validados, confiáveis e precisos. Além disso, o conteúdo deve motivar o aluno e ser baseado em teorias que são aceitáveis na atualidade. 
- Integridade e Abrangência de Conteúdo: o conteúdo deve abranger todos os temas principais, ideias e pontos-chave, tudo isso em uma quantidade adequada a um aplicativo de aprendizagem móvel que possui restrições de hardware.

- Conteúdo de Apresentação: deve-se utilizar uma variedade de mídias na apresentação do conteúdo. Elas devem ser de qualidade, evitando o excesso, para que a atenção do usuário não seja prejudicada.

- Organização do Conteúdo: a organização dos conteúdos deve ser adaptável ao usuário. Deve-se prover uma navegação fácil e intuitiva.

- Suporte e Feedback dos Alunos: o aplicativo deve reagir às ações dos alunos na quantidade e momento adequados. Deve-se sempre motivar o aluno e auxiliá-lo em suas dificuldades, fazendo com que o aplicativo tenha um comportamento estimulante.

- Controle: o aluno deve possuir controle sobre seu aplicativo e decidir se deseja receber sua ajuda ou não. Além disso, o aplicativo deve prover ferramentas para concepção de conteúdo, criação e organização, acompanhamento do aluno, avaliação, entre outros.

- Socioculturais

- Aceitabilidade: o aplicativo deve ser aberto a diversos valores, culturas, políticas, valores religiosos, além de não possuir nenhuma discriminação com relação à idade, gênero e questões relacionadas à saúde.

- Métodos de Interação Social: deve apoiar vários modos de comunicação e estilos, interação social, flexibilidade de comunicação e ser multilíngue.

- Sociabilidade: o aplicativo deve apoiar o aluno na socialização, cooperação, amizade, compreensão mútua, responsabilidade e participação ativa.

- Atitude: deve estimular a autoestima, confiança, pró-atividade e confiança do aluno.

- Visibilidade e Observabilidade: não devem existir atividades referentes às informações do aluno sendo executadas sem o seu consentimento. Dados, atividades e aplicações devem sempre estar visíveis ao aluno.

- Confiança, Privacidade e Propriedade Intelectual: a privacidade e propriedade intelectual do aluno devem ser asseguradas, ou seja, o aluno deve ter a convicção de que suas informações estão seguras.

- Moda: não deve ignorar as tendências e sim adequar-se a elas. 
- Socioeconômicas

- Custos Variados e Viabilidade Econômica: os custos envolvidos no desenvolvimento e na venda devem sempre ser mantidos o mais baixo possível.

- Eficácia de Custo: o aplicativo deve oferecer o melhor custo benefício em relação aos aplicativos semelhantes.

- Nível de Serviço: o aplicativo deve possuir vários contratos de nível de serviço, por exemplo, podem ser relacionados ao número de usuários, quantidade de conteúdo, entre outros.

\subsubsection{Benefícios e Limitações da Aprendizagem Móvel}

Atualmente existem várias pesquisas sobre os benefícios que a aprendizagem móvel pode trazer, bem como sobre as limitações encontradas na sua utilização. Estudos sugerem que a utilização da aprendizagem móvel desperta o interesse do aluno, estimula a interação social provendo mecanismos de comunicação entre os usuários do aplicativo, além de estimular a discussão sobre os materiais dos cursos (HUANG; LIN; CHENG, 2010; MISHRA; CHAVHAN, 2012; PICEK; GRCIC, 2013; FAZLINA; MANAP; RIAS, 2013; AL-ANI; HAMEED; FAISAL, 2013).

A aprendizagem móvel provê ao usuário autonomia para organizar a sua rotina de estudos, além de poder repetir as aulas quantas vezes for necessário, evitando a perda de conteúdo em caso de intercorrências durante sua execução (AL-ANI; HAMEED; FAISAL, 2013; PICEK; GRCIC, 2013).

A adoção da aprendizagem móvel não significa, entretanto, que o aprendizado deve ocorrer exclusivamente por meio do dispositivo móvel. Ela pode conviver em conjunto com outros métodos de aprendizagem, tornando-se, por exemplo, um complemento à aula presencial. Ainda, além de aumentar o interesse do aluno utilizando os dispositivos móveis, também facilita a colaboração dos pais ou outras pessoas que possam auxiliá-lo (LOOI et al., 2014; ABACHI; MUHAMMAD, 2014).

Os materiais de aprendizagem, além de estarem sempre disponíveis, podem ser atualizados com mais facilidade, apresentam menos erros e permitem a utilização de vários formatos de mídias no seu desenvolvimento (ABACHI; MUHAMMAD, 2014; PICEK; GRCIC, 2013).

Por outro lado, a aprendizagem móvel também possui limitações, que podem ser técnicas ou não (PICEK; GRCIC, 2013). Tais limitações variam de acordo com o aplicativo de aprendizagem móvel e contexto no qual está inserido.

Apesar da evolução dos dispositivos móveis, ainda existem limitações relacionadas ao hardware como, por exemplo (HUANG; LIN; CHENG, 2010; PICEK; GRCIC, 2013; 
AL-ANI; HAMEED; FAISAL, 2013): baixa capacidade de armazenamento, autonomia da bateria, a qual limita o uso do dispositivo móvel por um longo período de tempo e o tamanho das telas e dos teclados, que gera limitações à visualização e entrada de dados no aplicativo. Além disso, para terem mobilidade, os dispositivos móveis necessitam estar conectados na rede, que pode ser limitada por sua área de cobertura, banda estreita e alto custo de acesso (ABACHI; MUHAMMAD, 2014; PICEK; GRCIC, 2013).

Além das limitações técnicas citadas, existem limitações não técnicas como a dificuldade de iniciar o uso da tecnologia dos dispositivos móveis. Dependendo do contexto no qual o aplicativo de aprendizagem móvel é inserido, o usuário pode não ter o conhecimento e as habilidades necessárias para manusear este tipo de dispositivo (SU; CHENG, 2013). Além disso, os usuários também devem ser motivados a estudar fora do ambiente de ensino, de modo que a falta de interesse seja superada e não prejudique a conclusão das atividades propostas (MISHRA; CHAVHAN, 2012; PICEK; GRCIC, 2013). Outro ponto importante é que o usuário dispõe de um dispositivo com muitos recursos que podem distraí-lo facilmente (FAZLINA; MANAP; RIAS, 2013).

Outras limitações associadas à aprendizagem móvel são discutidas no mapeamento sistemático, apresentado no Capítulo 3. Nesse mapeamento são apresentadas as características técnicas, pedagógicas, socioeconômicas e socioculturais relacionadas à qualidade de um aplicativo de aprendizagem móvel.

\subsubsection{Exemplos de Aplicativos de Aprendizagem Móvel}

Atualmente existem vários aplicativos m-learning disponíveis para serem utilizados ou em desenvolvimento. Nesta seção, alguns destes aplicativos são descritos. Como critério de seleção dos aplicativos foi considerada a diversidade de objetivos de aprendizagem em cada uma delas.

\section{Blackboard Mobile Learn ${ }^{3}$}

Este aplicativo, desenvolvido para Android e iOS, proporciona aos alunos acesso aos cursos e conteúdos por meio de dispositivos móveis. Além disso, por meio dele, alunos e professores podem criar tópicos de discussão, acessar documentos, criar e postar comentários em blogs, verificar notas, entre outras funcionalidades. A Figura 1 ilustra a tela de cursos exibida pelo aplicativo.

\section{GeoTouch ${ }^{4}$}

O aplicativo GeoTouch, desenvolvido para o sistema operacional Android, auxilia o ensino e aprendizagem de geometria por meio de métodos pedagógicos que utilizam a tecnologia para apoiar a construção de conhecimento. Com este aplicativo, é possível

3 Blackboard Mobile Learn: http://www.blackboard.com/Platforms/Mobile/Overview.aspx

4 GeoTouch: http://project.caed-lab.com/geotouch 


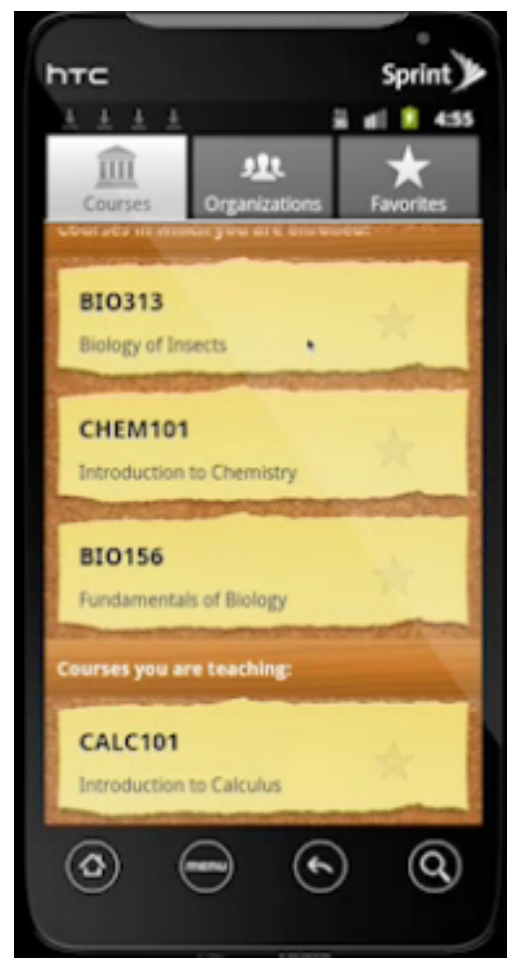

Figura 1 - Backboard Mobile Learn

construir os objetos geométricos utilizando os recursos multitoque dos dispositivos sensíveis ao toque. A Figura 2 ilustra a tela do aplicativo utilizado para a criação dos objetos geométricos.

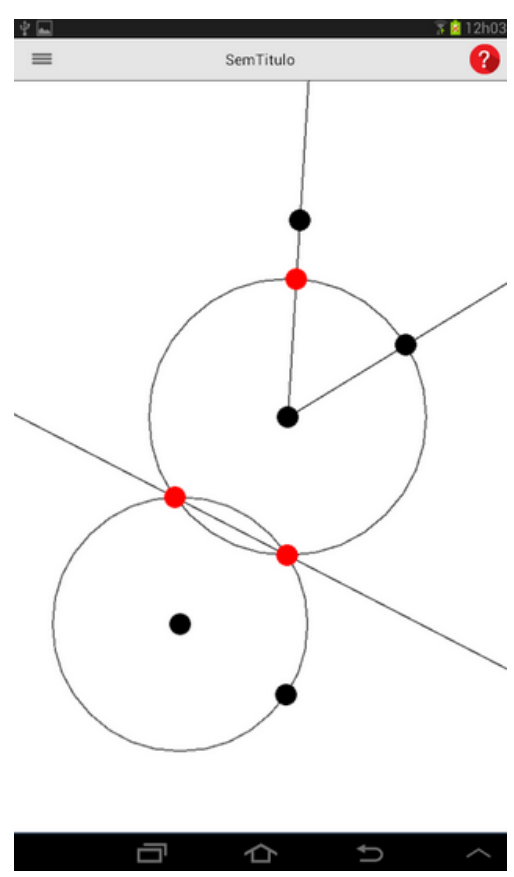

Figura 2 - GeoTouch 


\section{Duolingo ${ }^{5}$}

Duolingo é um aplicativo m-learning, desenvolvido para Android, iOS e Windows, que objetiva o ensino de idiomas por meio de dispositivos móveis. Este aplicativo também possui versão para desktop, além de já possuir um aplicativo para os novos dispositivos vestíveis que utilizam o sistema operacional Android. Os recursos disponíveis neste aplicativo permitem o exercício da leitura, escrita e dicção relacionados ao idioma que se deseja aprender. Este aplicativo aplica os conceitos de gamificação, incentivando o usuário atingir metas diárias, auxiliando assim na sua motivação. A Figura 3 ilustra a tela de estudos de idioma apresentada pelo aplicativo.

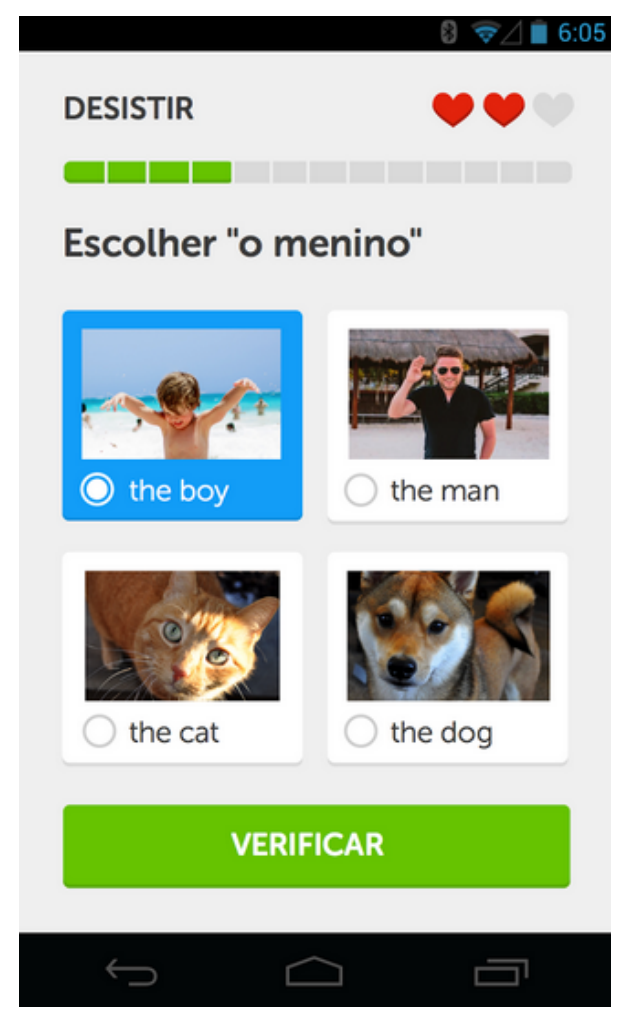

Figura 3 - Duolingo

\section{Learning Birds ${ }^{6}$}

O aplicativo Learning Birds, desenvolvido para Android, objetiva o ensino sobre as aves, tendo o seu foco voltado para crianças. Este aplicativo permite que o usuário aprenda a reconhecer as aves, seus sons, hábitos alimentares e outras informações a respeito delas. O aplicativo também fornece recursos como galeria de imagens, textos sobre as aves e quiz que fornecem perguntas relacionadas às aves. A Figura 4 ilustra a tela do aplicativo exibindo uma pergunta para o usuário.

5 Duolingo: https://www.duolingo.com

6 Learning Birds: https://play.google.com/store/apps/details?id=com.letsnurture.BirdApp 


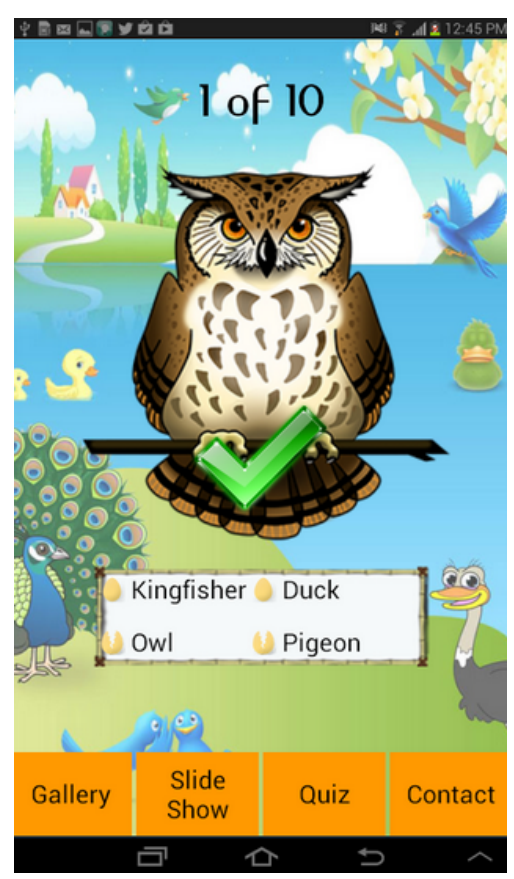

Figura 4 - Learning Birds

Os aplicativos apresentados anteriormente ilustram a variedade de tipos de aplicativos educacionais móveis existente, disponíveis para serem utilizados. Dessa maneira, observa-se a diversidade de aspectos abordados por este tipo de aplicativo, exemplificando, ainda a gama de oportunidades para desenvolvimento de aplicativos educacionais móveis.

\subsection{Qualidade de Software}

Qualidade de software é uma das sub-áreas de Engenharia de Software, sendo responsável por garantir a qualidade dos produtos de software por meio de processos definidos. A qualidade de software não aparece simplesmente "do nada"; ela é o resultado de um bom gerenciamento de projeto e uma prática consistente de Engenharia de Software (PRESSMAN, 2010). Ainda segundo Pressman (2010), a qualidade de software pode ser definida como a conformidade a requisitos funcionais e de desempenho explicitamente declarados, a padrões de desenvolvimento claramente documentados e a características implícitas que são esperadas de todo software profissionalmente desenvolvido.

A qualidade de software também pode ser entendida como um conjunto de características a serem satisfeitas em um determinado grau, de modo que o produto de software atenda às necessidades implícitas e explícitas de seus usuários (ISO/IEC 8402, 1994). Nesse contexto, as necessidades implícitas são aquelas que não são expressas, porém são necessárias para se ter o produto final. Por exemplo, um software que controla altitude de um avião precisa se recuperar em caso de erro e, por este motivo, mesmo que esta necessidade não seja citada no documento de requisitos, ela deve ser atendida. Já as necessidades explícitas são especificadas em documentos para serem atendidas pelo 
produto de software, ou seja, são necessidades definidas pelos interessados no produto a ser desenvolvido.

Desse modo, é importante que as necessidades explícitas sejam bem documentadas, já que de acordo com Koscianski e Soares (2007) a qualidade de um software depende em sua maior parte dos requisitos. Problemas de não-conformidades, conceituais, erros lógicos e omissões na especificação dos requisitos, podem ser propagados por todo o projeto, podendo ocasionar na construção de um software com baixa qualidade (KOSCIANSKI; SOARES, 2007).

Para definir o nível de qualidade de um produto de software é necessário uma avaliação de qualidade, que pode ser conduzida sob os aspectos do processo de desenvolvimento, que se refere às atividades realizadas durante as etapas do seu ciclo de vida, e sob a qualidade de produto, que se refere às características do produto após o seu desenvolvimento.

A ISO (do inglês, International Organization for Standardization), publicou em 1997 a norma ISO/IEC 14598 (ISO/IEC 14598, 1998), que é um guia para avaliação da qualidade em produtos de software. Sua principal finalidade é a definição de um processo de avaliação baseado na utilização da norma ISO/IEC 9126 (ISO/IEC 9126, 2001). O processo de avaliação proposto pode ser utilizado para avaliar produtos já existentes ou em desenvolvimento, independentemente do domínio ao qual pertençam.

A norma ISO/IEC 14598 é constituída basicamente por seis documentos distintos, que se relacionam entre si. Estes documentos são:

- ISO/IEC 14598-1, denominada por "Visão Geral", é contemplada a estrutura de funcionamento das normas. Este documento ensina a utilizar os outros documentos do grupo.

- ISO/IEC 14598-2, denominada "Planejamento e Gerenciamento", são requisitos e guias para suportar funções de avaliação dos produtos de software, que estão relacionados ao desenvolvimento, aquisição, padronização, controle, transferência e realimentação do uso de tecnologias de avaliação.

- ISO/IEC 14598-3, denominada de "Guia para Desenvolvedores", é usada durante o desenvolvimento e manutenção do software.

- ISO/IEC 14598-4, denominada "Guia para Aquisição", tem como objetivo ajudar na aceitação de um produto, ou seja, descreve a avaliação do ponto de vista de quem tem interesse em adquirir um produto.

- ISO/IEC 14598-5, denominada "Guia de Avaliação", possui orientações para a prática da avaliação do produto, definindo as atividades necessárias para analisar os 
requisitos de avaliação, ou seja, é descrito como avaliar do ponto de vista de quem certifica o produto.

- ISO/IEC 14598-6 é definida a estrutura e o conteúdo da documentação que será usada na descrição dos "Módulos de Avaliação", ou seja, é descrito o desenvolvimento e a validação dos módulos.

A norma ISO/IEC 9126 relacionada à qualidade de produto e ISO/IEC 14598 são amplamente utilizadas como guia para a elaboração e realização de inspeções de software.

A Figura 5 apresenta o relacionamento entre qualidade do processo e qualidade do produto de software. A qualidade do produto de software depende da qualidade do processo de avaliação utilizado que, por sua vez, sofre influências dos recursos e do ambiente no qual o uso do mesmo ocorre. A Figura 5 também ilustra o relacionamento entre os efeitos do produto de software relacionados à medição da qualidade em uso e o produto de software.

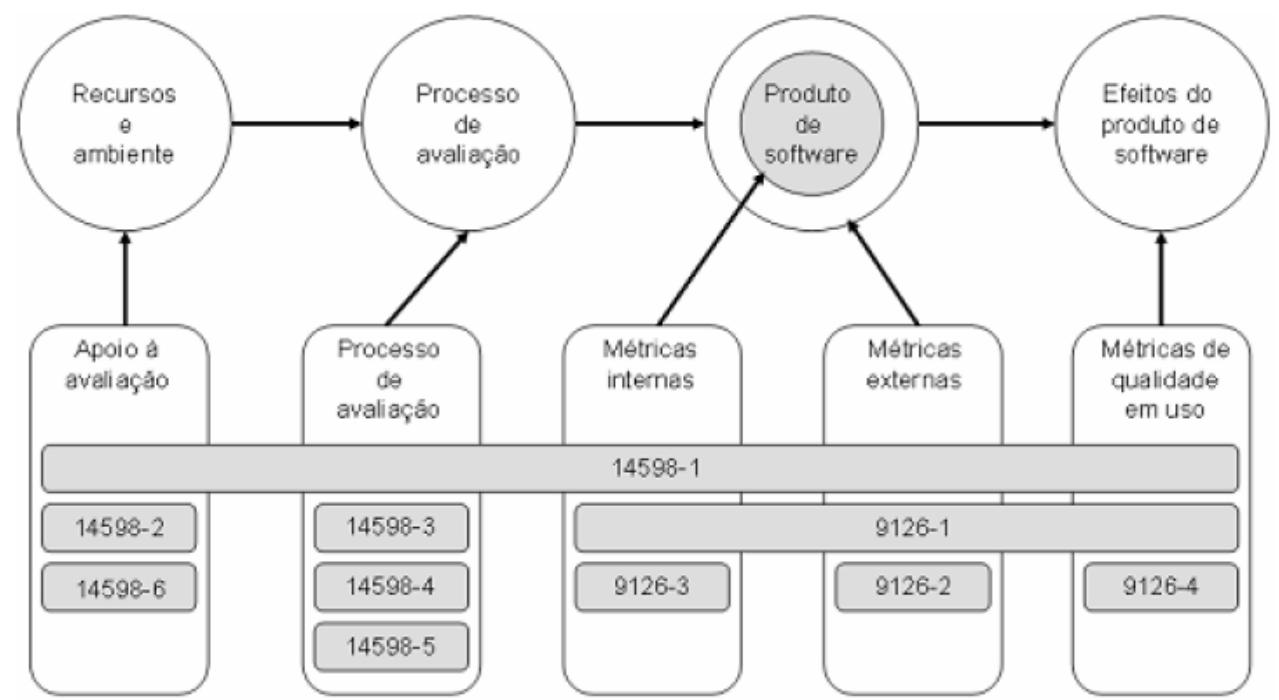

Figura 5 - Relacionamento entre a ISO/IEC 9126 e ISO/IEC 14598. Fonte: (ROCHA; MALDONADO; WEBER, 2001)

Uma vez que a aceitação do sistema é dada pelo usuário final, a qualidade do produto e os efeitos produzidos com o seu uso são os principais motivos para a realização dos estudos na área de qualidade de software. A qualidade em uso provê uma ligação entre os fatores humanos associados com a melhoria do produto, uma vez que está intimamente ligada a requisitos de negócio. Ela fornece meios potenciais para o desenvolvimento de sistemas que estarão adequados às necessidades de seus usuários (BEVAN, 1999).

\subsubsection{Modelos de Qualidade}

Um modelo de qualidade corresponde a um conjunto de características que se relacionam entre si e que fornecem a base para a especificação de requisitos de qualidade 
e avaliação de qualidade (ISO/IEC 9126, 2001).

Visando estabelecer formas de garantir a qualidade de um produto de software, diversos modelos e padrões vêm sendo estabelecidos. Nestes modelos, a especificação e avaliação da qualidade do produto de software são fatores fundamentais para a garantia da qualidade adequada.

Entre os modelos de qualidade existentes está o proposto pela norma ISO 25010, o qual é apresentado na Seção 2.3.1.3. Além do modelo proposto pela ISO 25010, existem ainda dois modelos que são considerados seminais no contexto de modelos de qualidade: o modelo de McCall (CAVANO; MCCALL, 1978) e o modelo de Boehm (BOEHM; BROWN; LIPOW, 1976), ambos sumarizados a seguir.

\subsubsection{Modelo de McCall}

O modelo de McCall é representado por uma hierarquia de fatores, critérios e métricas, como apresentado na Figura 6. Os fatores ficam no nível mais alto da hierarquia e representam as características do produto de software em um visão externa. No nível intermediário da hierarquia ficam os critérios, de forma que cada fator possua um conjunto de critérios. Estes critérios descrevem a visão interna do produto de software, ou seja, a visão do desenvolvedor. Por fim, no nível mais baixo da hierarquia, estão localizadas as métricas que fornecem medidas para os atributos de software (CAVANO; MCCALL, 1978).

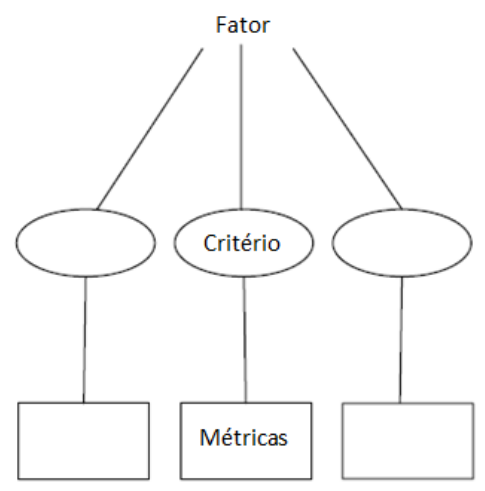

Figura 6 - Hierarquia do Modelo de McCall (CAVANO; MCCALL, 1978)

O modelo possui 11 fatores de qualidade, cada qual classificado em três grupos distintos, de acordo com o ciclo de vida do produto. A Figura 7 apresenta os grupos e fatores definidos.

Os fatores existentes no grupo "Operação" referem-se à capacidade do produto ser entendido, estável e funcional. Já o grupo "Transição" relaciona-se com as características de adaptação a novos ambientes. Por fim, o grupo "Revisão" está relacionado à correção de erros e à capacidade de manutenção. 


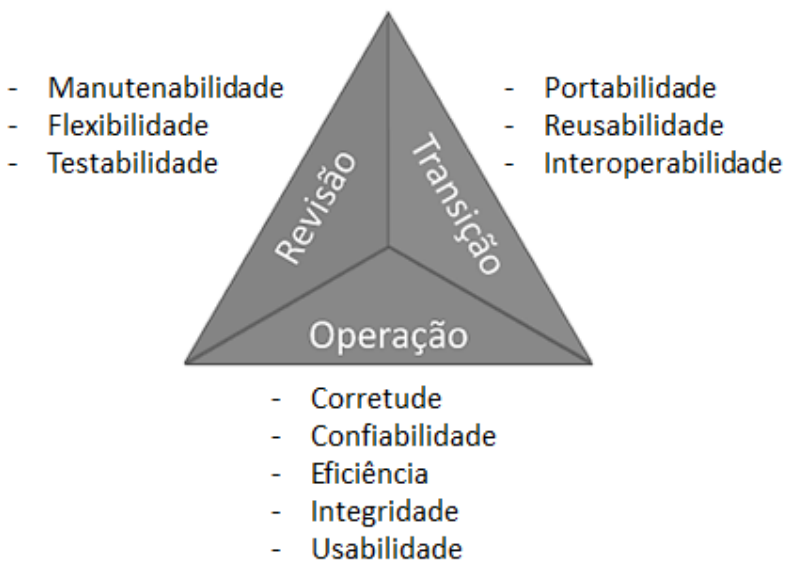

Figura 7 - Fatores da Qualidade de Software (CAVANO; MCCALL, 1978)

A partir dos critérios estabelecidos, determina-se as métricas relacionadas a cada critério. As métricas fornecem medidas para as características do software e, a partir delas, é possível atribuir um grau de qualidade ao produto de software.

Cavano e McCall (1978) definem o cálculo do fator de qualidade de software de acordo com a fórmula: $F_{q}=c_{1} m_{1}+c_{2} m_{2}+c_{3} m_{3}+\ldots+c_{n} m_{n}$, onde $F_{q}$ é o fator de qualidade de software, $c_{n}$ são os coeficientes de regressão (pode ser entendido como o peso da métrica) e $m_{n}$ são as métricas relacionadas as características de qualidade.

Baseando-se nos valores encontrados, é possível identificar a qualidade do produto de software, além de localizar os pontos do software que estão precisando de uma atenção especial, devido à falta de qualidade.

\subsubsection{Modelo de Boehm}

O modelo de Boehm, Brown e Lipow (1976), assim como o modelo de McCall, também define uma estrutura hierárquica de características. Sua principal diferença é que Boehm adiciona as necessidades dos usuários.

O nível mais alto da hierarquia é composto por três usos primários:

- Como é utilizado (as-is utility): refere-se a como o software é utilizado.

- Manutenabilidade (maintainability): relaciona-se com a facilidade de modificação e correção do software.

- Portabilidade (portability): refere-se à facilidade do software para se adaptar a novos ambientes.

No nível intermediário, são estabelecidas seis características: 
- Confiabilidade (reliability): refere-se à capacidade de realizar as funções de forma satisfatória.

- Eficiência (efficiency): refere-se à capacidade de otimizar a utilização dos recursos, ou seja, não deve haver desperdício.

- Engenharia Humana (human engineering): refere-se à facilidade de interação com o software.

- Testabilidade (testability): refere-se à facilidade de realizar testes e avaliações no software.

- Compreensibilidade (understandability): refere-se ao quão fácil é a compreensão do software.

- Modificabilidade (modifiability): refere-se à facilidade em modificar o software, permitindo assim que o mesmo esteja em constante evolução.

Por fim, no último nível estão as características que se relacionam com as do nível intermediário e do nível mais alto. Por este motivo, este modelo não é considerado puramente hierárquico. Estas características são: (i) independência de dispositivo (deviceindependence), (ii) auto-contido (self-containedness), (iii) acurácia (accuracy), (iv) completude (completeness), (v) robustez/integridade (robustness/integrity), (vi) consistência (consistency), (vii) responsabilidade (accountability), (viii) eficiência de dispositivo (device eficiency), (ix) acessibilidade (accessibility), (x) comunicatividade (communicativeness), (xi) auto-descrição (self-descriptiveness), (xii) estruturação (structuredness), (xiii) concisão (conciseness), (xiv) legibilidade (legibility) e (xv) capacidade de incremento (augmentability).

A partir das características do nível mais baixo são definidas as métricas de qualidade. Essas métricas são responsáveis por fornecer as medidas do grau de qualidade que um produto de software possa ter (BOEHM; BROWN; LIPOW, 1976).

Os modelos de McCall e Boehm possuem muitas características que estão presentes nos modelos atuais, inclusive no modelo de qualidade desenvolvido para o MoLEva. A seguir é apresentada a norma de qualidade ISO/IEC 25000, que serviu como base para a criação do método MoLEva.

\subsubsection{Norma de Qualidade ISO/IEC 25000 (Modelo SQuaRE)}

Com o objetivo de estabelecer formas de garantir a qualidade de um produto de software, alguns padrões foram propostos pela ISO. A série de normas ISO/IEC 25000 (2005), também chamada de modelo SQuaRE (do inglês, Software Product Quality Requirements and Evaluation), unifica as normas ISO/IEC 9126 (ISO/IEC 9126, 2001) e 
ISO/IEC 14598 (ISO/IEC 14598, 1998), criando assim um conjunto de normas logicamente organizado, que envolve dois processos principais: (i) a especificação de requisitos; e (ii) a avaliação da qualidade de software. A norma ISO/IEC 25000 possui cinco divisões, como ilustrado na Figura 8.

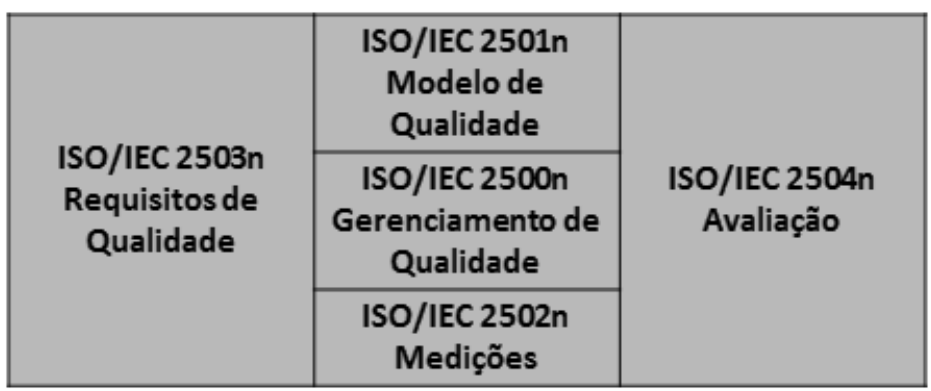

Figura 8 - Divisões da Norma ISO/IEC 25000. Fonte: (ISO/IEC 25000, 2005)

- ISO/IEC 2500n - Divisão de Gerenciamento de Qualidade: apresenta o modelo das normas, fazendo recomendações e sugestões sobre como utilizar o conjunto de normas, além de definir conceitos e termos que são utilizados nos documentos. Ela é composta por dois documentos: (i) a ISO/IEC 25000 - Guia para o SQuaRE, que define a estrutura, terminologias, visão geral, modelos de referências e públicoalvo; e (ii) a ISO/IEC 25001 - Planejamento e Gestão, que fornece os requisitos e orientações para o planejamento e gestão do processo de avaliação de produto de software.

- ISO/IEC 2501n - Divisão de Modelo de Qualidade: define um modelo hierárquico de características de qualidade, além de definir os conceitos de qualidade interna, externa e em uso. É composta por dois documentos: (i) a ISO/IEC 25010 - Guia de Modelo de Qualidade, que determina um modelo, características e subcaracterísticas para qualidade interna, externa e em uso; e (ii) a ISO/IEC 25012 Guia de Modelo de Qualidade de Dados, que define um padrão para uso de dados, tanto por pessoas quanto por sistemas.

- ISO/IEC 2502n - Divisão de Medições de Qualidade: apresenta um guia prático para a implementação do modelo, além de definir a padronização matemática das métricas de qualidade interna, externa e em uso. É composta por cinco documentos:

- ISO/IEC 25020 - Guia e Modelo de Referência: apresenta as explicações, modelo de referência e definições comuns para as primitivas de medição interna, externa e em uso. 
- ISO/IEC 25021 - Medição de Primitivas: apresenta as explicações, modelo de referência e definições comuns para as primitivas de medição interna, externa e em uso.

- ISO/IEC 25022 - Métricas para Qualidade Interna: define uma série de métricas para medir as características de qualidade interna.

- ISO/IEC 25023 - Métricas para Qualidade Externa: define uma série de métricas para medir as características de qualidade externa.

- ISO/IEC 25024 - Métricas para Qualidade Em Uso: define uma série de métricas para medir as características de qualidade em uso.

- ISO/IEC 2503n - Divisão de Requisitos de Qualidade: refere-se às normas destinadas à especificação de requisitos de qualidade e é composta por um documento, a ISO/IEC 25030 - Guia de Requisitos de Qualidade, que é um guia para a especificação dos requisitos de qualidade de produto de software.

- ISO/IEC 2504n - Divisão de Avaliação de Qualidade: são as normas que incluem os requisitos, recomendações e diretrizes para avaliação de qualidade de um produto de software. É composta por dois documentos: (i) a ISO/IEC 25040 - Guia e Modelo de Referência para Avaliação de Qualidade, que fornece uma estrutura destinada à identificação dos requisitos gerais e conceitos para especificação e avaliação; e (ii) a ISO/IEC 25041 - Documentação para o Módulo de Avaliação, que define um módulo de avaliação capaz de avaliar erros induzidos e detectados, além da maneira como o sistema trata e recupera estes eventos.

\section{ISO/IEC 25010}

A norma ISO/IEC 25010 (ISO/IEC 25010, 2010) faz parte do novo conjunto de normas ISO/IEC 25000, tendo substituído a ISO/IEC 9126 (ISO/IEC 9126, 2001). Esta norma define um modelo de qualidade composto por características internas (características do produto em seu projeto e construção) e externas (características do produto quando é avaliado em um ambiente simulado e com dados simulados) relacionadas ao produto de software. As características definidas, por sua vez, são subdivididas em subcaracterísticas.

Além das características citadas, a norma também define cinco características relacionadas à qualidade em uso, que tem como objetivo avaliar a qualidade do produto de software do ponto de vista do usuário, ou seja, quando ele é utilizado pelo usuário em um ambiente real e com dados reais. Algumas destas características também são subdivididas em subcaracterísticas. 


\section{Características de Qualidade Interna e Externa ${ }^{7}$}

1. Adequação funcional (functional suitability): mede o grau em que o produto de software disponibiliza funções que atendam às necessidades implícitas e explícitas, quando usado sob condições especificadas.

- Completude funcional (functional completeness): refere-se ao grau em que o conjunto de funções é apropriado para que o usuário atinja os seus objetivos, ou seja, esse conjunto de funções existentes permite que o usuário realize suas tarefas.

- Corretude funcional (functional correctness): refere-se ao grau em que um produto de software gera resultados corretos, com a precisão necessária.

- Funcionalidade apropriada (functional appropriateness): refere-se ao grau em que as funções fornecidas facilitam a realização de tarefas e objetivos especificados.

2. Eficiência do Desempenho (performance efficiency): verifica o desempenho em relação à quantidade de recursos utilizados sob condições estabelecidas, ou seja, refere-se à otimização do uso dos recursos disponíveis.

- Comportamento em relação ao tempo (time behavior): refere-se ao grau em que os tempos de resposta e processamento das funções do sistema são atendidos, de acordo com os requisitos estabelecidos.

- Utilização de recursos (resource utilization): refere-se ao grau em que a quantidade e os tipos de recursos são utilizados pelo produto de software ao realizar suas funções.

- Capacidade (capacity): avalia se os limites máximos estabelecidos pelos requisitos do sistema são atendidos.

3. Compatibilidade (compatibility): mede o grau em que um produto de software ou componente pode trocar informações e/ou realizar suas funções requeridas com outros produtos de softwares ou componentes, compartilhando o mesmo ambiente de hardware e/ou software.

- Coexistência (co-existence): refere-se ao grau em que um produto de software desempenha suas funções requeridas de forma eficiente ao compartilhar o ambiente e recursos com outros produtos, não causando impactos a eles.

7 As características internas, externas e em uso apresentadas foram baseadas na tradução da norma ISO/IEC 25010 (2010), realizada em Wazlawick (2013). 
- Interoperabilidade (interoperability): refere-se ao grau em que dois ou mais produtos de software podem trocar informações e utilizá-las, ou seja, mede a interação entre os produtos de software.

4. Usabilidade (usability): grau em que um produto de software pode ser utilizado em um contexto específico e por usuários específicos, a fim de alcançar objetivos específicos, permitindo assim que ele seja entendido, aprendido, utilizado e atraente ao usuário.

- Apropriação reconhecível (appropriateness recognisability): refere-se ao grau em que um usuário reconhece um produto de software como sendo adequado para suas necessidades.

- Inteligibilidade (learnability): avalia a facilidade com a qual um usuário consegue entender e aprender a utilizar o produto de software com eficiência, eficácia, livre de risco e satisfação.

- Operabilidade (operability): refere-se ao grau em que um produto de software é de fácil utilização e controle.

- Proteção contra erro de usuário (user error protection): refere-se ao grau em que o produto de software protege o usuário de cometer erros.

- Estética de interface com usuário (user interface aesthetics): refere-se ao grau em que a interface com o usuário proporciona uma interação agradável e satisfatória.

- Acessibilidade (accessibility): refere-se ao grau em que o produto de software pode ser utilizado por pessoas com necessidades especiais.

5. Confiabilidade (reliability): mede o grau em que um produto de software proporciona um comportamento consistente com o esperado durante um longo período de tempo.

- Maturidade (maturity): refere-se ao grau em que o produto de software atende às necessidades sem apresentar defeitos.

- Disponibilidade (availability): refere-se ao grau em que o produto de software está operacional e acessível ao ser necessária sua utilização.

- Tolerância a falhas (fault tolerance): refere-se ao grau em que o produto de software consegue se recuperar de falhas.

- Recuperabilidade (recoverability): refere-se ao grau em que o produto de software consegue se recuperar de eventos como falhas ou interrupções, estabelecendo assim os dados diretamente afetados e o seu estado desejado. 
6. Segurança (security): refere-se ao grau em que o produto de software protege as informações e dados, protegendo-os de acesso não autorizado e garantido seu acesso de acordo com os diferentes níveis de autorização.

- Confidencialidade (confidentiality): refere-se ao grau em que os dados são acessíveis apenas para quem está autorizado.

- Integridade (integrity): refere-se ao grau em que o produto de software impede o acesso ou modificações de dados por quem não está autorizado.

- Não repúdio (non-repudiation): refere-se ao grau em que se permite constatar que as ações ou eventos foram realmente realizadas, evitando que os mesmos sejam negados.

- Rastreabilidade de uso (accountability): refere-se ao grau em que as ações possam ser rastreadas.

- Autenticidade (authenticity): refere-se ao grau em que a identidade de uma pessoa ou recurso possa ser comprovada, evitando que uma pessoa ou recurso possa se passar por outro.

7. Portabilidade (portability): refere-se ao grau em que um produto de software pode ser transferido de um hardware ou software para outro.

- Adaptabilidade (adaptability): refere-se ao grau em que o produto de software pode ser adaptado para diferentes hardwares, softwares ou outros sistemas operacionais, sem que seja necessário utilizar meios além dos fornecidos pelo próprio produto de software.

- Instalabilidade (instalability): refere-se ao grau em que o produto de software pode ser instalado ou desinstalado com sucesso em um ambiente específico.

- Substituibilidade (replaceability): refere-se ao grau em que um produto de software pode ser substituído por outro em um mesmo ambiente e com os mesmos objetivos.

8. Capacidade de Manutenção (maintainability): mede o grau de eficiência e eficácia com que o produto de software pode ser modificado pelos desenvolvedores, a fim de evoluir o produto ou corrigir erros.

- Modularidade (modularity): refere-se ao grau em que o produto de software é subdividido em partes, a fim de que alterações nessas partes tenham o mínimo impacto possível nas outras.

- Reusabilidade (reusability): refere-se ao grau em que as partes do produto de software podem ser utilizadas para a construção de novos. 
- Analisabilidade (analyzability): refere-se ao grau em que é possível avaliar o impacto de uma mudança sobre o produto de software ou para diagnosticar a causa de defeitos e falhas, além de identificar partes que devem ser modificadas.

- Modificabilidade (modifiability): refere-se ao grau em que o produto de software pode ser modificado sem que sejam introduzidos novos defeitos ou se degrade a qualidade do produto.

- Testabilidade (testability): refere-se ao grau em que é possível estabelecer critérios de teste para um produto de software, e se estes testes podem ser executados para determinar se os critérios estabelecidos foram cumpridos.

\section{Características de Qualidade Em Uso}

As características de qualidade em uso medem o grau em que um produto de software pode ser utilizado atendendo aos objetivos especificados com eficiência, eficácia, livre de riscos e satisfação em um contexto de uso especificado. De acordo com Wazlawick (2013), este tipo de qualidade é difícil de ser avaliada em um ambiente de desenvolvimento, já que estas características refletem o uso do produto de software em um ambiente de uso final. As características de qualidade em uso são:

- Efetividade (effectiveness): avalia se o produto de software faz o usuário atingir seus objetivos com exatidão e integridade.

- Eficiência (efficiency): avalia os recursos gastos em relação à exatidão e integridade oferecidos pelo produto de software. Esta característica considera se os investimentos realizados obtiveram retorno. Os recursos não são necessariamente apenas financeiros, podendo ser o tempo para completar uma tarefa pelo usuário, ou seja, recursos humanos, assim como materiais.

- Satisfação (satisfaction): refere-se ao grau em que as necessidades do usuário são satisfeitas pelo produto de software em um contexto de uso especificado.

- Utilidade (usefulness): mede o grau em que o usuário está satisfeito com a obtenção percebida dos objetivos pragmáticos, incluindo os resultados e as consequências do seu uso.

- Confiança (trust): considera o grau em que o usuário ou as partes interessadas têm confiança de que o produto de software irá ter o comportamento esperado.

- Prazer (pleasure): avalia o grau em que o usuário obtém prazer ao utilizar o produto de software para satisfazer suas necessidades. 
- Conforto (comfort): refere-se ao grau em que o usuário se sente confortável em relação ao esforço físico e mental ao utilizar o produto de software.

- Uso sem riscos (freedom from risk): refere-se ao grau em que o produto de software mitiga os riscos em potencial relacionados as pessoas, negócios e meio ambiente.

- Mitigação de risco econômico (economic risk mitigation): refere-se ao grau em que o produto de software mitiga os riscos potenciais relacionados à situação financeira, eficiência das operações, propriedades comerciais, reputação das pessoas, entre outros recursos nos contextos de uso.

- Mitigação de risco à saúde (health and safety risk mitigation): referese ao grau em que o produto de software mitiga os riscos em potencial relacionados à saúde das pessoas.

- Mitigação de risco ambiental (environmental risk mitigation): referese ao grau em que o produto de software mitiga os riscos em potencial relacionados ao ambiente ou propriedades em seu contexto de uso.

- Cobertura de contexto (context coverage): refere-se ao grau em que o produto de software pode ser utilizado com eficácia, eficiência, sem riscos e satisfação tanto no contexto de uso especificado quanto em outros contextos.

- Completude de contexto (context completeness): avalia o grau em que o produto de software pode ser utilizado com eficácia, eficiência, sem riscos e satisfação em todos os contextos especificados.

- Flexibilidade (flexibility): avalia o grau em que o produto de software pode ser utilizado com eficácia, eficiência, sem riscos e satisfação em contextos diferentes dos especificados.

As características definidas pela norma ISO/IEC 25010 foram fundamentais para a proposição do método MoLEva, já que esta norma define características de qualidade gerais para os produtos de software. Dessa maneira, é possível utilizar as características definidas incorporando-as ao modelo MoLEva, além de auxiliar no desenvolvimento da hierarquia do modelo de qualidade MoLEva.

\subsubsection{Modelo de Qualidade TUP}

Outro modelo de qualidade existente é o TUP (Technology Usability Pedagogy) definido e discutido em Bednarik et al. (2004) e Bednarik (2002). A importância desse modelo no contexto do método MoLEva é que o TUP foi criado para avaliar softwares 
educacionais. A principal diferença entre o modelo utilizado pelo MoLEva e o TUP referese à inclusão das características relacionadas aos aplicativos móveis, as quais não são consideradas no TUP.

Basicamente, o modelo TUP provê a avaliação de três aspectos de qualidade em ambientes educacionais, por meio de uma lista de verificação. Os aspectos definidos são:

- Tecnologia: avalia as questões das interações entre software e hardware;

- Usabilidade: avalia as questões de usabilidade dos ambientes educacionais;

- Pedagogia: avalia as questões pedagógicas dos ambientes educacionais.

A avaliação de qualidade do TUP é feita por meio de uma lista de verificação, que corresponde a um conjunto de perguntas objetivas que coletam as informações necessárias para se obter o resultado da avaliação. As perguntas da lista de verificação possuem respostas baseadas no conceito de concordo/discordo, utilizando a escala Likert (LIKERT, 1932), que permite capturar a sensação do usuário em relação aos questionamentos ou afirmações da lista de verificação.

A Figura 9 sumariza o modelo TUP e suas características. Suas descrições são apresentadas a seguir:

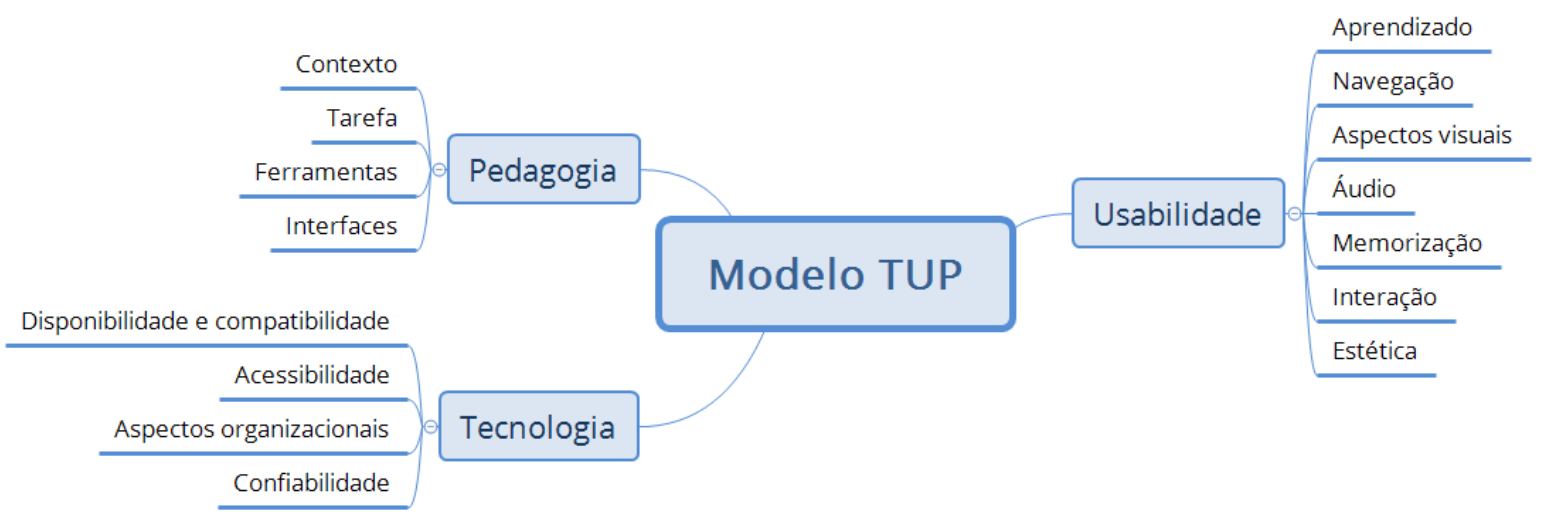

Figura 9 - Modelo de Qualidade TUP. Adaptado de Bednarik (2002)

- Pedagogia

- Contexto: capacidade em se adaptar ao contexto do usuário, considerando as diferenças étnicas e culturais, proporcionando ganho de conhecimento considerando as necessidades particulares de cada aluno;

- Tarefa: capacidade em oferecer atividades que compõem o ambiente de aprendizado, considerando os meios, ambiente e condições que contribuem para alcançar os objetivos de aprendizagem; 
- Ferramentas: capacidade em fornecer ferramentas que possibilitam a compreensão de todo o processo de aprendizagem;

- Interfaces: capacidade em adaptar a interface de acordo com as tarefas executadas e as necessidades dos usuários.

- Tecnologia

- Disponibilidade e compatibilidade: capacidade em disponibilizar e manter a compatibilidade do software, considerando fatores que representam possíveis influências do equipamento para os usuários e seu desempenho;

- Acessibilidade: capacidade em se adequar aos diferentes grupos de usuários na perspectiva das suas características e limitações;

- Aspectos organizacionais: capacidade em considerar as questões de treinamento, administração, manutenção, integração das tarefas e aspectos financeiros relacionados ao software;

- Confiabilidade: capacidade do software se comportar da maneira que se espera, além de prover formas de garantia da confiabilidade.

- Usabilidade

- Aprendizado: capacidade em possibilitar a familiaridade rápida com o software, não necessitando de grandes períodos de treinamento, além de fornecer opções avançadas para usuários mais experientes;

- Navegação: capacidade em fornecer navegação fácil e natural para os usuários;

- Aspectos visuais: capacidade em prover textos legíveis, imagens e gráficos adequadamente, além de disponibilizar esses recursos de forma organizada;

- Áudio: capacidade em utilizar os sons adequadamente;

- Memorização: capacidade em fornecer funções intuitivas e fáceis de memorizar, evitando que o usuário necessite reaprender funcionalidades que já utilizou antes;

- Interação: capacidade me fornecer diferentes maneiras de interação entre o usuário e o software;

- Estética: capacidade em oferecer ao usuário um software visivelmente agradável, colaborando assim para a satisfação do usuário.

Apesar do modelo TUP oferecer a avaliação de qualidade considerando a perspectiva de softwares educacionais, ele não considera os aspectos de aplicativos móveis. Além disso, o TUP não possui uma classificação final do aplicativo, que permitiria indicar o nível de qualidade. 


\subsection{Considerações Finais}

Neste capítulo foi apresentada uma visão geral sobre a aprendizagem móvel, suas definições e características, além dos tipos de dispositivos móveis existentes. Por meio dessas informações, percebe-se que a variedade de dispositivos e as limitações de hardware e infraestrutura de rede fazem com que os aplicativos tenham uma maior complexidade em seu desenvolvimento. Também foram apresentados os benefícios e limitações da aprendizagem móvel, assim como exemplos de aplicativos que estão disponíveis para uso. As informações apresentadas são importantes para a concepção do método MoLEva, já que para fazer uma avaliação de qualidade é necessário conhecer o contexto de aprendizagem móvel, além de suas vantagens e limitações.

Além disso, neste capítulo foram apresentados conceitos sobre qualidade de software e modelos de qualidade existentes. Também foi descrita a norma ISO/IEC 25000, que estabelece formas de garantir a qualidade de um produto de software. O entendimento desta norma é fundamental, já que este trabalho a utiliza como guia durante seu desenvolvimento.

Outro modelo de qualidade importante apresentado foi o TUP, que tem como objetivo a avaliação de qualidade de softwares educacionais. Esse modelo foi fundamental no desenvolvimento e avaliação do método MoLEva, descrito no Capítulo 4.

A partir das informações obtidas neste capítulo, observou-se a necessidade de um estudo sobre as características de qualidade relacionadas aos aplicativos educacionais móveis, já que dentre os modelos apresentados nenhum era específico para este contexto.

Assim, no próximo capítulo é apresentado um mapeamento sistemático realizado com o propósito de identificar as características de qualidade relacionadas aos aplicativos m-learning e suas respectivas métricas, caso existam. 

CAPÍTULO

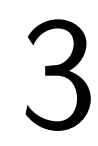

\section{CARACTERÍSTICAS DE QUALIDADE DE APLICATIVOS EDUCACIONAIS MÓVEIS: UM MAPEAMENTO SISTEMÁTICO}

\subsection{Considerações Iniciais}

A qualidade de um aplicativo educacional móvel pode ser descrita a partir das características de qualidade de software definidas para esse contexto (SARRAB; ELBASIR; ALNAELI, 2016). Embora existam padrões de qualidade que definem essas características como, por exemplo, a norma ISO 25010 (ISO/IEC 25010, 2010), o contexto de aplicativos educacionais móveis possui especificidades que esses padrões genéricos não apoiam.

De fato, em aplicativos educacionais móveis existem aspectos técnicos e não técnicos (pedagógicos, socioeconômicos e socioculturais) que devem ser considerados como critérios de qualidade em um aplicativo desse tipo (ECONOMIDES, 2008).

Devido a essas particularidades e considerando que um dos componentes do método de qualidade MoLEva é o seu modelo de qualidade que, por sua vez, é composto por um conjunto de características de qualidade para o contexto de aplicativos educacionais móveis, optou-se por fazer um estudo que identificasse tais características de qualidade.

Para o desenvolvimento desse estudo, foi realizado um mapeamento sistemático. De acordo com Kitchenham e Charters (2007), o mapeamento sistemático é um estudo que tem como objetivo identificar os estudos primários referentes a uma área de pesquisa, permitindo ter uma visão ampla. Esse tipo de estudo é caracterizado por ser um estudo secundário, já que ele é composto por um conjunto de estudos primários. Dessa forma, é possível identificar evidências e também lacunas sobre a pesquisa desejada.

O conjunto de características identificados no mapeamento sistemático contribuiu 
para o desenvolvimento do método MoLEva, sobre tudo no estabelecimento de seu modelo de qualidade.

Este capítulo está organizado da seguinte maneira: na Seção 3.2 é descrito o planejamento do mapeamento sistemático. Na Seção 3.3 é apresentada a condução do mapeamento sistemático, sendo descritos os objetivos e questões de pesquisa, a construção da string de busca e a seleção dos estudos. Na Seção 3.4 é apresentada a análise dos resultados obtidos. Por fim, na Seção 3.5 são apresentadas as considerações finais.

\subsection{Planejamento do Mapeamento Sistemático}

O mapeamento sistemático conduzido tem como objetivo identificar, classificar e analisar estudos que definem características de qualidade relacionadas aos aplicativos educacionais móveis e, caso existam, identificar também as métricas relacionadas a eles. Dessa forma, é possível identificar as possíveis características de qualidade a serem consideradas no método MoLEva.

Para categorizar as características identificadas, foram consideradas quatro categorias: (i) técnicas, (ii) pedagógicas, (iii) socioeconômicas, e (iv) socioculturais.

Além disso, este estudo também tem como objetivo identificar as características relacionadas aos dispositivos móveis que porventura possam afetar a qualidade de um aplicativo m-learning. A identificação dessas características é importante, já que o desenvolvimento de um aplicativo deve considerar as limitações desse tipo de dispositivo.

Por fim, para a condução desse estudo foi utilizado o processo de mapeamento sistemático definido em Kitchenham e Charters (2007), que sugere uma sequência de seis etapas definidas em um protocolo de pesquisa. As etapas são: (i) definição das questões de pesquisa; (ii) definição da string de pesquisa; (iii) definição dos critérios de inclusão e exclusão; (iv) seleção dos estudos primários relevantes; (v) extração dos dados; e (vi) síntese dos resultados.

\subsubsection{Questões de Pesquisa}

Para atingir os objetivos estabelecidos, é fundamental que as questões de pesquisa sejam bem definidas. Para tal, utilizou-se o critério de definição PICOC (Population, Interventation, Comparison, Outcome, Context), proposto por Petticrew e Roberts (2008). A definição do PICOC, para este contexto, obteve o seguinte resultado:

- População (population): aplicativos m-learning;

- Intervenção (interventation): características de qualidade, métricas e dispositivos móveis; 
- Comparação (comparison): não se aplica;

- Resultados (outcome): características e métricas relacionadas à qualidade de um aplicativo m-learning;

- Contexto (context): acadêmico e industrial.

Após o preenchimento dos critérios definidos no PICOC e considerando a divisão de características de qualidade para aplicativos m-learning definidas por Economides (2008), as seguintes questões de pesquisa foram criadas:

- QP1 - Quais são as características dos dispositivos móveis que podem afetar a qualidade dos aplicativos m-learning?

- QP2 - Quais são as características técnicas relacionadas à qualidade dos aplicativos m-learning?

- QP2.1 - Existem métricas definidas?

- QP3 - Quais são as características pedagógicas relacionadas à qualidade dos aplicativos m-learning?

- QP3.1 - Existem métricas definidas?

- QP4 - Quais são as características socioeconômicas relacionadas à qualidade dos aplicativos m-learning?

- QP4.1 - Existem métricas definidas?

- QP5 - Quais são as características socioculturais relacionadas à qualidade dos aplicativos m-learning?

- QP5.1 - Existem métricas definidas?

\subsubsection{Estratégia de Busca}

Nesta seção são definidas as estratégias de busca utilizadas na recuperação dos estudos, bem como as fontes de busca, idiomas dos textos, palavras-chave e os critérios de inclusão e exclusão. 


\section{Fontes de Busca}

As fontes de busca foram definidas considerando-se as principais bases de pesquisa que indexam estudos relacionados a Ciências da Computação. Portanto, as bases definidas foram: IEEEXplorer ${ }^{1}, \mathrm{ACM}^{2}$, Science Direct ${ }^{3}$, Scopus $^{4}$ e Web of Science ${ }^{5}$.

Além das fontes de busca apresentadas, também foram realizadas buscas nos seguintes periódicos: Computer \& Education, IEEE Transactions on Learning, ACM Transactions on Computing Education, International Journal on E-Learning, Ubiquitous Learning: An International Journal e International Journal of Interactive Mobile Technologies. Além disso, foram realizadas buscas nos anais: Mobile Learning Conference, Simpósio Brasileiro de Qualidade de Software e International Conference on Quality Software.

\section{Idioma dos Textos}

Os idiomas dos estudos pesquisados foram definidos considerando-se o idioma mais utilizado nas publicações internacionais e o idioma local dos pesquisadores que conduziram o mapeamento sistemático. Sendo assim, os idiomas escolhidos foram inglês e português.

\section{Palavras-chave}

As palavras-chave definidas para realização do mapeamento sistemático foram: aprendizagem móvel, características de qualidade, qualidade de software, métrica de qualidade, modelo de qualidade e avaliação de qualidade.

\subsubsection{Seleção de Estudos}

O processo de seleção dos estudos é feito por meio de critérios de inclusão e exclusão, definidos de acordo com os objetivos da pesquisa. Para realizar a seleção dos estudos obtidos neste mapeamento sistemático, foram definidos os seguintes critérios de inclusão:

- Estudos relacionados a m-learning e que apresentam características de qualidade;

- Estudos que apresentam métricas de qualidade relacionadas a m-learning;

- Estudos relacionados a avaliações de qualidade para m-learning.

Além dos critérios de inclusão, os estudos devem respeitar os critérios de exclusão, para definir se eles devem ser selecionados ou não. Os critérios de exclusão são:

\footnotetext{
1 IEEEXplorer: ieeexplore.ieee.org

2 ACM: dl.acm.org

3 Science Direct: www.sciencedirect.com

4 Scopus: www.scopus.com

5 Web of Science: webofknowledge.com
} 
- Estudos duplicados;

- Estudos em idiomas que não sejam inglês ou português;

- Estudos não disponíveis para acesso.

\subsection{Condução do Mapeamento Sistemático}

Nesta seção é detalhado como o mapeamento sistemático foi conduzido, apresentando a construção da string de busca e as seleções preliminares e finais dos estudos.

\subsubsection{Construção da String de Busca}

Para a construção da string de busca foram consideradas as palavras-chave relacionadas aos objetivos do estudo. As palavras-chave que compõem a string foram selecionadas após testes nas bases de pesquisa nas quais elas seriam aplicadas.

Após os testes, a string de busca genérica construída foi:

("m-learning" $\boldsymbol{O R}$ "mobile learning") $\boldsymbol{A} \boldsymbol{N D}$ ("quality characteristic" $\boldsymbol{O R}$ "quality metric" $\boldsymbol{O R}$ "quality model" $\boldsymbol{O R}$ "software quality" $\boldsymbol{O R}$ "quality evaluation")

\subsubsection{Seleção Preliminar dos Estudos}

A seleção preliminar dos estudos foi realizada executando a string de busca nas fontes de pesquisa definidas.

Após cada execução da string, foram extraídas as informações: título, resumo e palavras-chave. Baseando-se na extração dessas informações, foram aplicados os critérios de inclusão. O resultado da seleção preliminar é apresentado na Tabela 2.

As buscas foram realizadas em outubro de 2014, considerando todos os estudos publicados anteriormente a esta data. Apesar do mapeamento ter sido executado em 2014, essas características foram atualizadas no decorrer da pesquisa. Sua evolução é mostrada no Capítulo 4, no qual o método MoLEva é apresentado.

\subsubsection{Seleção dos Estudos}

Após a seleção preliminar, foram selecionados 19 estudos, dos quais nove foram considerados após a aplicação dos critérios de exclusão. Com o objetivo de identificar mais estudos relacionados às características de qualidade de aplicativos educacionais móveis, optou-se por realizar buscas informais a fim de complementar o mapeamento sistemático. 
Capítulo 3. Características de Qualidade de Aplicativos Educacionais Móveis: Um

Tabela 2 - Resultado da Seleção Preliminar

\begin{tabular}{l|l|l}
\hline Fonte de Busca & Resultado & Selecionados \\
\hline IEEEXplorer & 6 & 3 \\
\hline ACM & 18 & 2 \\
\hline Science Direct & 11 & 0 \\
\hline Scopus & 8 & 8 \\
\hline Web of Science & 4 & 4 \\
\hline Computers \& Education & 0 & 0 \\
\hline IEEE Transactions on Learning & 1 & 0 \\
\hline ACM Transactions on Computing Education & 0 & 0 \\
\hline International Journal on E-Learning & 0 & 0 \\
\hline Ubiquitous Learning: An International Journal & 0 & 0 \\
\hline International Journal of Interactive Mobile Technologies & 2 & 2 \\
\hline Mobile Learning Conference & 0 & 0 \\
\hline Simpósio Brasileiro de Qualidade de Software & 1 & 0 \\
\hline International Conference on Quality Software & 0 & 0 \\
\hline \hline Total & $\mathbf{5 1}$ & $\mathbf{1 9}$
\end{tabular}

As buscas informais foram conduzidas utilizando-se a base de pesquisa Google Scholar ${ }^{6}$. Para tal, utilizaram-se as palavras-chave contidas na string de busca definida para serem executadas nas fontes de pesquisa. Além disso, também foram realizadas buscas nas referências dos estudos selecionados.

O resultado das buscas informais foi a seleção de 14 estudos, que adicionados às pesquisas anteriores, totalizaram 23 estudos, conforme apresentado na Tabela 3.

\subsection{Resultados e Análise}

Após a seleção e leitura completa dos estudos, foram extraídos os dados relevantes para responder as questões de pesquisa. Analisando o gráfico da Figura 10, é possível observar que houve um aumento na quantidade de estudos relacionados à qualidade de aplicativos m-learning considerando-se o período de 2003 à 2014 (o volume baixo de 2014 se deve ao fato dos estudos publicados neste ano ainda não estarem disponíveis).

Entretanto, o número de estudos ainda é baixo. Um reflexo desse resultado foram os poucos estudos selecionados durante a pesquisa. Esse resultado mostra que essa é uma área de estudo em que mais pesquisas precisam ser conduzidas.

A síntese e análise das informações extraídas dos estudos são apresentadas a seguir, de acordo com cada questão de pesquisa.

QP1 - Quais são as características dos dispositivos móveis que podem afetar

6 Google Scholar: https://scholar.google.com.br 
Tabela 3 - Resultado da Seleção dos Estudos

\begin{tabular}{|c|c|}
\hline Ref. & Título \\
\hline (ALI; OUDA; CAPRETZ, 2012) & $\begin{array}{l}\text { A Conceptual Framework for Measuring the Quality Aspects of Mobile } \\
\text { Learning }\end{array}$ \\
\hline $\begin{array}{l}\text { (DUARTE-FILHO; BARBOSA, } \\
\text { 2013a) }\end{array}$ & $\begin{array}{l}\text { A contribution to the quality evaluation of mobile learning environ- } \\
\text { ments }\end{array}$ \\
\hline (PARSONS; RYU, 2006) & A Framework for Assessing the Quality of Mobile Learning \\
\hline $\begin{array}{l}\text { (DUARTE-FILHO; BARBOSA, } \\
\text { 2013b) }\end{array}$ & A requirements catalog for mobile learning environments \\
\hline (TAYLOR, 2004) & $\begin{array}{l}\text { A task-centred Approach to Evaluating a Mobile Learning Environment } \\
\text { for Pedagogical Soundness }\end{array}$ \\
\hline (BOJA; BATAGAN, 2009) & Analysis of M-Learning Application Quality \\
\hline $\begin{array}{l}\text { (MOSTAKHDEMIN-HOSSEINI, } \\
2009)\end{array}$ & Analysis of Pedagogical Considerations of M-Le \\
\hline (ACHARYA; SINHA, 2013) & Assessing the Quality of M-Learning Systems using ISO \\
\hline $\begin{array}{l}\text { (POCATILU; DOINEA; CIUREA, } \\
2010)\end{array}$ & Development of distributed mobile lea \\
\hline $\begin{array}{l}\text { (REIS; } \quad \text { ESCUDEIRO; } \\
\text { DEIRO, 2012) }\end{array}$ & Educational Res \\
\hline $\begin{array}{l}\text { (AVELLIS; SCARAMUZZI; FIN- } \\
\text { KELSTEIN, 2003) }\end{array}$ & $\begin{array}{l}\text { Evaluating non functional requirements in mobile learning contents and } \\
\text { multimedia educational software }\end{array}$ \\
\hline $\begin{array}{l}\text { (ESCUDEIRO; } \quad \text { ESCUDEIRO, } \\
2012)\end{array}$ & $\begin{array}{l}\text { Evaluation of Serious Games in Mobile Platforms with QEF: QEF } \\
\text { (Quantitative Evaluation Framework) }\end{array}$ \\
\hline $\begin{array}{l}\text { (DUARTE-FILHO; BARBOSA, } \\
2012 \text { ) }\end{array}$ & $\begin{array}{l}\text { Estudo e Definição de um Conjunto de Características e Requisitos para } \\
\text { Ambientes de Aprendizagem Móvel }\end{array}$ \\
\hline (AVELLIS, 2014) & $\begin{array}{l}\text { Mobile Learning and Multimidia Educational Software Requirements' } \\
\text { Evaluation }\end{array}$ \\
\hline (ZORAN et al., 2012) & Quality Aspects and Metrics in M-Learning Information Systems \\
\hline $\begin{array}{l}\text { (SPRIESTERSBACH; } \quad \text { SPRIN- } \\
\text { GER, 2004) }\end{array}$ & Quality Attributes in Mobile Web Application Development \\
\hline (POCATILU; BOJA, 2009) & Quality Characteristics and Metrics related to M-Learning Process \\
\hline (ZAMFIROIU, 2014) & Quality Metrics for Evaluation Process in M-Learning Environment \\
\hline (GAFNI, 2009) & Quality Metrics for PDA-based M-Learning Information Systems \\
\hline $\begin{array}{l}\text { (VISOIU; BATAGAN; BOJA, } \\
\text { 2009) }\end{array}$ & Quality Model for M-Learning Applications \\
\hline (ECONOMIDES, 2008) & Requirements of Mobile Learning Applications \\
\hline $\begin{array}{lll}\text { (HUJAINAH; } & \text { DAHLAN; } & \text { AL- } \\
\text { HAIMI, 2013) } & & \end{array}$ & Usability Guidelines of Mobile Learning Application \\
\hline (BOJA; BaTaGAN; VIsOIU, 2011) & $\begin{array}{l}\text { Validation of a multi-criteria model used to evaluate M-Learning a } \\
\text { cations quality }\end{array}$ \\
\hline
\end{tabular}

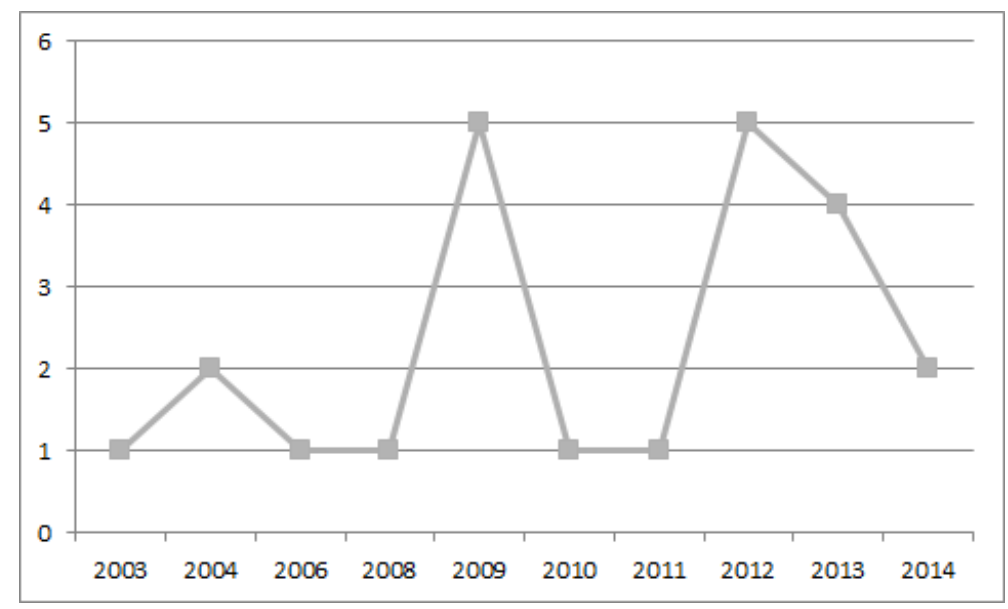

Figura 10 - Estudos sobre Qualidade Publicados no Período de 2003 - 2014

\section{a qualidade dos aplicativos m-learning?}

As características dos dispositivos móveis podem afetar diretamente a qualidade de 
um aplicativo m-learning. Por este motivo, deve-se entender suas características visando adequar o aplicativo para diminuir os seus impactos.

Para responder esta questão de pesquisa, as características dos dispositivos móveis foram divididas em duas categorias: comunicação e hardware. Considerando estas categorias, foram identificadas três características relacionadas à comunicação (banda estreita, falta de cobertura e instabilidade da conexão) e seis ao hardware (teclado pequeno, tela pequena, memória com pouca capacidade, baixo poder de processamento, baixa autonomia da bateria e diversidade de dispositivos), conforme apresentado na Tabela 4.

Tabela 4 - Características dos Dispositivos Móveis que Podem Afetar a Qualidade de Aplicativos m-learning

\begin{tabular}{|c|c|c|}
\hline Categoria & Característica & Descrição \\
\hline \multirow[t]{3}{*}{ Comunicação } & Banda estreita & $\begin{array}{l}\text { Com uma banda estreita, os aplicativos podem } \\
\text { não funcionar corretamente, vindo a ter um de- } \\
\text { sempenho inferior. Por este motivo, os aplicativos } \\
\text { precisam adaptar-se de acordo com a largura da } \\
\text { banda. }\end{array}$ \\
\hline & Falta de cobertura & $\begin{array}{l}\text { As operadoras de telefonia possuem falhas em sua } \\
\text { cobertura. Por este motivo, os aplicativos podem } \\
\text { ficar desconectados. Este problema é ainda mais } \\
\text { sério quando o aplicativo é totalmente dependente } \\
\text { de uma conexão com a Internet. }\end{array}$ \\
\hline & Instabilidade da conexão & $\begin{array}{l}\text { A conexão do dispositivo com a Internet pode so- } \\
\text { frer instabilidades, fazendo com que seja perdida } \\
\text { ou fique com uma velocidade menor, prejudicando } \\
\text { assim o aplicativo que a está utilizando. }\end{array}$ \\
\hline \multirow[t]{6}{*}{ Hardware } & Teclado pequeno & $\begin{array}{l}\text { Pode prejudicar a entrada de dados nos aplicati- } \\
\text { vos, devido ao seu tamanho. }\end{array}$ \\
\hline & Tela pequena & $\begin{array}{l}\text { Devido ao tamanho da tela, pode-se ter limitações } \\
\text { na apresentação de dados para o usuário. }\end{array}$ \\
\hline & Memória com pouca capacidade & $\begin{array}{l}\text { Os aplicativos precisam ser otimizados, a fim de } \\
\text { consumir apenas a quantidade de memória neces- } \\
\text { sária, evitando assim o desperdício. }\end{array}$ \\
\hline & Baixo poder de processamento & $\begin{array}{l}\text { Apesar da evolução dos processadores dos dispo- } \\
\text { sitivos móveis, o poder de processamento sempre } \\
\text { deve ser uma característica considerada no desen- } \\
\text { volvimento de aplicativos. Por esse motivo, elas } \\
\text { devem ser desenvolvidas sempre pensando na oti- } \\
\text { mização, permitindo que o aplicativo possa ser uti- } \\
\text { lizado em diversos tipos de dispositivos. }\end{array}$ \\
\hline & Baixa autonomia da bateria & $\begin{array}{l}\text { Devido à pouca autonomia das baterias, deve-se } \\
\text { economizar o seu uso, evitando a execução de pro- } \\
\text { cessos que possam consumi-la sem necessidade. }\end{array}$ \\
\hline & Diversidade de dispositivos & $\begin{array}{l}\text { Os aplicativos devem ser construídos com base na } \\
\text { diversidade de dispositivos móveis disponíveis no } \\
\text { mercado. }\end{array}$ \\
\hline
\end{tabular}

\section{QP2 - Quais são as características técnicas relacionadas à qualidade dos apli- cativos m-learning?}

Para auxiliar na síntese das informações extraídas para responder esta questão, as informações foram classificadas de acordo com os aspectos de qualidade definidos pela ISO/IEC 25010 (2010). A Tabela 5 apresenta o resultado relacionado à Adequação Funcional, que é definida como a capacidade de disponibilizar funções que atendam às necessidades implícitas e explícitas em relação ao aplicativo. 
Tabela 5 - Características Relacionadas à Adequação Funcional

\begin{tabular}{|c|c|}
\hline Característica & Descrição \\
\hline $\begin{array}{l}\text { Capacidade de comunicação } \\
\text { (BOJA; BATAGAN, 2009; } \\
\text { DUARTE-FILHO; BARBOSA, } \\
\text { 2013b; ECONOMIDES, 2008) }\end{array}$ & $\begin{array}{l}\text { Deve permitir a transmissão de dados entre múltiplos dispositivos, sem } \\
\text { que os mesmos sejam danificados. Aborda, desta forma, mais uma ca- } \\
\text { racterística que é a confiabilidade. }\end{array}$ \\
\hline $\begin{array}{l}\text { Recursos multimídia (POCATILU; } \\
\text { BOJA, 2009; DUARTE-FILHO; } \\
\text { BARBOSA, 2013b; ECONOMI- } \\
\text { DES, 2008) }\end{array}$ & $\begin{array}{l}\text { Deve apoiar diferentes tipos de mídias, como vídeo, texto, áudio, entre } \\
\text { outros. A exploração dos recursos multimídia deve ser feita com cuidado, } \\
\text { já que alguns deles podem afetar o desempenho do aplicativo. }\end{array}$ \\
\hline $\begin{array}{l}\text { Completude das características } \\
\text { (ACHARYA; SINHA, 2013) }\end{array}$ & $\begin{array}{l}\text { As características propostas durante o projeto do aplicativo devem ser } \\
\text { realmente implementadas. Algumas melhorias no projeto podem ser } \\
\text { identificadas durante o desenvolvimento. Por este motivo, pode-se subs- } \\
\text { tituir ou incluir novas características, porém a definição final deverá } \\
\text { apresentar todas as características estabelecidas. }\end{array}$ \\
\hline $\begin{array}{l}\text { Compactação de mensagem } \\
\text { (ACHARY; SINHA, 2013) }\end{array}$ & $\begin{array}{l}\text { O grau em que o sistema permite a fácil troca de SMS entre os alunos e } \\
\text { tutores, independente de hora e local. A compactação da mensagem agi- } \\
\text { liza a comunicação, já que as mensagens serão mais curtas, permitindo } \\
\text { maior agilidade na escrita e na leitura. }\end{array}$ \\
\hline $\begin{array}{l}\text { Precisão (DUARTE-FILHO; BAR- } \\
\text { BOSA, 2013b; ECONOMIDES, } \\
\text { 2008) }\end{array}$ & $\begin{array}{l}\text { Fornecer resultados precisos, ou seja, os resultados fornecidos devem } \\
\text { ser exatos, não podendo conter erros. Se esta característica não for } \\
\text { satisfeita, ela pode afetar a confiabilidade do aplicativo. }\end{array}$ \\
\hline $\begin{array}{l}\text { Concisão das mensagens (GAFNI, } \\
\text { 2009) }\end{array}$ & $\begin{array}{l}\text { As mensagens operacionais e de erro devem ser concisas, ou seja, de- } \\
\text { vem ser resumidas, precisas e exatas, além de serem armazenadas na } \\
\text { memória e fáceis de serem lidas na tela do dispositivo. }\end{array}$ \\
\hline $\begin{array}{l}\text { Eficácia de execução de tare- } \\
\text { fas (SPRIESTERSBACH; SPRIN- } \\
\text { GER, 2004) }\end{array}$ & $\begin{array}{l}\text { Facilidade de execução das tarefas, minimizando o tempo, os gastos com } \\
\text { conexão e a quantidade de dados transportados durante as operações. }\end{array}$ \\
\hline $\begin{array}{l}\text { Mudança de contexto (SPRIES- } \\
\text { TERSBACH; SPRINGER, 2004) }\end{array}$ & $\begin{array}{l}\text { Comportamento do aplicativo ao mudar o contexto (por exemplo, } \\
\text { quando um campo de entrada depende da localização do usuário, ele de- } \\
\text { verá ser alterado quando o usuário se mover). As funções que dependem } \\
\text { da localização também devem se adequar às mudanças. }\end{array}$ \\
\hline $\begin{array}{l}\text { Variação da rede (SPRIESTERS- } \\
\text { BACH; SPRINGER, 2004) }\end{array}$ & $\begin{array}{l}\text { Comportamento do aplicativo ao variar sua conexão (por exemplo, } \\
\text { pode-se optar por trabalhar apenas com texto, eliminando as imagens } \\
\text { e permitindo o funcionamento mesmo com uma conexão ruim). }\end{array}$ \\
\hline $\begin{array}{l}\text { Adaptação as condições físicas } \\
\text { (DUARTE-FILHO; BARBOSA, } \\
\text { 2013b; ECONOMIDES, 2008) }\end{array}$ & $\begin{array}{l}\text { O grau em que o aplicativo se adapta às condições físicas, por exemplo, } \\
\text { ajuste de luz, controle de ruído, condições climáticas, entre outros. }\end{array}$ \\
\hline $\begin{array}{l}\text { Interface amigável (HUJAINAH; } \\
\text { DAHLAN; AL-HAIMI, 2013; ECO- } \\
\text { NOMIDES, 2008) }\end{array}$ & $\begin{array}{l}\text { O grau de superação das dificuldades para inserir dados por meio de } \\
\text { telas e teclados pequenos. Uma interface amigável é necessária já que } \\
\text { existem diversos tipos de dispositivos, alguns com teclados outros sem, } \\
\text { além de diferentes tamanhos de telas. }\end{array}$ \\
\hline $\begin{array}{l}\text { Carregamento do display (GAFNI, } \\
\text { 2009; HUJAINAH; DAHLAN; AL- } \\
\text { HAIMI, 2013) }\end{array}$ & $\begin{array}{l}\text { Mede a carga dos displays. Devido ao tamanho pequeno da tela, a com- } \\
\text { preensibilidade é menor quando está sobrecarregada. Por este motivo, } \\
\text { é necessário manter o mínimo possível de elementos na tela. }\end{array}$ \\
\hline $\begin{array}{l}\text { Telas por tarefa (GAFNI, 2009; HU- } \\
\text { JAINAH; DAHLAN; AL-HAIMI, } \\
\text { 2013) }\end{array}$ & $\begin{array}{l}\text { Mede o número de telas envolvidas em uma tarefa. Quanto menos telas, } \\
\text { melhor a eficácia da utilização da funcionalidade, já que assim o usuário } \\
\text { vai chegar mais rápido ao seu objetivo. Entretanto, deve-se evitar o } \\
\text { excesso de informações dispostas em uma única tela. }\end{array}$ \\
\hline $\begin{array}{l}\text { Facilidade de preenchimento dos } \\
\text { dados de entrada (GAFNI, 2009; } \\
\text { BOJA; BATAGAN, 2009; ECONO- } \\
\text { MIDES, 2008) }\end{array}$ & $\begin{array}{l}\text { Mede o quão fácil é o preenchimento dos campos de entrada, como o } \\
\text { uso de valores padrão, lista de valores e autocompletar. Deve-se sem- } \\
\text { pre minimizar a quantidade de dados necessárias para a execução das } \\
\text { tarefas do aplicativo. }\end{array}$ \\
\hline $\begin{array}{l}\text { Facilidade da saída de dados para } \\
\text { usuário (GAFNI, 2009; ECONOMI- } \\
\text { DES, 2008) }\end{array}$ & $\begin{array}{l}\text { Mede a adequação do comprimento da saída e o tamanho da tela do } \\
\text { dispositivo. Como os dispositivos possuem telas de diferentes tamanhos, } \\
\text { é necessário sempre adequar a saída de dados de acordo com elas. }\end{array}$ \\
\hline
\end{tabular}

Já para o aspecto Eficiência do Desempenho, que está relacionado com a verificação do desempenho do aplicativo em relação à quantidade de recursos utilizados sob condições estabelecidas, foram encontradas as características apresentadas na Tabela 6 .

A Tabela 7 apresenta as características relacionadas à Compatibilidade, que se refere à capacidade do aplicativo trocar informações ou realizar operações com outros 
Tabela 6 - Características Relacionadas à Eficiência do Desempenho

\begin{tabular}{l|l}
\hline Característica & Descrição \\
\hline Transferência de Dados (SPRIES- & $\begin{array}{l}\text { Os dados devem ser minimizados ao máximo, diminuindo assim seu } \\
\text { tempo de transferência. Além de diminuir o tempo de transferência, } \\
\text { esta característica ajuda o usuário a economizar a utilização do seu } \\
\text { pOCATILU; BOJA, 2009) }\end{array}$ \\
\hline Tempo de Carregamento (BOJA; & $\begin{array}{l}\text { Refere-se ao tempo de carregamento dos dados, ou seja, o tempo de } \\
\text { espera do usuário pelo carregamento completo das informações solici- }\end{array}$ \\
BATAGAN, 2009; VISOIU; BATA- \\
GAN; BOJA, 2009; POCATILU; \\
tadas. \\
VIsOIU, 2009; BOJA; BaTaGAN;
\end{tabular}

aplicativos, compartilhando o mesmo ambiente de hardware e/ou software.

Tabela 7 - Características Relacionadas à Compatibilidade

\begin{tabular}{l|l}
\hline Característica & Descrição \\
\hline Coexistência do aplicativo & $\begin{array}{l}\text { O grau em que vários outros aplicativos podem ser executados em um } \\
\text { dispositivo móvel durante a execução do aplicativo m-learning sem cau- } \\
\text { (ACHARY; SINHA, 2013; } \\
\text { DUARTE-FILHO; BARBOSA, } \\
\text { sar qualquer impacto negativo. }\end{array}$ \\
\hline $\begin{array}{l}\text { Expansibilidade (DUARTE- } \\
\text { FILHO; BARBOSA, 2013b; }\end{array}$ & $\begin{array}{l}\text { Grau em que o aplicativo pode se expandir por meio da comunicação } \\
\text { com outros aplicativos, ou seja, deve fornecer flexibilidade e integração. } \\
\text { ECONOMIDES, 2008) }\end{array}$ \\
& $\begin{array}{l}\text { Uma arquitetura orientada a serviços pode oferecer estas características } \\
\text { a um aplicativo m-learning. }\end{array}$ \\
\hline
\end{tabular}

A Tabela 8 apresenta o resultado associado à Usabilidade, que se refere à capacidade do aplicativo em ser utilizado por usuários específicos em um contexto específico, oferecendo maneiras que permitam o aplicativo ser entendido, aprendido, utilizado e atraente ao usuário.

Já para o aspecto Confiabilidade, que se refere à capacidade do aplicativo em proporcionar um comportamento consistente com o esperado durante um longo período de tempo, as características identificadas são apresentadas na Tabela 9.

Para o aspecto Segurança, que se refere à capacidade do aplicativo em proteger as informações e dados, protegendo-os de acesso não autorizado e garantindo seu acesso 
Tabela 8 - Características Relacionadas à Usabilidade

\begin{tabular}{|c|c|}
\hline Característica & Descrição \\
\hline $\begin{array}{l}\text { Tempo de aprendizado (SPRIESTERSBACH; } \\
\text { SPRINGER, 2004; BOJA; BATAGAN, 2009; } \\
\text { POCATILU; BOJA, 2009; DUARTE-FILHO; } \\
\text { BARBOSA, 2013b; REIS; ESCUDEIRO; ESCU- } \\
\text { DEIRO, 2012; ESCUDEIRO; ESCUDEIRO, 2012; } \\
\text { ALI; OUDA; CAPRETZ, 2012) }\end{array}$ & $\begin{array}{l}\text { Tempo em que o usuário consegue aprender a utilizar o } \\
\text { aplicativo. }\end{array}$ \\
\hline $\begin{array}{l}\text { Ajuda (DUARTE-FILHO; BARBOSA, 2013b; } \\
\text { REIS; ESCUDEIRO; ESCUDEIRO, 2012; ES- } \\
\text { CUDEIRO; ESCUDEIRO, 2012; ECONOMIDES, } \\
\text { 2008) }\end{array}$ & $\begin{array}{l}\text { Deve prover ajuda para o usuário na utilização do apli- } \\
\text { cativo, podendo ser incluído no próprio aplicativo ou dis- } \\
\text { ponível on-line. }\end{array}$ \\
\hline $\begin{array}{l}\text { Tempo de compreensão (SPRIESTERSBACH; } \\
\text { SPRINGER, 2004; ALI; OUDA; CAPRETZ, } \\
\text { 2012; HUJAINAH; DAHLAN; AL-HAIMI, 2013) }\end{array}$ & $\begin{array}{l}\text { Tempo gasto para que o usuário compreenda o aplica- } \\
\text { tivo. Para isso, a estrutura do aplicativo deve ser clara e } \\
\text { auxiliar sua compreensão. }\end{array}$ \\
\hline $\begin{array}{l}\text { Homogeneidade do layout (BOJA; BATAGAN, } \\
\text { 2009; VISOIU; BATAGAN; BOJA, 2009; POCA- } \\
\text { TILU; BOJA, 2009; BOJA; BaTaGAN; VIsOIU, } \\
\text { 2011) }\end{array}$ & $\begin{array}{l}\text { Os componentes de layout devem ser padronizados, ou } \\
\text { seja, deve-se manter as suas características em todas as } \\
\text { telas do aplicativo. }\end{array}$ \\
\hline $\begin{array}{l}\text { Homogeneidade dos componentes (BOJA; BATA- } \\
\text { GAN, 2009; VISOIU; BATAGAN; BOJA, 2009; } \\
\text { POCATILU; BOJA, 2009; BOJA; BaTaGAN; VI- } \\
\text { sOIU, 2011) }\end{array}$ & $\begin{array}{l}\text { Os componentes utilizados no aplicativo devem seguir um } \\
\text { padrão, evitando o uso de uma variedade muito grande } \\
\text { de componentes, o que poderia afetar no aprendizado da } \\
\text { utilização do aplicativo. }\end{array}$ \\
\hline $\begin{array}{l}\text { Entrada de dados (ACHARYA; SINHA, 2013; } \\
\text { SPRIESTERSBACH; SPRINGER, 2004; VI- } \\
\text { SOIU; BATAGAN; BOJA, 2009; POCATILU; } \\
\text { BOJA, 2009; BOJA; BaTaGAN; VIsOIU, 2011) }\end{array}$ & $\begin{array}{l}\text { Grau em que é facilitada a entrada de dados no aplica- } \\
\text { tivo. Não se deve exigir a entrada de muitos dados em } \\
\text { um aplicativo m-learning, já que existem dificuldades re- } \\
\text { lacionadas ao tamanho da tela e do teclado, diminuindo } \\
\text { a agilidade na entrada de dados para o aplicativo. }\end{array}$ \\
\hline $\begin{array}{l}\text { Navegação (BOJA; BATAGAN, 2009; ZORAN } \\
\text { et al., 2012; VISOIU; BATAGAN; BOJA, 2009; } \\
\text { POCATILU; BOJA, 2009; BOJA; BaTaGAN; VI- } \\
\text { sOIU, 2011; REIS; ESCUDEIRO; ESCUDEIRO, } \\
\text { 2012; AVELLIS, 2014; AVELLIS; SCARAMUZZI; } \\
\text { FINKELSTEIN, 2003; HUJAINAH; DAHLAN; } \\
\text { AL-HAIMI, 2013; ECONOMIDES, 2008; ESCU- } \\
\text { DEIRO; ESCUDEIRO, 2012) }\end{array}$ & $\begin{array}{l}\text { Eficiência da navegação pelo aplicativo (por exemplo, nú- } \\
\text { mero de passos que o usuário deve seguir para acessar } \\
\text { uma dada funcionalidade). O aplicativo deve ser bem es- } \\
\text { truturado permitindo fácil acesso aos conteúdos e ativi- } \\
\text { dades, além de permitir que os usuários possam controlar } \\
\text { suas ações. }\end{array}$ \\
\hline $\begin{array}{l}\text { Continuidade (BOJA; BATAGAN, 2009; VI- } \\
\text { SOIU; BATAGAN; BOJA, 2009; POCATILU; } \\
\text { BOJA, 2009; BOJA; BaTaGAN; VIsOIU, 2011) }\end{array}$ & $\begin{array}{l}\text { O usuário não deve chegar a um ponto do aplicativo sem } \\
\text { saída, ou seja, onde ele não consiga mais navegar pelo } \\
\text { aplicativo. }\end{array}$ \\
\hline $\begin{array}{l}\text { Apresentação de informações (SPRIESTERS- } \\
\text { BACH; SPRINGER, 2004; DUARTE-FILHO; } \\
\text { BARBOSA, 2013b; REIS; ESCUDEIRO; ES- } \\
\text { CUDEIRO, 2012; HUJAINAH; DAHLAN; AL- } \\
\text { HAIMI, 2013) }\end{array}$ & $\begin{array}{l}\text { Grau de limitação das informações de acordo com a área } \\
\text { de exibição da tela. As informações devem ser adaptadas } \\
\text { ao tamanho da tela ou divididas em páginas. }\end{array}$ \\
\hline $\begin{array}{l}\text { Atração/Motivação (BOJA; BATAGAN, 2009; } \\
\text { DUARE-FILHO; BARBOSA, 2013b; AVEL- } \\
\text { LIS, 2014; AVELLIS; SCARAMUZZI; FINKELS- } \\
\text { TEIN, 2003; HUJAINAH; DAHLAN; AL-HAIMI, } \\
\text { 2013) }\end{array}$ & $\begin{array}{l}\text { O aplicativo deve ser atrativo e motivar os usuários. Deve } \\
\text { ser esteticamente atraente e agradável de usar. }\end{array}$ \\
\hline $\begin{array}{l}\text { Diversidade de dispositivos (BOJA; BATAGAN, } \\
\text { 2009; DUARTE-FILHO; BARBOSA, 2013b; } \\
\text { ECONOMIDES, 2008) }\end{array}$ & $\begin{array}{l}\text { Os botões que um dispositivo apresenta podem ser úteis } \\
\text { para melhorar a usabilidade de maneira exclusiva. Os ele- } \\
\text { mentos como fundo, menus, botões e ícones da barra de } \\
\text { ferramentas devem ter uma harmonia estrutural. }\end{array}$ \\
\hline
\end{tabular}

de acordo com os diferentes níveis de autorização, foram identificadas as características apresentadas na Tabela 10.

Por fim, a Tabela 11 apresenta as características relacionadas à Portabilidade, que se refere à capacidade do aplicativo ser transferido de um hardware ou software para outro.

Com relação à característica "Capacidade de Manutenção", ela não será considerada, pois em nenhum estudo foi especificada alguma característica voltada especialmente 
Tabela 9 - Características Relacionadas à Confiabilidade

\begin{tabular}{|c|c|}
\hline Característica & Descrição \\
\hline $\begin{array}{l}\text { Acessível (DUARTE-FILHO; BAR- } \\
\text { BOSA, 2013b; ECONOMIDES, } \\
\text { 2008) }\end{array}$ & $\begin{array}{l}\text { O aplicativo deve estar disponível e acessível a qualquer hora e em } \\
\text { qualquer lugar. }\end{array}$ \\
\hline $\begin{array}{l}\text { Transferência } \text { de } r \text { dados } \\
\text { (ACHARYA; SINHA, 2013; } \\
\text { DUARTE-FILHO; } \quad \text { BARBOSA, } \\
\text { 2013b) }\end{array}$ & $\begin{array}{l}\text { Os dados devem ser transferidos, mesmo com desconexões, e caso não } \\
\text { seja possível a transferência, deve-se evitar a perda dos dados. Deve } \\
\text { também ser capaz de reparar os erros com o mínimo esforço e recursos, } \\
\text { além de ser transparente para os usuários. }\end{array}$ \\
\hline $\begin{array}{l}\text { Tempo de recuperação após desco- } \\
\text { nexão (ACHARYA; SINHA, 2013; } \\
\text { BOJA; BATAGAN, 2009; HUJAI- } \\
\text { NAH; DAHLAN; AL-HAIMI, 2013; } \\
\text { ECONOMIDES, 2008) }\end{array}$ & $\begin{array}{l}\text { O grau em que o aplicativo consegue restabelecer a conexão após uma } \\
\text { desconexão. O aplicativo deve funcionar mesmo com interrupções ines- } \\
\text { peradas. Caso ocorra, deve ser capaz de se recuperar ou guiar o usuário } \\
\text { para a recuperação. Desta forma, o usuário será capaz de reconhecer, } \\
\text { diagnosticar e recuperar-se de erros. }\end{array}$ \\
\hline
\end{tabular}

Tabela 10 - Características Relacionadas à Segurança

\begin{tabular}{|c|c|}
\hline Característica & Descrição \\
\hline $\begin{array}{l}\text { Acesso (ACHARYA; SINHA, 2013; DUARTE- } \\
\text { FILHO; BARBOSA, 2013b; POCATILU; DOI- } \\
\text { NEA; CIUREA, 2010; ECONOMIDES, 2008) }\end{array}$ & $\begin{array}{l}\text { Deve-se prover acesso seguro e privado, ou seja, o usuário } \\
\text { e seus dados devem ter a privacidade assegurada. }\end{array}$ \\
\hline $\begin{array}{l}\text { Criptografia (ACHARYA; SINHA, 2013; POCA- } \\
\text { TILU; DOINEA; CIUREA, 2010) }\end{array}$ & $\begin{array}{l}\text { Deve-se prover criptografia para os dados sensíveis trafe- } \\
\text { gados e armazenados pelo aplicativo. }\end{array}$ \\
\hline $\begin{array}{l}\text { Mensagens seguras e informações no dispositivo } \\
\text { (GAFNI, 2009) }\end{array}$ & $\begin{array}{l}\text { Mede o grau de utilização de mecanismos de segurança, } \\
\text { como identificação, autorização e confidencialidade. }\end{array}$ \\
\hline $\begin{array}{l}\text { Confiança (DUARTE-FILHO; BARBOSA, 2013b; } \\
\text { POCATILU; DOINEA; CIUREA, 2010; ECONO- } \\
\text { MIDES, 2008) }\end{array}$ & $\begin{array}{l}\text { Deve-se prover acesso apenas a usuários e aplicativos au- } \\
\text { torizados. }\end{array}$ \\
\hline $\begin{array}{l}\text { Permitir salvar pontos de backup em caso de } \\
\text { bateria baixa (POCATILU; DOINEA; CIUREA, } \\
\text { 2010) }\end{array}$ & $\begin{array}{l}\text { Como os dispositivos móveis podem ficar sem bateria, } \\
\text { é importante que existam pontos de backup, a fim de } \\
\text { recuperar o último estado do aplicativo em caso de falta } \\
\text { de energia. }\end{array}$ \\
\hline $\begin{array}{l}\text { Rastreabilidade (POCATILU; DOINEA; CIU- } \\
\text { REA, 2010) }\end{array}$ & $\begin{array}{l}\text { Deve-se manter os registros de eventos gravados. Desta } \\
\text { maneira é possível rastrear os caminhos feitos pelo usuá- } \\
\text { rio no aplicativo. }\end{array}$ \\
\hline $\begin{array}{l}\text { Autenticidade (POCATILU; DOINEA; CIUREA, } \\
\text { 2010) }\end{array}$ & Deve-se garantir a autenticidade das ações do usuário. \\
\hline Utilização de perfil de usuário (GAFNI, 2009) & $\begin{array}{l}\text { Mede o alcance em que o aplicativo se baseia no perfil } \\
\text { do usuário, ajustando entradas e saídas para usuário e } \\
\text { dispositivo. }\end{array}$ \\
\hline
\end{tabular}

Tabela 11 - Características Relacionadas à Portabilidade

\begin{tabular}{|c|c|}
\hline Característica & Descrição \\
\hline $\begin{array}{l}\text { Adaptação de dispositivos (SPRI- } \\
\text { ESTERSBACH; SPRINGER, } \\
\text { 2004; DUARTE-FILHO; BAR- } \\
\text { BOSA, 2013b) }\end{array}$ & $\begin{array}{l}\text { Grau em que o aplicativo consegue se adaptar a diferentes tipos de } \\
\text { dispositivos móveis. Com a grande quantidade de dispositivos móveis } \\
\text { e suas variadas características, o aplicativo deve conseguir se adaptar, } \\
\text { permitindo assim o acesso ao aplicativo por diversos dispositivos mó- } \\
\text { veis. }\end{array}$ \\
\hline $\begin{array}{l}\text { Sucesso de instalação (ACHARYA; } \\
\text { SINHA, 2013; GAFNI, 2009) }\end{array}$ & $\begin{array}{l}\text { O grau em que um aplicativo m-learning pode ser instalado ou desins- } \\
\text { talado com sucesso considerando vários tipos de redes e dispositivos. }\end{array}$ \\
\hline $\begin{array}{l}\text { Facilidade de instalação (GAFNI, } \\
\text { 2009; DUARTE-FILHO; BAR- } \\
\text { BOSA, 2013b; ECONOMIDES, } \\
\text { 2008) }\end{array}$ & $\begin{array}{l}\text { Tempo de instalação do aplicativo nos dispositivos. Deve ser facilmente } \\
\text { instalado no dispositivo móvel, evitando problemas de versão, sistemas } \\
\text { operacionais, distribuição, entre outros. }\end{array}$ \\
\hline 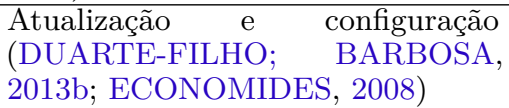 & $\begin{array}{l}\text { O aplicativo deve ser atualizado e configurado frequentemente. Essa } \\
\text { operação deve ser rápida e automática. }\end{array}$ \\
\hline
\end{tabular}

para aplicativos m-learning, sendo citado apenas que elas devem possuir as subcaracterísticas: Modularidade, Reusabilidade, Analisabilidade, Modificabilidade e Testabilidade. 
Algumas métricas específicas para características técnicas de aplicativos móveis também foram definidas. As métricas são apresentadas na Tabela 12.

QP3 - Quais são as características pedagógicas relacionadas à qualidade dos aplicativos m-learning?

As características pedagógicas identificadas foram divididas entre quatro categorias: (i) interatividade; (ii) aprendizagem; (iii) conteúdo; e (iv) aplicação. O primeiro resultado para essa questão de pesquisa é apresentado na Tabela 13, que possui as características relacionadas à Interatividade, que se refere à interação do usuário com a aplicação.

A Tabela 14, apresenta o resultado referente à Aprendizagem, que aborda as características relacionadas ao aprendizado.

A Tabela 15 apresenta as características relacionadas ao Conteúdo, que se refere aos materiais disponíveis para prover o aprendizado.

Por fim, a Tabela 16 apresenta as características relacionadas à Aplicação, que se refere aos aspectos técnicos do aplicativo relacionados às questões pedagógicas.

\section{QP3.1 - Existem métricas definidas?}

A Tabela 17 apresenta as métricas definidas sobre as características pedagógicas, sendo apresentadas em Acharya e Sinha (2013), Parsons e Ryu (2006) e Pocatilu e Boja (2009).

QP4 - Quais são as características socioeconômicas relacionadas à qualidade dos aplicativos m-learning?

As características socioeconômicas identificadas nos estudos selecionados são apresentadas na Tabela 18.

\section{QP4.1 - Existem métricas definidas?}

Não foram encontradas métricas definidas para as características socioeconômicas. QP5 - Quais são as características socioculturais relacionadas à qualidade dos aplicativos m-learning?

As características socioculturais encontradas durante a extração de dados dos estudos são apresentadas na Tabela 19.

\section{QP5.1 - Existem métricas métricas definidas?}

Não foram encontradas métricas definidas para as características socioculturais. 
Tabela 12 - Métricas relacionadas às características técnicas

\begin{tabular}{l}
\hline Métrica \\
\hline Caráter uniforme (padrão) dos componentes de \\
layout (VISOIU; BATAGAN; BOJA, 2009) \\
\hline Carregamento do display (GAFNI, 2009) \\
\hline Coexistência de aplicativo (ACHARYA; SINHA, \\
2013) \\
\hline Compactação de mensagem (ACHARYA; SINHA, \\
2013) \\
\hline Completude das características (ACHARYA; SI- \\
NHA, 2013) \\
\hline Comprimento do caminho (VISOIU; BATAGAN; \\
BOJA, 2009) \\
\hline Concisão das mensagens (GAFNI, 2009) \\
\hline Continuidade de interação (VISOIU; BATAGAN; \\
BOJA, 2009) \\
\hline Facilidade de instalação (GAFNI, 2009) \\
\hline Facilidade da saída de dados para usuário \\
(GAFNI, 2009) \\
\hline Facilidade de preenchimento dos dados de entrada \\
(GAFNI, 2009) \\
\hline Facilidade de uso: telas por tarefa (GAFNI, 2009) \\
Gomogeneidade da interface (VISOIU; BATA- \\
\hline BA 2009)
\end{tabular}

Interface amigável (ACHARYA; SINHA, 2013)

\section{Descrição}

Avalia o nível de padronização dos componentes de layout.

Mede a carga dos displays, devido ao tamanho pequeno da tela a compreensibilidade é menor quando a tela está sobrecarregada.

Grau em que várias outros aplicativos podem ser executados em um dispositivo móvel durante a execução do aplicativo m-learning sem causar qualquer impacto negativo.

Grau em que o aplicativo permite a fácil troca de SMS entre alunos e tutores, independentemente da hora e local.

Grau em que todas as características propostas no projeto podem ser realmente implementadas.

Indica a qualidade do percurso, ou seja, qual o tamanho do caminho para se ter acesso as funcionalidades

Mede a concisão das mensagens de texto operacionais e de erro.

Verifica o nível de qualidade da navegação no aplicativo, ou seja, permite o usuário navegar aos diversos pontos do aplicativo com facilidade.

Mede o tempo de instalação do aplicativo nos dispositivos.

Mede a adequação do comprimento da saída e o tamanho da tela do dispositivo.

Mede o quão fácil é o preenchimento dos campos de entrada

Mede o número de telas envolvidas em uma tarefa.

Verifica o nível de homogeneidade dos componentes de entrada, ou seja, verifica se os componentes utilizados para entrada de dados são sempre os mesmos seguindo um padrão

Grau de superação das dificuldades para inserir dados por meio de telas e teclados pequenos.

Limpeza de memória do dispositivo (GAFNI, 2009)

Mensagens seguras e informações no dispositivo (GAFNI, 2009)

Probabilidade média de recuperação de informações da memória do dispositivo (ACHARYA; SINHA, 2013)

Verifica o nível de limpeza de memória após executar uma tarefa.

Mede o grau de utilização de mecanismos de segurança, como identificação, autorização e confidencialidade.

Grau em que certos dados são gerados durante o processo e não podem ser transmitidos devido a problemas de rede e portanto, ficam armazenados na memória do dispositivo.

Qualidade baseada em cinco aspectos (ZORAN et al., 2012)

Mede a qualidade do aplicativo baseado em cinco aspectos: (i) qualidade do software; (ii) qualidade do dispositivo móvel; (iii) qualidade do acesso à Internet; (iv) nível de personalização do material de aprendizagem; e (v) competência dos responsáveis pelo ensino

Quantidade de entradas de dados (VISOIU; BATAGAN; BOJA, 2009)

Sistema de segurança (ACHARYA; SINHA, 2013)

Sucesso de instalação (ACHARYA; SINHA, 2013; GAFNI, 2009)

Taxa de compressão (POCATILU; BOJA, 2009)

Tempo de carregamento (VISOIU; BATAGAN; BOJA, 2009)

Tempo de resposta para obter informação do cache (GAFNI, 2009)

Tempo médio de recuperação após uma desconexão (ACHARYA; SINHA, 2013)

Tempo médio de resposta do servidor (ACHARYA; SINHA, 2013)

Utilização de perfil de usuário (GAFNI, 2009)
Avalia a quantidade de informações que o usuário precisa inserir no aplicativo.

Grau ao qual existe autenticação, encriptação e mecanismo de confidencialidade no aplicativo.

Grau em que um aplicativo m-learning pode ser instalado ou desinstalado com sucesso através de vários tipos de redes e dispositivos.

Mede o grau de influência das características de desempenho do aplicativo.

Mede o nível de qualidade em relação ao tempo de carregamento. zenadas na memória do dispositivo.

Grau em que o aplicativo consegue restabelecer a conexão após uma desconexão. consultas do usuário do aplicativo, independentemente da localização e horário.

Mede o alcance em que o aplicativo se baseia no perfil do usuário para ajustar as entradas e saídas para o usuário e o dispositivo.
Mede o tempo de resposta para obter informações arma-

Grau em que o aplicativo fornece resposta adequada às 
Tabela 13 - Características Relacionadas à Interatividade

\begin{tabular}{l|l}
\hline Característica & Descrição \\
\hline Feedback (PARSONS; RYU, 2006; DUARTE- & $\begin{array}{l}\text { Deve permitir o feedback recíproco entre professores e } \\
\text { alunos. }\end{array}$ \\
FILHO; BARBOSA, 2013b; MOSTAKHDEMIN- & \\
HOSSEINI, 2009; AVELLIS, 2014; AVELLIS; & \\
SCARAMUZZI; FINKELSTEIN, 2003; ECONO- & \\
MIDES, 2008) & \\
\hline Interação entre usuários (PARSONS; RYU, 2006; & $\begin{array}{l}\text { Deve permitir a interação entre os usuários do aplicativo } \\
\text { BOJA; BATAGAN, 2009; POCATILU; BOJA, }\end{array}$ \\
(por exemplo, entre alunos com alunos e tutores com alu- \\
MO09; DUARTE-FILHO; BARBOSA, 2013b; & nos). Essa interação pode ser realizada utilizando blogs, \\
MOSTAKHDEMIN-HOSSEINI, 2009; ECONO- & fóruns, grupos, entre outros. \\
MIDES, 2008) & \\
\hline
\end{tabular}

Tabela 14 - Características Relacionadas à Aprendizagem

\begin{tabular}{|c|c|}
\hline Característica & Descrição \\
\hline $\begin{array}{l}\text { Identificação de deficiências (PARSONS; RYU, } \\
\text { 2006) }\end{array}$ & $\begin{array}{l}\text { Deve auxiliar na identificação de lacunas de conheci- } \\
\text { mento. }\end{array}$ \\
\hline $\begin{array}{l}\text { Identificação de perfis (BOJA; BATAGAN, 2009; } \\
\text { AVELLIS, 2014; AVELLIS; SCARAMUZZI; FIN- } \\
\text { KELSTEIN, 2003; HUJAINAH; DAHLAN; AL- } \\
\text { HAIMI, 2013; ECONOMIDES, 2008) }\end{array}$ & $\begin{array}{l}\text { Identificar o perfil do aluno de acordo com suas caracte- } \\
\text { rísticas como idade, nível de conhecimento, habilidades } \\
\text { entre outros. }\end{array}$ \\
\hline $\begin{array}{l}\text { Processos educativos e de aprendizagem de- } \\
\text { finidos (BOJA; BATAGAN, 2009; AVELLIS, } \\
\text { 2014; AVELLIS; SCARAMUZZI; FINKELS- } \\
\text { TEIN, 2003; ECONOMIDES, 2008) }\end{array}$ & $\begin{array}{l}\text { Os processos educacionais e de aprendizagem envolvidos } \\
\text { no aplicativo devem ser bem definidos. }\end{array}$ \\
\hline $\begin{array}{l}\text { Ambiente de aprendizagem (ZORAN et al., 2012; } \\
\text { MOSTAKHDEMIN-HOSSEINI, 2009; REIS; ES- } \\
\text { CUDEIRO; ESCUDEIRO, 2012; ESCUDEIRO; } \\
\text { ESCUDEIRO, 2012; ECONOMIDES, 2008) }\end{array}$ & $\begin{array}{l}\text { Deve prover um ambiente que favoreça a aprendizagem } \\
\text { do aluno. O aplicativo deve permitir atividades que man- } \\
\text { tenham a curiosidade e o interesse dos alunos pelo con- } \\
\text { teúdo, sem provocar ansiedade. }\end{array}$ \\
\hline Ganho de conhecimento (ZORAN et al., 2012) & $\begin{array}{l}\text { O grau de ganho de conhecimento ao utilizar o aplica- } \\
\text { tivo. Para verificar este ganho de conhecimento é neces- } \\
\text { sário prover um sistema de avaliação, objetivando assim } \\
\text { a coleta dessa informação. }\end{array}$ \\
\hline $\begin{array}{l}\text { Conhecimento na hora certa (DUARTE-FILHO; } \\
\text { BARBOSA, 2013b) }\end{array}$ & $\begin{array}{l}\text { O conhecimento deve ser fornecido na hora certa (por } \\
\text { exemplo, para ensinar um conteúdo que necessite de pré- } \\
\text { requisito, deve-se primeiro garantir que o pré-requisito } \\
\text { foi atendido). }\end{array}$ \\
\hline $\begin{array}{l}\text { Atividades } \\
\text { BARBOSA, 2013b; REIS; ESCUDEIRO; ES- } \\
\text { CUDEIRO, 2012; ESCUDEIRO; ESCUDEIRO, } \\
\text { 2012) }\end{array}$ & $\begin{array}{l}\text { O aplicativo deve fornecer atividades voltadas para a edu- } \\
\text { cação. Deve fornecer diferente tipos de atividades para a } \\
\text { aquisição de conhecimento, além de fornecer ajuda para } \\
\text { os alunos como tutoria, orientação de atividades e refor- } \\
\text { ços. }\end{array}$ \\
\hline $\begin{array}{l}\text { Adaptação ao contexto (DUARTE-FILHO; BAR- } \\
\text { BOSA, 2013b) }\end{array}$ & $\begin{array}{l}\text { O aplicativo deve ser capaz de se adaptar ao contexto do } \\
\text { usuário, por exemplo, se adaptar a um usuário com idade } \\
\text { adulta e escolaridade baixa. }\end{array}$ \\
\hline 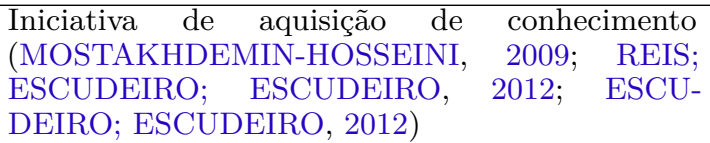 & $\begin{array}{l}\text { Deve estimular o usuário a tomar a iniciativa em adquirir } \\
\text { conhecimento fora do aplicativo m-learning. Deve permi- } \\
\text { tir que o aluno decida sobre quais tarefas realizar e a } \\
\text { escolha do assunto relacionado ao estudo. }\end{array}$ \\
\hline $\begin{array}{l}\text { Atividades de instrução (MOSTAKHDEMIN- } \\
\text { HOSSEINI, 2009) }\end{array}$ & $\begin{array}{l}\text { Deve fornecer instruções para guiar o usuário durante a } \\
\text { aprendizagem. }\end{array}$ \\
\hline
\end{tabular}

\subsection{Considerações Finais}

Neste capítulo foi apresentado um mapeamento sistemático que teve como objetivo identificar tanto características de qualidade para aplicativos m-learning como características de dispositivos móveis que podem afetar a sua qualidade.

Foram identificados, no total, 23 estudos. Apesar da quantidade de estudos ser baixa, foi possível identificar uma grande quantidade de características de qualidade. Além disso, também foi possível identificar métricas de qualidade, fornecendo evidências de téc- 
Tabela 15 - Características Relacionadas ao Conteúdo

\begin{tabular}{l|l}
\hline Característica & Descrição \\
\hline Qualidade de conteúdo (PARSONS; RYU, 2006; & $\begin{array}{l}\text { Deve prover conteúdo de alta qualidade. As informações } \\
\text { devem ser bem estruturadas e adequadas. O conteúdo } \\
\text { ZORAN et al., 2012; REIS; ESCUDEIRO; ESCU- relacionado com situações e problemas de in- } \\
\text { DEIRO, 2012; ESCUDEIRO; ESCUDEIRO, 2012; } \\
\text { ECONOMse do aluno. Não devem possuir erros ortográficos, } \\
\text { mensagens invasivas, negativas e com conteúdo de discri- } \\
\text { minação racial ou religiosa. }\end{array}$ \\
\hline $\begin{array}{l}\text { Usuário alvo (POCATILU; BOJA, 2009; AVEL- } \\
\text { LIS, 2014; AVELLIS; SCARAMUZZI; FINKELS- } \\
\text { TEIN, 2003) }\end{array}$ & $\begin{array}{l}\text { Deve-se definir o tipo de usuário que se deseja atingir. } \\
\text { Complexidade de multimídia (BOJA; BATAGAN, } \\
\text { 2009; POCATILU; BOJA, 2009) }\end{array}$ \\
\hline Fonte de conteúdo (POCATILU; BOJA, 2009) & O material disponibilizado deve ser de fonte confiável. \\
\hline $\begin{array}{l}\text { Gerenciamento de conteúdo (DUARTE-FILHO; } \\
\text { BARBOSA, 2013b) }\end{array}$ & $\begin{array}{l}\text { O conteúdo deve ser gerenciado, controlado e monito- } \\
\text { rado. }\end{array}$ \\
\hline $\begin{array}{l}\text { Integração de conteúdo (MOSTAKHDEMIN- } \\
\text { HOSSEINI, 2009) }\end{array}$ & $\begin{array}{l}\text { Os conteúdos devem ser integrados, provendo assim um } \\
\text { fluxo entre eles. }\end{array}$ \\
\hline Recursos didáticos (BOJA; BATAGAN, 2009) & $\begin{array}{l}\text { Deve prover recursos didáticos, auxiliando assim no } \\
\text { aprendizado. }\end{array}$ \\
\hline $\begin{array}{l}\text { Reutilização de conteúdo de aprendizagem } \\
\text { (ACHARYA; SINHA, 2013) }\end{array}$ & Deve-se utilizar o reuso de conteúdo. \\
\hline $\begin{array}{l}\text { Complexidade de conteúdo (POCATILU; BOJA, } \\
\text { 2009) }\end{array}$ & $\begin{array}{l}\text { O conteúdo não deve possuir excesso de informações nas } \\
\text { lições, além de não possuir uma complexidade que possa } \\
\text { afetar a compreensão do usuário. }\end{array}$ \\
\hline
\end{tabular}

Tabela 16 - Características Relacionadas à Aplicação

\begin{tabular}{l|l}
\hline Característica & Descrição \\
\hline $\begin{array}{l}\text { Visualizações separadas (DUARTE-FILHO; } \\
\text { BARBOSA, 2013b) }\end{array}$ & $\begin{array}{l}\text { Separar visão de aluno e tutor, ou seja, o aplicativo deve } \\
\text { prover visões diferentes de acordo com o perfil do usuário } \\
\text { que está acessando-o. }\end{array}$ \\
\hline $\begin{array}{l}\text { Esforço cognitivo das atividades (REIS; ESCU- } \\
\text { DEIRO; ESCUDEIRO, 2012; ESCUDEIRO; ES- }\end{array}$ & $\begin{array}{l}\text { O grau de esforço cognitivo que um usuário deve ter para } \\
\text { utilizar o aplicativo e adquirir conhecimento. }\end{array}$ \\
CUDEIRO, 2012) & $\begin{array}{l}\text { Deve prover a aprendizagem com qualidade nas mídias } \\
\text { utilizadas. }\end{array}$ \\
DEIRO, 2012; ECONOMIDES, 2008)
\end{tabular}

Tabela 17 - Métricas Relacionadas às Características Pedagógicas

\begin{tabular}{l|l}
\hline Métrica & Descrição \\
\hline $\begin{array}{l}\text { Reutilização de conteúdo de aprendizagem } \\
\text { (ACHARYA; SINHA, 2013) }\end{array}$ & Grau de reutilização do conteúdo de aprendizagem. \\
\hline Interatividade (PARSONS; RYU, 2006) & Grau de interação entre os alunos e os tutores. \\
\hline $\begin{array}{l}\text { Conteúdos de aprendizagem (PARSONS; RYU, } \\
2006)\end{array}$ & Grau de qualidade do conteúdo de aprendizagem. \\
\hline $\begin{array}{l}\text { Complexidade dos conteúdos (POCATILU; } \\
\text { BOJA, 2009) }\end{array}$ & $\begin{array}{l}\text { Mede a quantidade de informação em uma lição m- } \\
\text { learning e o esforço necessário para que possa ser com- } \\
\text { preendida pelo usuário. }\end{array}$ \\
\hline $\begin{array}{l}\text { Complexidade de multimídia (POCATILU; } \\
\text { BOJA, 2009) }\end{array}$ & $\begin{array}{l}\text { Mede o impactado do conteúdo de aprendizagem ao uti- } \\
\text { lizar diferentes tipos de mídias. }\end{array}$ \\
\hline Fonte de conteúdo (POCATILU; BOJA, 2009) & $\begin{array}{l}\text { Mede as fontes de conteúdo confiáveis utilizadas no apli- } \\
\text { cativo. }\end{array}$ \\
\hline
\end{tabular}

nicas que avaliam algumas características de modo a reduzir a subjetividade da avaliação.

As características identificadas no mapeamento sistemático foram fundamentais para a concepção do método MoLEva. Essas características serviram como base para o desenvolvimento do modelo de qualidade associada ao método. A partir dos resultados obtidos também foi possível observar a existência de muitos desafios para que os desenvolvedores de aplicativos m-learning consigam satisfazer, todas ou ao menos parte, das 
Tabela 18 - Características Socioeconômicas Identificadas

\begin{tabular}{l|l}
\hline Característica & Descrição \\
\hline $\begin{array}{l}\text { Custo para desenvolver o material de aprendiza- } \\
\text { gem (ZORAN et al., 2012) }\end{array}$ & $\begin{array}{l}\text { Refere-se aos gastos com o desenvolvimento do material } \\
\text { de aprendizagem (por exemplo, gastos com tutores que } \\
\text { criam o material). }\end{array}$ \\
\hline $\begin{array}{l}\text { Tempo para desenvolver o material de aprendiza- } \\
\text { gem (ZORAN et al., 2012) }\end{array}$ & $\begin{array}{l}\text { Refere-se ao tempo que se leva para desenvolver o mate- } \\
\text { rial (por exemplo, tempo de desenvolvimento do material } \\
\text { de um curso). }\end{array}$ \\
\hline $\begin{array}{l}\text { Plano de continuidade (DUARTE-FILHO; BAR- } \\
\text { BOSA, 2013b) }\end{array}$ & $\begin{array}{l}\text { Possuir estratégias e procedimentos de recuperação dos } \\
\text { ambientes de aprendizagem móvel, evitando assim a in- } \\
\text { terrupção das práticas de aprendizagem. }\end{array}$ \\
\hline $\begin{array}{l}\text { Acordo de nível de serviço (SLA, do inglês Service } \\
\text { Level Agreement) (DUARTE-FILHO; BARBOSA, } \\
\text { 2013b; ECONOMIDES, 2008) }\end{array}$ & $\begin{array}{l}\text { Deve possuir diferentes SLAs, de acordo com o número de } \\
\text { participantes, quantidade de materiais e funcionalidades. }\end{array}$ \\
\hline $\begin{array}{l}\text { Custo-benefício (DUARTE-FILHO; BARBOSA, } \\
\text { 2013b; ECONOMIDES, 2008) }\end{array}$ & $\begin{array}{l}\text { Os custos de desenvolvimento, aquisição e manutenção } \\
\text { devem ser baixos. Além disso, o aplicativo deve ser eco- } \\
\text { nomicamente viável. }\end{array}$ \\
\hline $\begin{array}{l}\text { Personalização (DUARTE-FILHO; BARBOSA, } \\
\text { 2013b; ECONOMIDES, 2008) } \\
\text { deve ser adaptada para o usuário final de acordo com seu } \\
\text { perfil, preferências e restrições. Além disso, as respostas } \\
\text { a qualquer mudança (física ou ambiental) devem ser tra- } \\
\text { tadas de forma clara. }\end{array}$ \\
\hline
\end{tabular}

Tabela 19 - Características Socioculturais Identificadas

\begin{tabular}{l|l}
\hline Característica & Descrição \\
\hline $\begin{array}{l}\text { Curva de aprendizado (POCA- } \\
\text { TILU; BOJA, 2009) }\end{array}$ & $\begin{array}{l}\text { O tempo em que o usuário consegue aprender a manusear a tecnologia } \\
\text { móvel. }\end{array}$ \\
\hline $\begin{array}{l}\text { Idade do usuário (POCATILU; } \\
\text { BOJA, 2009) }\end{array}$ & $\begin{array}{l}\text { O aplicativo deve ser adaptável a fim de atender as diferentes idades } \\
\text { dos usuários. }\end{array}$ \\
\hline $\begin{array}{l}\text { Satisfação do usuário (POCATILU; } \\
\text { BOJA, 2009; HUJAINAH; DAH- }\end{array}$ & $\begin{array}{l}\text { O aplicativo deve atingir as expectativas dos usuários, a fim de lhes } \\
\text { proporcionar satisfação com o aplicativo. }\end{array}$ \\
LAN; AL-HAIMI, 2013) & $\begin{array}{l}\text { Os aplicativos de m-learning devem prover ferramentas e mecanismos } \\
\text { Colaboração (DUARTE-FILHO; }\end{array}$ \\
$\begin{array}{l}\text { BARBOSA, 2013b; ECONOMI- } \\
\text { DES, 2008) }\end{array}$ & $\begin{array}{l}\text { Os aplicativos m-learning devem fornecer atividades individuais e em } \\
\text { grupos, motivando o desenvolvimento de tarefas em conjunto. }\end{array}$ \\
\hline $\begin{array}{l}\text { Atividades individuais e em grupos } \\
\text { (ECONOMIDES, 2008) }\end{array}$
\end{tabular}

características encontradas durante o mapeamento conduzido.

No próximo capítulo é apresentada a concepção e definição do método MoLEva, para avaliação de qualidade de aplicativos educacionais móveis. 

CAPÍTULO

\section{4}

\section{MOLEVA: UM MÉTODO DE AVALIAÇÃO DE QUALIDADE PARA APLICATIVOS EDUCACIONAIS MÓVEIS}

\subsection{Considerações Iniciais}

Possuir um alto nível de qualidade é um objetivo importante para qualquer aplicativo, visto que a qualidade tem um grande impacto na sua relação com o usuário (VISOIU; BATAGAN; BOJA, 2009). Apesar de um aplicativo educacional móvel fornecer benefícios como ubiquidade e melhor utilização do tempo ocioso do seu usuário, um aplicativo com uma qualidade baixa pode ocasionar na invalidação desses benefícios (ACHARYA; SINHA, 2013).

Devido à preocupação para garantir a qualidade de um aplicativo, métodos de avaliação de qualidade se fazem necessários. Os métodos estabelecem mecanismos que, além de avaliar o nível de qualidade de um aplicativo, também estabelecem um conjunto de características de qualidade que se relacionam entre si, fornecendo uma base para especificações de requisitos de qualidade. Dessa forma, os métodos de avaliação proporcionam a identificação de lacunas e problemas no aplicativo avaliado. Com o objetivo de criar um método de avaliação de qualidade para aplicativos educacionais móveis, foi desenvolvido o método MoLEva (Mobile Learning Evaluation).

Este capítulo está organizado da seguinte maneira: na Seção 4.2 é apresentada a definição do método MoLEva, descrevendo as suas etapas de desenvolvimento. Na Seção 4.3 é apresentada a ferramenta web desenvolvida para auxiliar na aplicação do método MoLEva. Na Seção 4.4 é descrita uma das validações do método MoLEva, realizada durante seu desenvolvimento. Por fim, na Seção 4.5 são apresentadas as considerações finais. 


\subsection{Definição do Método MoLEva}

Com o objetivo de desenvolver o método de avaliação de qualidade para aplicativos educacionais móveis, foi necessário realizar estudos sobre as características de qualidade presentes nesse tipo de aplicativo. Para isso, foi conduzido um mapeamento sistemático a fim de obter um conjunto de características de qualidade para aplicativos educacionais móveis, conforme apresentado no Capítulo 3.

A partir dos resultados obtidos no mapeamento sistemático, foi definido um conjunto de características de qualidade para o contexto de aplicativos educacionais móveis, estabelecendo assim a base para a criação do modelo de qualidade para o método MoLEva.

Além disso, o método também teve como base as melhores práticas e conhecimentos estabelecidos na norma ISO 14598 (ISO/IEC 14598, 1998). Outras pesquisas como DuarteFilho e Barbosa (2013a) e Acharya e Sinha (2013) também foram utilizadas para auxiliar na definição das etapas do processo de avaliação utilizado pelo método MoLEva.

Em linhas gerais, o processo de desenvolvimento do método MoLEva é composto por seis etapas, em conformidade com a ISO/IEC 14598 (ISO/IEC 14598, 1998), as quais foram simplificadas e adaptadas para o contexto de aplicativos educacionais móveis. Essas etapas são apresentadas na Figura 11 e descritas a seguir.

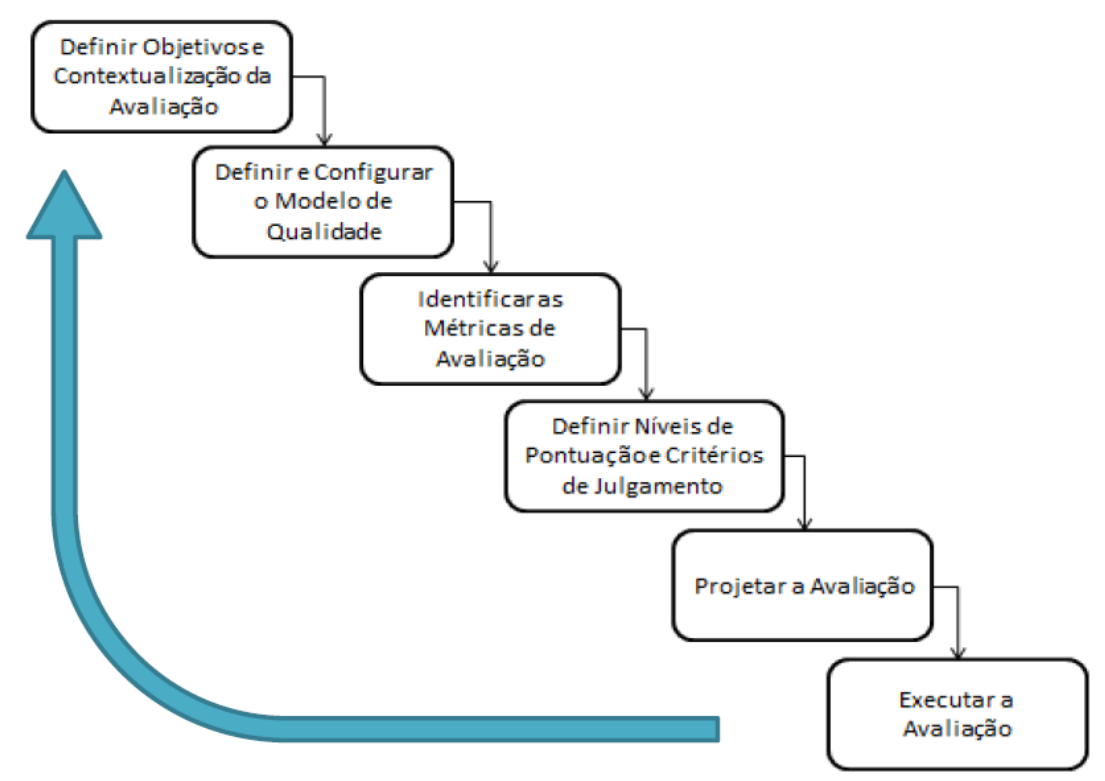

Figura 11 - Etapas do Processo de Desenvolvimento do Método de Avaliação de Qualidade para Aplicativos Educacionais Móveis. Adaptado de Duarte-Filho e Barbosa (2013a)

- Definir objetivos e contextualização da avaliação: o objetivo definido para o método MoLEva é analisar e comparar os aplicativos educacionais móveis em relação aos aspectos técnicos, educacionais, socioeconômicos e socioculturais, identificando pontos fortes e fracos de cada aplicativo considerado. 
- Definir e configurar o modelo de qualidade: o modelo de qualidade a ser adotado no processo estabelece um conjunto bem definido de critérios e requisitos para aplicativos educacionais móveis. É essencial que o modelo definido nessa etapa seja configurado de acordo com o contexto de aplicativos educacionais, pois dessa maneira, é possível fornecer uma base de características que esse tipo de aplicativo deve satisfazer para conseguir excelência em seu nível de qualidade.

- Identificar métricas de avaliação: nesta etapa, os requisitos de qualidade são mapeados em atributos que podem ser medidos. Em suma, os atributos mensuráveis são configurados com base no conhecimento de especialistas, por meio da criação de perguntas simples e diretas, que são avaliadas e pontuadas por meio de um checklist. Para a proposta de avaliação, utilizou-se como base o checklist definido em Duarte-Filho (2016), adaptado para o contexto de aplicativos educacionais móveis.

As adaptações feitas no checklist estão em conformidade com as características identificadas no mapeamento sistemático conduzido por Soad, Duarte-Filho e Barbosa (2015).

- Definir níveis de pontuação e critérios de julgamento: nesta etapa, são definidos os níveis de pontuação para as perguntas do checklist. Para isso, foi necessário primeiramente especificar os tipos de respostas nominais que seriam aplicadas às questões. Além disso, nessa etapa também são definidos os critérios de julgamento, que por sua vez definirão qual o nível de qualidade do aplicativo.

- Projetar a avaliação: nessa etapa deve ser definido o plano de avaliação que deverá ser seguido durante a execução da avaliação. Esse plano deve conter as diretrizes e procedimentos necessários para que as avaliações sejam feitas, além de definir a técnica de coleta de dados. No caso do MoLEva, a técnica utilizada para avaliação é o checklist. Para facilitar na definição do plano de avaliação, alguns pontos são sugeridos por Duarte-Filho e Barbosa (2013a), como: (i) identificar o perfil dos avaliadores; (ii) mapear os recursos necessários para viabilizar a avaliação; (iii) tempo médio estipulado para a execução da avaliação; e (iv) como serão apresentados os resultados gerados pela avaliação.

- Executar a avaliação: na fase final, o avaliador deve executar três tarefas principais: (i) coletar as medidas de qualidade; (ii) comparar as medidas em relação aos critérios de qualidade pré-definidos; e (iii) avaliar os dados obtidos durante a avaliação. As etapas citadas devem ser executadas por desenvolvedores e especialistas em qualidade de software.

As etapas do processo citadas anteriormente foram executadas algumas vezes, com o objetivo de refinar o método MoLEva. Dessa forma, foi possível estabelecer o método de avaliação de qualidade, que consiste em três etapas para a avaliação de um aplicativo educacional móvel, que são: (i) configuração da avaliação, que possibilita a configuração dos critérios de qualidade que devem ser considerados, além de possibilitar a customização 
dos critérios de julgamento; (ii) execução da avaliação, que é a etapa na qual o checklist é aplicado; e (iii) análise dos resultados da avaliação, que apresenta os resultados obtidos com a execução da avaliação.

Para definir os principais componentes do método MoLEva, utilizou-se como base a norma ISO/IEC 14598 (ISO/IEC 14598, 1998), estabelecendo assim um método formado por três componentes fundamentais (Figura 12):

- Modelo de qualidade: define um conjunto de características de qualidade para aplicativos educacionais móveis, fornecendo assim a base para a avaliação de qualidade;

- Métricas: definem a forma de coleta de dados para possibilitar a medição da qualidade dos aplicativos;

- Critérios de julgamento: definem como o aplicativo será julgado a partir dos dados coletados durante a avaliação.

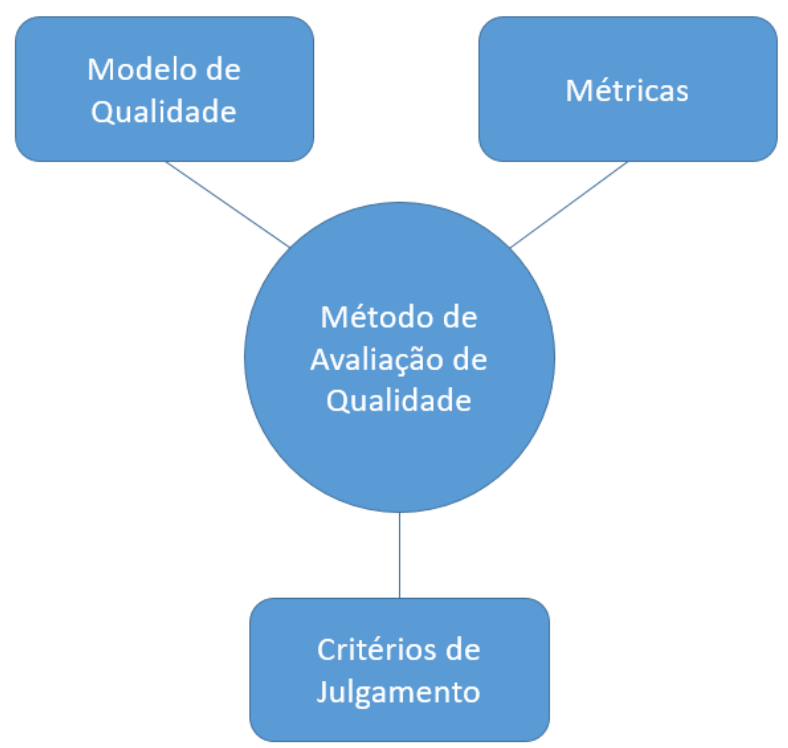

Figura 12 - Componentes do Método de Avaliação de Qualidade MoLEva

\subsubsection{Modelo de Qualidade}

O principal componente do MoLEva é seu modelo de qualidade, responsável por definir o conjunto de características que fornece a base para a avaliação de qualidade de aplicativos educacionais móveis. O modelo de qualidade do método MoLEva é dividido em três categorias, fundamentadas na divisão dos requisitos de qualidade para aplicativos m-learning definidos em Soad, Duarte-Filho e Barbosa (2015) e Duarte-Filho e Barbosa (2013b), além disso o modelo foi avaliado no estudo publicado em Soad et al. (2017). As categorias são: 
- Pedagógica: são os aspectos educacionais presentes no aplicativo, ou seja, são as características que têm como foco o aprendizado do aluno;

- Social: referem-se aos aspectos sociais presentes no aplicativo, abordando características econômicas e culturais;

- Técnica: são os aspectos técnicos do aplicativo, ou seja, referem-se às características do aplicativo que contribuem para seu uso e funcionamento.

O modelo de qualidade possui uma estrutura composta por categorias, critérios e características de qualidade, dispostos de maneira hierárquica. Essa divisão foi fundamentada na norma ISO/IEC 25010 (ISO/IEC 25010, 2010).

Além disso, o modelo é composto por características que se originaram na pesquisa apresentada no Capítulo 3. Posteriormente, o modelo foi atualizado com novas pesquisas relacionadas às características de qualidade para aplicativos educacionais móveis. A Figura 13 apresenta uma visão geral do modelo de qualidade que compõe o MoLEva.

As categorias definidas no modelo possuem uma subdivisão, totalizando 12 critérios de qualidade. Para a categoria Pedagógica, são definidos três critérios de qualidade. O primeiro é o critério Aprendizagem que é definido pela capacidade do aplicativo em disponibilizar funcionalidades que contribuam para o aprendizado do aluno. Suas características são apresentadas na Tabela 20.

Tabela 20 - Características de Qualidade Relacionadas ao Critério Aprendizagem

\begin{tabular}{l|l}
\hline Característica & Descrição \\
\hline Limitações na aprendizagem & Capacidade de auxiliar na identificação de lacunas de conhecimento. \\
\hline Estilo de aprendizagem & $\begin{array}{l}\text { Identificação dos diferentes perfis de aprendizagem do usuário (auditi- } \\
\text { vos, visuais e cinestésicos). }\end{array}$ \\
\hline $\begin{array}{l}\text { Processos de ensino e de } \\
\text { aprendizagem }\end{array}$ & Processos de ensino e de aprendizagem utilizados são bem definidos. \\
\hline $\begin{array}{l}\text { Efetividade da aprendiza- } \\
\text { gem }\end{array}$ & $\begin{array}{l}\text { Capacidade de avaliar se o usuário está efetivamente adquirindo conhe- } \\
\text { cimento. }\end{array}$ \\
\hline Conhecimento na hora certa & $\begin{array}{l}\text { Conteúdo oferecido no estágio correto de aprendizagem, evitando ofere- } \\
\text { cer um conteúdo muito avançado que dependa de conhecimento ainda } \\
\text { não obtido. }\end{array}$ \\
\hline Atividades educacionais & $\begin{array}{l}\text { Diferentes tipos de atividades relacionadas à educação, permitindo a } \\
\text { aquisição de conhecimento, orientação de um tutor nas atividades, ins- } \\
\text { truções para guiar o usuário durante a aprendizagem, entre outros. }\end{array}$ \\
\hline Adaptação ao contexto & $\begin{array}{l}\text { Capacidade de adaptação ao contexto do usuário considerando idade, } \\
\text { gênero, escolaridade, condições físicas do ambiente, entre outros. }\end{array}$ \\
\hline Motivação & $\begin{array}{l}\text { Estímulos que levam o usuário a agir em relação à aquisição de conhe- } \\
\text { cimento. }\end{array}$ \\
\hline Engajamento & $\begin{array}{l}\text { Compromisso funcional com papéis e responsabilidades para que se } \\
\text { atinja um objetivo aliado ao envolvimento emocional em desempenhar } \\
\text { tais atividades. }\end{array}$ \\
\hline Criatividade & $\begin{array}{l}\text { Capacidade de resolver tarefas ou desenvolver ideias de maneira dife- } \\
\text { rente do padrão normal intencionadamente com o fim de estabelecer } \\
\text { certo propósito. }\end{array}$ \\
\hline $\begin{array}{l}\text { Acompanhamento de pro- } \\
\text { gresso }\end{array}$ & $\begin{array}{l}\text { Uso de um conjunto de informações do cotidiano de ensino e apren- } \\
\text { geral do progresso do aprendiz. }\end{array}$ \\
\hline
\end{tabular}




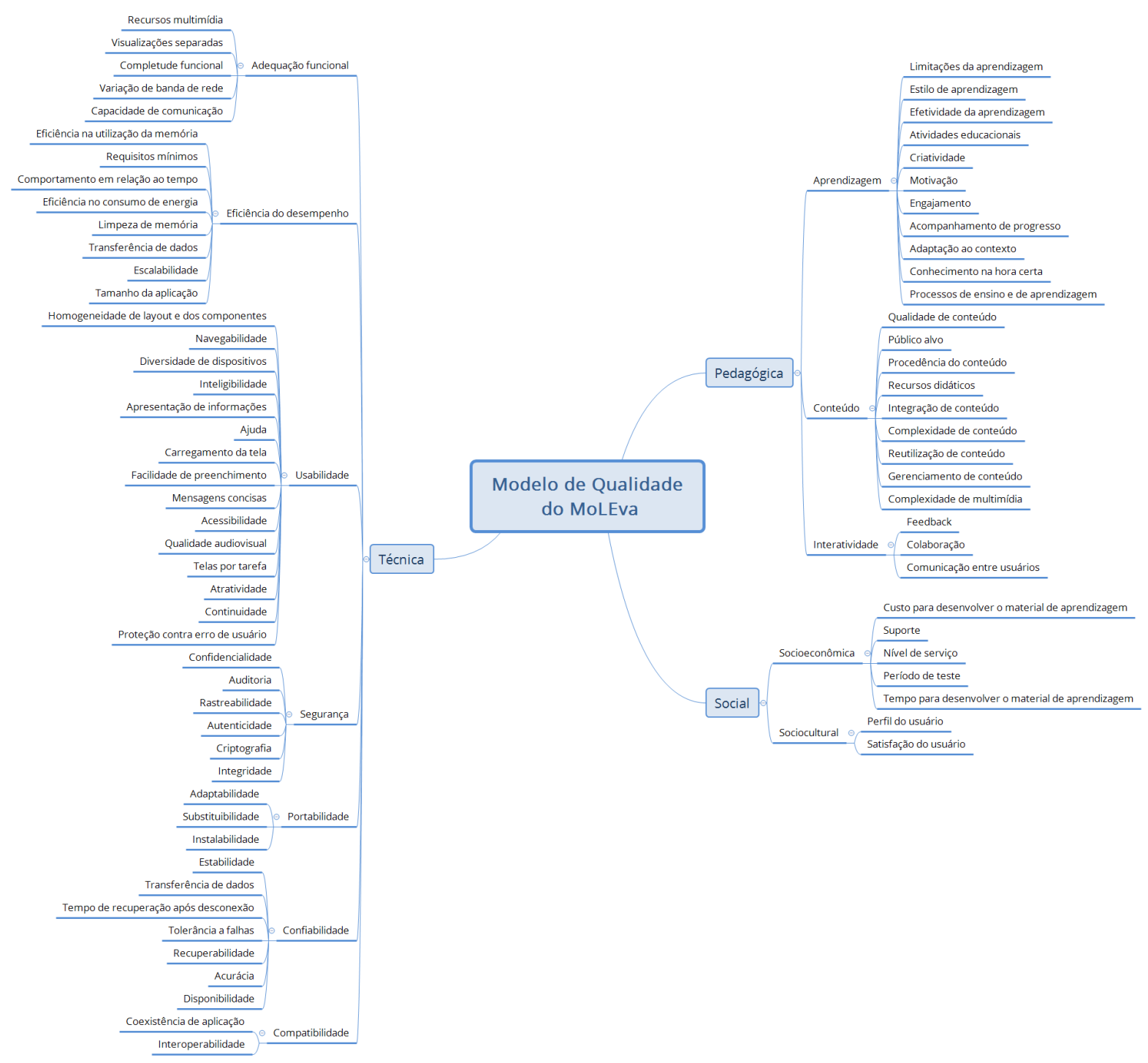

Figura 13 - Modelo de Qualidade do MoLEva

O próximo critério pedagógico é Conteúdo, que é definido pela capacidade em fornecer conteúdo gerenciável e de qualidade. Suas características são apresentadas na Tabela 21.

O terceiro (e último) critério pedagógico existente no modelo é a Interatividade, que é definida como a capacidade do aplicativo em disponibilizar funcionalidades que contribuam para que os usuários interajam entre si e com o aplicativo. As características relacionadas à Interatividade são apresentadas na Tabela 22.

A próxima categoria estabelecida no modelo de qualidade do MoLEva é a categoria Social. Para essa categoria são definidos dois critérios de qualidade. O primeiro é o critério Socioeconômico, que é caracterizado pela capacidade em proporcionar viabilidade na utilização do aplicativo, fazendo uma relação de custo e benefício. Suas características são apresentadas na Tabela 23. 
Tabela 21 - Características de Qualidade Relacionadas ao Critério Conteúdo

\begin{tabular}{l|l}
\hline Característica & Descrição \\
\hline Qualidade de conteúdo & $\begin{array}{l}\text { Conteúdo de qualidade relacionado a situações e problemas de interesse } \\
\text { do aprendiz, livre de erros ortográficos, mensagens invasivas, negativas } \\
\text { e/ou com qualquer tipo de discriminação. }\end{array}$ \\
\hline Público alvo & $\begin{array}{l}\text { Segmento da sociedade com determinadas características em comum } \\
\text { (idade, sexo, profissão, interesses, etc.) ao qual se dirige o aplicativo. }\end{array}$ \\
\hline $\begin{array}{l}\text { Complexidade de multimí- } \\
\text { dia }\end{array}$ & $\begin{array}{l}\text { Definição de um limite de elementos multimídia de modo que estes não } \\
\text { distraiam o usuário. }\end{array}$ \\
\hline Procedência do conteúdo & Todo material disponibilizado deve ser de fonte confiável. \\
\hline Gerenciamento de conteúdo & Controle, gerenciamento e monitoramento dos conteúdos oferecidos. \\
\hline Integração de conteúdo & Integração dos conteúdos, provendo um fluxo definido entre eles. \\
\hline Recursos didáticos & Recursos didáticos oferecidos para auxiliar o aprendizado. \\
\hline Reutilização de conteúdo & Capacidade de reuso de conteúdo. \\
\hline Complexidade de conteúdo & $\begin{array}{l}\text { Adequação gradativa da complexidade do conteúdo de acordo com o } \\
\text { nível do usuário, de modo a evitar que um conteúdo complexo se torne } \\
\text { um impeditivo para a compreensão. }\end{array}$ \\
\hline
\end{tabular}

Tabela 22 - Características de Qualidade Relacionadas ao Critério Interatividade

\begin{tabular}{l|l}
\hline Característica & Descrição \\
\hline Feedback & Capacidade de permitir o feedback recíproco entre alunos e professores. \\
\hline Comunicação entre usuários & $\begin{array}{l}\text { Comunicação entre usuários (aprendizes, tutores e/ou professores) por } \\
\text { meio de blogs, fóruns, grupos, e outros meios de comunicação. }\end{array}$ \\
\hline Colaboração & $\begin{array}{l}\text { Colaboração nas atividades, permitindo que os aprendizes, tutores e } \\
\text { professores se relacionem por meio de wiki, jogos, microblogs, fóruns, } \\
\text { grupos, entre outros. }\end{array}$ \\
\hline
\end{tabular}

Tabela 23 - Características de Qualidade Relacionadas ao Critério Socioeconômico

\begin{tabular}{l|l}
\hline Característica & Descrição \\
\hline $\begin{array}{l}\text { Custo para desenvolver o } \\
\text { material de aprendizagem }\end{array}$ & $\begin{array}{l}\text { Diminução dos custos de criação do material de aprendizagem, pois } \\
\text { estes influenciam diretamente os gastos com o aplicativo e, consequen- } \\
\text { temente, no investimento feito pelo usuário. }\end{array}$ \\
\hline $\begin{array}{l}\text { Tempo para desenvolver o } \\
\text { material de aprendizagem }\end{array}$ & $\begin{array}{l}\text { Adoção de mecanismos para facilitar o desenvolvimento do material de } \\
\text { aprendizagem, diminuindo o seu tempo de criação e, consequentemente, } \\
\text { seu custo. }\end{array}$ \\
\hline Nível de serviço & $\begin{array}{l}\text { Estabelecimento de níveis de serviço, possibilitando maior segurança } \\
\text { na utilização dos aplicativos bem como a continuidade no seu uso. Os } \\
\text { níveis estabelecidos devem ser: (i) plano de continuidade: estratégias e } \\
\text { procedimentos de recuperação dos ambientes m-learning, evitando a in- } \\
\text { terrupção das práticas de aprendizagem; (ii) acordo de nível de serviço: } \\
\text { acordo baseado no número de participantes, quantidade de matérias e } \\
\text { funcionalidades do aplicativo; e (iii) custo-benefício: viabilidade econô- } \\
\text { mica do aplicativo, ocasionada por baixos custos de desenvolvimento, } \\
\text { aquisição e manutenção. }\end{array}$ \\
\hline Pisponibilização de um período de teste do aplicativo ou permissão de \\
acesso às funcionalidades básicas para permitir que o usuário experi- \\
mente o aplicativo antes da aquisição.
\end{tabular}

O segundo critério relacionado à categoria Social é o Sociocultural. Ele é caracterizado pela capacidade do aplicativo em se adaptar ao contexto sociocultural do usuário, considerando características como idade, nível de ensino, determinado grupo cultural, entre outros. Suas características são apresentadas na Tabela 24.

A última categoria a ser apresentada é a Técnica, que é composta por sete critérios de qualidade. O primeiro critério apresentado é a Adequação Funcional, que é definido como a capacidade do aplicativo em disponibilizar funções que atendam as necessidades implícitas e explícitas em relação ao aplicativo. Suas características são apresentadas na 
Capítulo 4. MoLEva: Um Método de Avaliação de Qualidade para Aplicativos Educacionais 80

Tabela 24 - Características de Qualidade Relacionadas ao Critério Sociocultural

\begin{tabular}{l|l}
\hline Característica & Descrição \\
\hline Perfil do usuário & $\begin{array}{l}\text { Configurabilidade do aplicativo para tratar diferentes possíveis limita- } \\
\text { ções de acordo com a idade, sexo, religião, raça, entre outras caracte- } \\
\text { rísticas dos usuários. }\end{array}$ \\
\hline Satisfação do usuário & $\begin{array}{l}\text { Satisfação das expectativas do usuário, evitando o abandono e o des- } \\
\text { conforto na utilização do aplicativo. }\end{array}$ \\
\hline
\end{tabular}

Tabela 25.

Tabela 25 - Características de Qualidade Relacionadas ao Critério Adequação Funcional

\begin{tabular}{l|l}
\hline Característica & Descrição \\
\hline Capacidade de comunicação & Capacidade de transmissão de dados entre dispositivos. \\
\hline Recursos multimídia & $\begin{array}{l}\text { Capacidade de suportar diferentes tipos de mídias, como vídeo, texto, } \\
\text { áudio, entre outros. }\end{array}$ \\
\hline Variação de banda de rede & Capacidade de se adaptar à variação da conexão com a rede. \\
\hline Visualizaçóes separadas & $\begin{array}{l}\text { Fornecimento de visões diferentes de acordo com o perfil de usuário (ex: } \\
\text { professor, aluno). }\end{array}$ \\
\hline Completude funcional & $\begin{array}{l}\text { Capacidade do aplicativo em abranger todas as funcionalidades previs- } \\
\text { tas pelos usuários. }\end{array}$ \\
\hline
\end{tabular}

O próximo critério de qualidade apresentado é a Eficiência do Desempenho. Ele é caracterizado pela capacidade do aplicativo em fornecer um bom desempenho em relação à quantidade de recursos utilizados sob condições estabelecidas, ou seja, refere-se à otimização do uso dos recursos disponíveis. Suas características são apresentadas na Tabela 26.

Tabela 26 - Características de Qualidade Relacionadas ao Critério Eficiência do Desempenho

\begin{tabular}{l|l}
\hline Característica & Descrição \\
\hline Transferência de dados & $\begin{array}{l}\text { Capacidade de minimização dos dados, para melhorar o tempo de trans- } \\
\text { ferência, gastos com conexão e quantidade de dados trafegados. }\end{array}$ \\
\hline $\begin{array}{l}\text { Comportamento em relação } \\
\text { ao tempo }\end{array}$ & $\begin{array}{l}\text { Tempo de espera do usuário até o carregamento completo das informa- } \\
\text { çôes solicitadas. }\end{array}$ \\
\hline Tamanho do aplicativo & $\begin{array}{l}\text { Quantidade de espaço necessário para que o aplicativo possa ser utili- } \\
\text { zado no dispositivo. }\end{array}$ \\
\hline $\begin{array}{l}\text { Eficiência na utilização da } \\
\text { memória }\end{array}$ & Utilização de técnicas para otimizar o uso da memória do dispositivo. \\
\hline $\begin{array}{l}\text { Eficiência no consumo de de } \\
\text { energia }\end{array}$ & $\begin{array}{l}\text { Utilização eficiente para não desperdiçar energia, dadas as limitações } \\
\text { das baterias dos dispositivos. }\end{array}$ \\
\hline Limpeza de memória & $\begin{array}{l}\text { Não armazenamento de dados desnecessários no dispositivo, como ar- } \\
\text { quivos que não serão mais utilizados pelo aplicativo. }\end{array}$ \\
\hline Escalabilidade & $\begin{array}{l}\text { Capacidade do aplicativo de manipular uma porção crescente de traba- } \\
\text { lho de forma uniforme ou estar preparado para crescer. }\end{array}$ \\
\hline Requisitos mínimos & $\begin{array}{l}\text { Cumprimento dos requisitos mínimos estabelecidos para uso do aplica- } \\
\text { tivo, permitindo sua utilização sem perda de desempenho. }\end{array}$ \\
\hline
\end{tabular}

O próximo critério é definido como Compatibilidade. Ele se caracteriza como a capacidade do aplicativo em trocar informações ou realizar operações com outros aplicativos, compartilhando o mesmo ambiente de hardware e software. Suas características são apresentadas na Tabela 27.

O próximo critério apresentado é a Usabilidade. Esse critério é definido como a capacidade do aplicativo em ser utilizado por usuários específicos em um contexto 
Tabela 27 - Características de Qualidade Relacionadas ao Critério Compatibilidade

\begin{tabular}{l|l}
\hline Característica & Descrição \\
\hline Coexistência de aplicativo & $\begin{array}{l}\text { Capacidade de vários aplicativos serem executados no mesmo disposi- } \\
\text { tivo sem ocasionar impactos negativos de uns nos outros. }\end{array}$ \\
\hline Interoperabilidade & $\begin{array}{l}\text { Capacidade de expansão de um aplicativo por meio da comunicação } \\
\text { com outros aplicativos. }\end{array}$ \\
\hline
\end{tabular}

específico, oferecendo maneiras que possibilitam o aplicativo ser entendido, aprendido, utilizado e atraente ao usuário. Suas características são apresentadas na Tabela 28.

Tabela 28 - Características de Qualidade Relacionadas ao Critério Usabilidade

\begin{tabular}{|c|c|}
\hline Característica & Descrição \\
\hline Inteligibilidade & $\begin{array}{l}\text { Facilidade de entendimento dos conceitos-chave do aplicativo e, con- } \\
\text { sequentemente, no seu uso, sendo influenciada pelo tempo e esforço } \\
\text { cognitivo do usuário ao aprender a utilizar o aplicativo. }\end{array}$ \\
\hline Carregamento da tela & Quantidade de informações e elementos em uma tela. \\
\hline Facilidade de preenchimento & $\begin{array}{l}\text { Capacidade de facilitar o preenchimento de dados pelo usuário. A quan- } \\
\text { tidade de campos para entrada de dados no aplicativo é considerada e, } \\
\text { já que existem limitações de tela e teclado, não se deve exigir a entrada } \\
\text { de muitos dados. }\end{array}$ \\
\hline Navegabilidade & Facilidade de acesso aos conteúdos e atividades. \\
\hline Continuidade & Fluidez do aplicativo, impedindo restrições de navegação. \\
\hline Diversidade de dispositivos & $\begin{array}{l}\text { Variedade de dispositivos existentes, permitindo melhorias de usabili- } \\
\text { dade exclusivas de acordo com o dispositivo utilizado (exemplo: botão } \\
\text { voltar Android x iOS). }\end{array}$ \\
\hline Telas por tarefa & Quantidade de telas utilizadas durante a execução de uma tarefa. \\
\hline $\begin{array}{l}\text { Apresentação de informa- } \\
\text { ções }\end{array}$ & Limitação das informações de acordo com a área de exibição da tela. \\
\hline $\begin{array}{l}\text { Homogeneidade de layout } \mathrm{e} \\
\text { dos componentes }\end{array}$ & $\begin{array}{l}\text { Padronização da aparência dos componentes, mantendo suas caracterís- } \\
\text { ticas por todas as telas do aplicativo, e padronização dos componentes } \\
\text { devido aos diversos tipos de componentes que possibilitam a mesma } \\
\text { funcionalidade. }\end{array}$ \\
\hline Atratividade & Aplicativo atraente e motivador aos usuários que o utilizarão. \\
\hline $\begin{array}{l}\text { Proteção contra erro de } \\
\text { usuário }\end{array}$ & $\begin{array}{l}\text { Proteção do usuário contra o cometimento de erros (exemplo: inclusão } \\
\text { de validações em campos de entrada abertos). }\end{array}$ \\
\hline Qualidade audiovisual & Utilização de mídias com qualidade para promover aprendizagem. \\
\hline Acessibilidade & $\begin{array}{l}\text { Mecanismos de acessibilidade, permitindo a utilização por pessoas com } \\
\text { necessidades especiais. }\end{array}$ \\
\hline Ajuda & Oferecimento de ajuda para o usuário em relação ao uso do aplicativo. \\
\hline Mensagens concisas & $\begin{array}{l}\text { Mensagens operacionais do aplicativo exatas e de fácil compreensão, } \\
\text { provendo agilidade na comunicação. }\end{array}$ \\
\hline
\end{tabular}

O próximo critério de qualidade apresentado é definido como Confiabilidade. Ele é caracterizado pela capacidade do aplicativo em proporcionar um comportamento consistente com o esperado durante um longo período de tempo. Suas características são apresentadas na Tabela 29.

O próximo critério de qualidade apresentado é definido como Segurança. Esse critério é caracterizado pela capacidade do aplicativo em proteger as informações e dados, protegendo-os de acesso não autorizado e garantindo seu acesso de acordo com os diferentes níveis de autorização. Suas características são apresentadas na Tabela 30.

Por fim, o último critério de qualidade é definido como Portabilidade. Este critério é caracterizado pela capacidade do aplicativo ser transferido de um hardware ou software para outro. Suas características são apresentadas na Tabela 31. 
Tabela 29 - Características de Qualidade Relacionadas ao Critério Confiabilidade

\begin{tabular}{l|l}
\hline Característica & Descrição \\
\hline Estabilidade & Ausência de defeitos no aplicativo. \\
\hline Disponibilidade & Disponibilidade e acessibilidade a qualquer hora e em qualquer lugar. \\
\hline $\begin{array}{l}\text { Tempo de recuperação após } \\
\text { desconexão }\end{array}$ & $\begin{array}{l}\text { Restabelecimento da conexão após uma desconexão, mantendo seu fun- } \\
\text { cionamento apesar destas interrupções inesperadas. }\end{array}$ \\
\hline Transferência de dados & $\begin{array}{l}\text { Transferência de dados, mesmo ocorrendo desconexões. Ainda que a } \\
\text { transferência não seja possível, o aplicativo deve garantir que os dados } \\
\text { não serão perdidos. }\end{array}$ \\
\hline Acurácia & $\begin{array}{l}\text { Fornecimento de resultados exatos e livre de erros. } \\
\text { Recuperabilidade }\end{array}$ \\
$\begin{array}{l}\text { Salvamento de pontos de backup em caso de bateria baixa, automático } \\
\text { ou por opção do usuário. }\end{array}$ \\
\hline Tolerância a falhas & $\begin{array}{l}\text { Reação diante de uma situação anômala, ou seja, o aplicativo continua } \\
\text { funcionando mesmo que ocorram falhas. }\end{array}$ \\
\hline
\end{tabular}

Tabela 30 - Características de Qualidade Relacionadas ao Critério Segurança

\begin{tabular}{l|l}
\hline Característica & Descrição \\
\hline Confidencialidade & Acesso seguro e privado para os usuários e aplicativos autorizados. \\
\hline Criptografia & $\begin{array}{l}\text { Utilização de criptografia nos dados sensíveis que são trafegados e arma- } \\
\text { zenados pelo aplicativo (exemplo: senhas ou documentos do usuário). }\end{array}$ \\
\hline Integridade & $\begin{array}{l}\text { Utilização de diferentes perfis de usuário, restringindo assim o acesso a } \\
\text { determinadas funcionalidades do aplicativo. }\end{array}$ \\
\hline Auditoria & $\begin{array}{l}\text { Registro de cada ação no aplicativo, auxiliando na não negação da ação } \\
\text { caso o usuário negue-as. }\end{array}$ \\
\hline Rastreabilidade & $\begin{array}{l}\text { Armazenamento dos registros de eventos ocorridos no aplicativo, sendo } \\
\text { possível assim rastrear os caminhos realizados pelo usuário. }\end{array}$ \\
\hline Autenticidade & Garantia de autenticidade das ações do usuário. \\
\hline
\end{tabular}

Tabela 31 - Características de Qualidade Relacionadas ao Critério Portabilidade

\begin{tabular}{l|l}
\hline Característica & Descrição \\
\hline Adaptabilidade & $\begin{array}{l}\text { Capacidade do aplicativo em se adaptar a diferentes tipos de dispositi- } \\
\text { vos móveis. }\end{array}$ \\
\hline Instalabilidade & $\begin{array}{l}\text { Capacidade do aplicativo ser instalado e desinstalado em diferentes } \\
\text { dispositivos móveis sem implicar em erros. }\end{array}$ \\
\hline Substituibilidade & Atualização e configuração de maneira rápida e automática. \\
\hline
\end{tabular}

\subsubsection{Métricas}

Para determinar o valor associado às características de qualidade definidas pelo método MoLEva, é necessário uma medição. Dessa maneira, é possível medir e interpretar a qualidade do critério que está sendo avaliado.

O termo "métrica" utilizado não possui o sentido matemático usual, mas se refere à uma escala e um método que pode ser utilizado para medição. Essa definição é fundamentada nas diretrizes da ISO/IEC 14598 (ISO/IEC 14598, 1998), na fase de especificação da avaliação.

As métricas que compõem o método de qualidade MoLEva foram definidas mapeando as características de qualidade em atributos mensuráveis, permitindo assim que elas fossem medidas e pontuadas. Para isso, optou-se em utilizar a técnica de "lista de verificação" (checklist). A aplicação dessa técnica consiste em um conjunto de perguntas objetivas, que permitem a coleta de informações por meio de respostas simples e objetivas.

O desenvolvimento da lista de verificação do MoLEva (Apêndice A) utilizou como 
base o checklist proposto em Duarte-Filho (2016). As perguntas contidas nesse checklist foram adaptadas para o contexto de aplicativos educacionais móveis. Além disso, o modelo de qualidade descrito na seção anterior e ilustrado na Figura 13, foi essencial para a criação de novas perguntas, já que ele é a base para o método de avaliação MoLEva.

Ao final do desenvolvimento, o checklist foi composto por 85 perguntas, abordando os 12 critérios (sub-categorias) de qualidade definidos no modelo da Figura 13. Esse conjunto de perguntas é fundamental para a avaliação de qualidade, já que a partir dele são coletadas as informações necessárias para definição do nível de qualidade do aplicativo.

Para as perguntas contidas na lista de verificação foram definidos dois tipos de respostas:

- Binárias: esse tipo de resposta atribui o valor verdadeiro ou falso para as perguntas. $\mathrm{Na}$ lista de verificação do MoLEva, as perguntas que possuem esse tipo de resposta foram preparadas para a resposta "Sim", indicando um ponto positivo do aplicativo e para a resposta "Não", indicando um ponto negativo do aplicativo sendo avaliado;

- Grau de concordância: esse tipo de resposta tem como objetivo identificar o grau de concordância do avaliador a respeito da pergunta que lhe foi colocada. Essa estratégia de coleta de informação utiliza a escala de Likert (LIKERT, 1932), com cinco níveis, que tem como objetivo identificar o grau de concordância que o avaliador expressa em relação a uma afirmação ou questionamento. Além da definição da escala, também foi utilizado o diferencial semântico de Osgood (OSGOOD, 1964), que sugere a criação de dois adjetivos bipolares que auxiliam o avaliador na sua decisão sobre a resposta. Os adjetivos criados para essas perguntas são: (i) eficiente; e (ii) ineficiente.

É importante destacar-se que o checklist contempla todos os critérios de qualidade definidos no método MoLEva, apresentados na Figura 13. Além disso, cada pergunta refere-se a apenas um critério de qualidade, possibilitando que a avaliação possa retornar como resultado o nível de qualidade específico de cada critério.

\subsubsection{Critérios de Julgamento}

A definição de critérios de julgamento permite determinar o nível de qualidade de um aplicativo educacional móvel. Por meio dessa definição, é possível fazer comparações entre os aplicativos, identificando-se, também, possibilidades de melhorias.

Para definir o nível de qualidade do aplicativo a ser avaliado e identificar os possíveis pontos de atenção, é necessário atribuir valores quantitativos para as perguntas contidas na lista de verificação. Por esse motivo, as respostas obtidas na aplicação da 
avaliação de qualidade devem ser convertidas em dados quantitativos. Para as respostas binárias, os valores atribuídos são apresentados na Tabela 32.

Tabela 32 - Pontuações Definidas para as Respostas Binárias

\begin{tabular}{l|l}
\hline Resposta & Pontuação \\
\hline Sim & 10 \\
\hline Não & 0 \\
\hline
\end{tabular}

Com relação às respostas por grau de concordância, a pontuação atribuída é mostrada na Tabela 33. Para cada grau de concordância, foi atribuído um significado possível, objetivando traduzir o dado quantitativo em qualitativo, facilitando assim o significado numérico da resposta. Os valores atribuídos para as respostas foram baseados nos critérios de pontuação definidos em Duarte-Filho e Barbosa (2013a).

Tabela 33 - Pontuações Definidas para as Respostas por Grau de Concordância

\begin{tabular}{l|l|l}
\hline Grau de concordância & Significado da resposta & Pontuação \\
\hline 5 & Eficiente & 10 \\
\hline 4 & Aceitável & 7.5 \\
\hline 3 & Regular & 5 \\
\hline 2 & Deficiente & 2.5 \\
\hline 1 & Ineficiente & 0 \\
\hline
\end{tabular}

As pontuações são atribuídas a cada pergunta da lista de verificação. Essas perguntas contemplam os 12 critérios de qualidade definidos no método MoLEva. O cálculo final do nível de qualidade é definido pela média aritmética da pontuação de cada critério.

Para efeito de normalização dos resultados, os critérios de qualidade recebem a porcentagem de pontos equivalentes à pontuação recebida. Por exemplo, para um critério que possua a pontuação máxima igual a 80 pontos, esses pontos serão equivalentes a 100\% de qualidade.

Outro fator que interfere no cálculo do nível de qualidade são as respostas que não possuem pontuação e as perguntas que não devem ser consideradas no cálculo da qualidade, que são:

- Não se aplica: é utilizada para proposições que fazem referência a um aspecto que não se enquadra ao domínio do aplicativo móvel sendo avaliado;

- Avaliação prejudicada: refere-se a proposições que o avaliador não está em condições de avaliar. Isso pode ocorrer por falta de recursos, informações ou conhecimento específico.

Nesse caso o resultado final deve ser normalizado inferindo o valor $100 \%$ para o total possível das questões de cada critério avaliado. O cálculo para obter o nível de qualidade por critério é dado pela fórmula a seguir: 


$$
N Q C R=\frac{\left(p_{1}+p_{2}+p_{3}+\ldots+p_{n}\right) * 10}{T P C}
$$

onde:

- $N Q C R$ é o Nível de Qualidade por Critério;

- $\boldsymbol{T P C}$ é o Total de Perguntas consideradas por Critério;

- $\boldsymbol{p}$ é a pontuação atribuída para cada pergunta;

- $\boldsymbol{n}$ é o total de perguntas do critério avaliado.

A partir dos resultados obtidos para cada critério, é possível calcular o nível de qualidade para cada uma das três categorias definidas no modelo (Pedagógica, Social e Técnica). O cálculo para obter o nível de qualidade por categoria é dado pela fórmula a seguir:

$$
N Q C A=\frac{N Q C R_{1}+N Q C R_{2}+N Q C R_{3}+\ldots+N Q C R_{n}}{T C Q}
$$

onde:

- $\boldsymbol{N Q C A}$ é o Nível de Qualidade por Categoria;

- $\boldsymbol{T C Q}$ é o Total de Critérios de Qualidade relacionados à categoria avaliada;

- $\boldsymbol{n}$ é o total de critérios relacionados à categoria avaliada.

Por fim, o resultado final que representa o nível de qualidade geral do aplicativo, considerando-se as três categorias é calculado. O cálculo para obter o nível de qualidade geral do aplicativo é dado pela fórmula a seguir:

$$
N Q A=\frac{N Q P+N Q S+N Q T}{T C}
$$

onde:

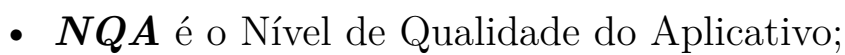

- $\boldsymbol{N Q P}$ é o Nível de Qualidade da categoria Pedagógica;

- $\boldsymbol{N Q S}$ é o Nível de Qualidade da categoria Social;

- $\boldsymbol{N Q T}$ é o Nível de Qualidade da categoria Técnica;

- $\boldsymbol{T} \boldsymbol{C}$ é o Total de Categorias avaliadas, nesse caso será igual a três.

Para definir o nível de qualidade, o resultado final é atribuído de acordo com os critérios de julgamento definidos a partir do trabalho de Martinez et al. (1999) e também utilizado em Duarte-Filho e Barbosa (2013a). Esta definição foi feita com o objetivo de 
definir um valor padrão, porém os valores podem ser customizados para cada avaliação. Dessa maneira, o nível de qualidade do aplicativo é dividido em três com seus respectivos valores padrões:

- Superior: pontuação igual ou maior que 80\%;

- Médio: pontuação igual ou maior que $50 \%$ e menor que $80 \%$;

- Baixo: pontuação menor que $50 \%$.

De acordo com os possíveis níveis de qualidade do aplicativo, considera-se que um aplicativo com o nível superior possui um bom nível de qualidade, já que para obter essa pontuação o aplicativo conseguiu satisfazer os critérios de qualidade avaliados. Por outro lado, um nível de qualidade médio revela que o aplicativo necessita de melhorias. A avaliação final do método MoLEva indica os critérios com menor pontuação, permitindo a visualização dos principais pontos de melhoria para o aplicativo.

Por fim, um nível de qualidade baixo sugere que o aplicativo não conseguiu alcançar níveis satisfatórios de qualidade. Dessa maneira, o resultado da avaliação sugere que esse aplicativo deva passar por uma restruturação, com base nos critérios de qualidade não satisfeitos a partir da avaliação conduzida.

Embora o método MoLEva defina pontuações para suas questões, é importante ressaltar que os valores definidos podem ser alterados de acordo com os objetivos da avaliação. Dessa maneira, é possível inclusive atribuir pesos diferentes para cada critério de qualidade. Essa possibilidade permite que o método possa ser adaptado para cada necessidade. Por este motivo, a definição da pontuação exige conhecimento e bom senso do especialista que deseja customizá-las e atribuí-las ao método.

\subsection{Ferramenta Web MoLEva}

O método MoLEva possui uma grande quantidade de questões, totalizando 85 perguntas que devem ser respondidas pelos avaliadores. Além dessas perguntas, quando se tem uma quantidade maior de avaliadores, torna-se mais difícil gerenciar e calcular os valores que representam o nível de qualidade manualmente. Por este motivo, foi desenvolvida uma ferramenta web para apoiar a utilização do método.

A ferramenta web MoLEva foi desenvolvida na linguagem de programação Java ${ }^{1}$, além disso, também foi utilizado o framework Bootstrap ${ }^{2}$, que fornece um conjunto de componentes que padronizam e auxiliam o desenvolvimento do front-end de aplicações

1 https://www.oracle.com/br/java/index.html

2 http://getbootstrap.com 
web. Os componentes fornecidos pelo Bootstrap também facilitam que a ferramenta desenvolvida seja responsiva, possibilitando sua utilização em dispositivos com diferentes tamanhos de tela.

Para disponibilizar a ferramenta na web, foi utilizado o OpenShift ${ }^{3}$, que é uma plataforma como serviço (PaaS). O OpenShift permite que os desenvolvedores possam construir, testar e executar aplicações na nuvem. Dessa maneira, o desenvolvedor não precisa se preocupar com o gerenciamento da infraestrutura, permitindo que seus esforços sejam concentrados no desenvolvimento da ferramenta (SHIPLEY, 2014).

A partir do uso das tecnologias citadas, obteve-se como resultado a ferramenta web MoLEva (Figura 14). Dentre suas funcionalidades, a ferramenta disponibiliza:

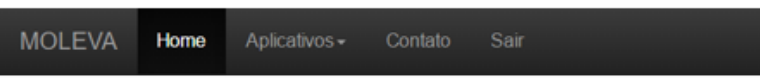

Criar Avaliação

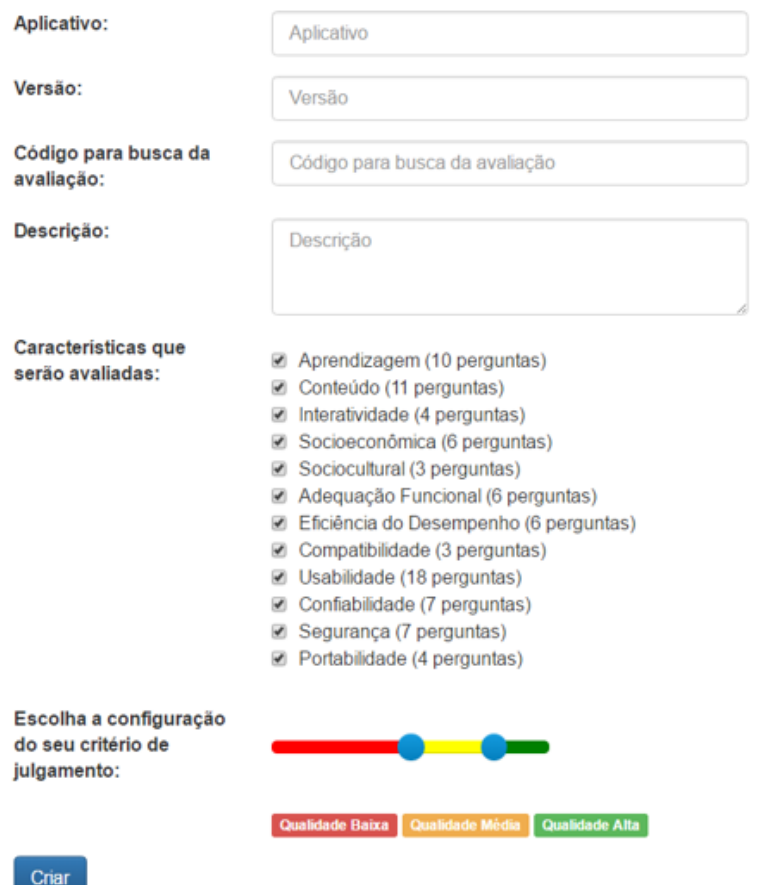

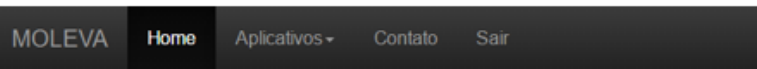

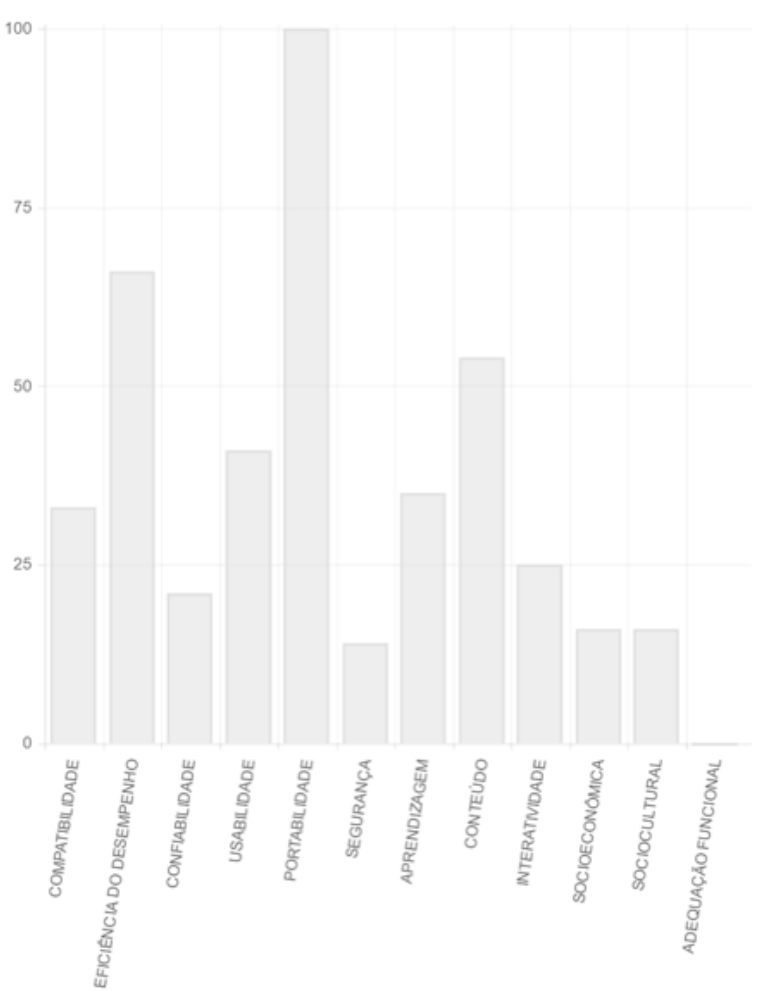

Figura 14 - Ferramenta Desenvolvida para Utilização do Método MoLEva (http://molevagustavosoad.rhcloud.com)

- Criação de avaliação: esta funcionalidade permite que seja criada uma avaliação de qualidade para um determinado aplicativo. No momento da criação da avaliação é possível selecionar os critérios de qualidade que devem ser considerados. Além disso, é possível configurar também o critério de julgamento, ou seja, é possível definir quais intervalos de pontuação representam os níveis baixo, médio e superior;

3 https://www.openshift.com 
- Avaliação de aplicativos: esta funcionalidade possibilita ao usuário a avaliação dos aplicativos por meio da ferramenta, permitindo dessa maneira que o usuário possa avaliar o aplicativo independentemente da sua localização. Além disso, a avaliação pode ser executada em etapas, não sendo necessária a sua finalização de imediato;

- Visualização de resultados: esta funcionalidade fornece ao usuário a visualização dos resultados da avaliação do aplicativo. Ela disponibiliza a visualização dos resultados por categoria e critério de qualidade. Além disso, é possível visualizar os resultados de uma maneira geral ou por avaliador, permitindo, dessa maneira, a análise detalhada das avaliações.

Como trabalhos futuros, destaca-se a possibilidade de inclusão de novas funcionalidades à ferramenta. Entre elas, destacam-se a possibilidade de comparação de avaliações de diferentes aplicativos educacionais e a inclusão de comentários sobre os resultados das avaliações.

Por fim, as funcionalidades disponibilizadas pela ferramenta possibilitam a utilização do método MoLEva por qualquer pessoa, além de permitir que uma avaliação possa ser feita por diversos avaliadores, em diferentes localizações. Dessa forma, a ferramenta facilita a utilização do método, além de possibilitar a análise dos dados de seu uso para eventuais evoluções do MoLEva.

\subsection{MoLEva: Uma Aplicação Prática Durante o Desen- volvimento}

Desde o início da concepção do MoLEva até sua versão atual, o método passou por várias evoluções. A validação preliminar do método foi importante para sua evolução, resultando, inclusive em uma publicação associada (SOAD; DUARTE-FILHO; BARBOSA, 2016).

Nesse estudo, com o objetivo de validar o método MoLEva, foram selecionados três aplicativos utilizados no ensino de idiomas. Este domínio foi escolhido devido a diversidade de aplicativos disponíveis para os diferentes sistemas operacionais. A diversidade de sistemas operacionais é importante para a validação, pois permite maior variação dos testes. Além disso, tais aplicativos são consolidados e possuem uma alta taxa de adesão pelos usuários de dispositivos móveis.

Os aplicativos selecionados foram escolhidos por meio de buscas no Google Play 4 na categoria educação. Os critérios para a seleção dos aplicativos foi o ensino do idioma inglês, o número de instalações do aplicativo pelos usuários e estar disponível em pelo

4 Google Play: http://play.google.com 
menos duas plataformas diferentes. Ao final da pesquisa, foram selecionados os aplicativos (Figura 15): (i) Duolingo ${ }^{5}$; (ii) Wlingua ${ }^{6}$; e (iii) Rosetta Stone ${ }^{7}$.

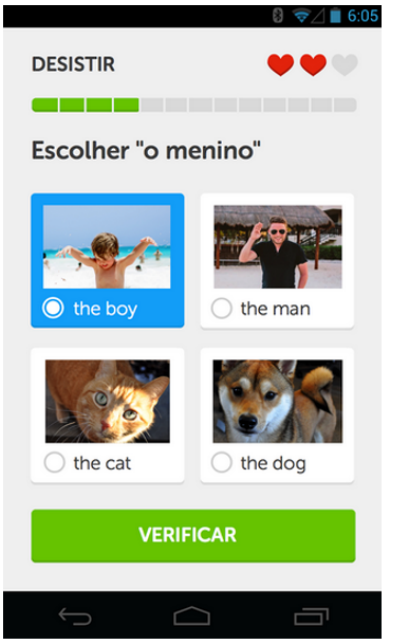

(i) Duolingo

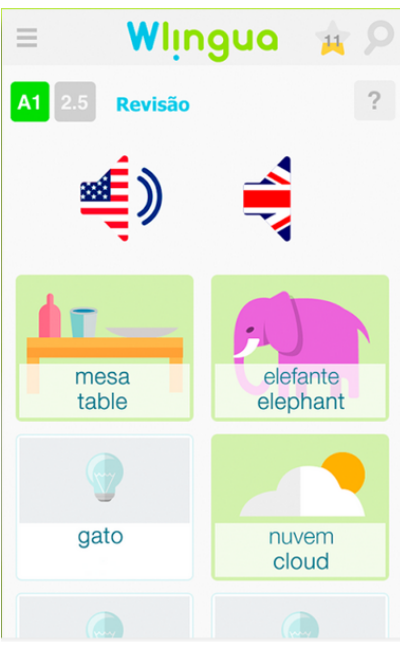

(ii) Wlingua

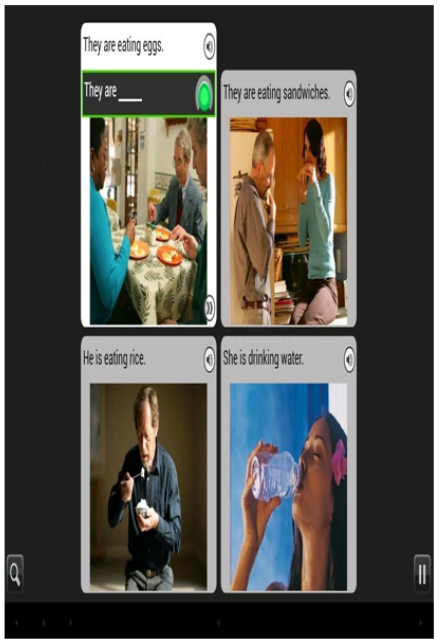

(iii) Rosetta Stone

Figura 15 - Aplicativos Educacionais Móveis Selecionados

Uma das diferenças do método MoLEva atual em relação à versão utilizada em sua primeira validação refere-se a definição dos critérios de qualidade. Naquela versão, o método possuía oito critérios de qualidade (na versão atual são 12 critérios). A Tabela 34 apresenta os critérios de qualidade e seus principais objetivos.

Tabela 34 - Critérios de Qualidade e seus Principais Objetivos

\begin{tabular}{l|l}
\hline Critério de Qualidade & Principais Objetivos \\
\hline Funcionalidade & $\begin{array}{l}\text { Avaliar aspectos de funcionalidade, como a precisão e facilidade de re- } \\
\text { alização de tarefas. }\end{array}$ \\
\hline Segurança & $\begin{array}{l}\text { Avaliar aspectos de segurança, como confidencialidade, autenticidade, } \\
\text { rastreabilidade e integridade. }\end{array}$ \\
\hline Desempenho & $\begin{array}{l}\text { Avaliar aspectos de desempenho, como o comportamento em relação ao } \\
\text { tempo, capacidade e utilização de recursos. }\end{array}$ \\
\hline Pedagógico & $\begin{array}{l}\text { Avaliar aspectos pedagógicos, como conteúdo, interatividade e aprendi- } \\
\text { zagem. }\end{array}$ \\
\hline Usabilidade & $\begin{array}{l}\text { Avaliar aspectos de usabilidade, verificando se o aplicativo m-learning } \\
\text { pode ser entendido, aprendido, usado e atraente ao usuário. }\end{array}$ \\
\hline Suporte & $\begin{array}{l}\text { Avaliar aspectos relacionados ao suporte, como tratamento de inciden- } \\
\text { tes e auxilio na resolução de erros. }\end{array}$ \\
\hline Comunicação & $\begin{array}{l}\text { Avaliar aspectos de comunicação do aplicativo, como notificações e fer- } \\
\text { ramentas de colaboração. }\end{array}$ \\
\hline Portabilidade & $\begin{array}{l}\text { Avaliar aspectos de portabilidade, como a facilidade da adaptação e } \\
\text { instalação do aplicativo em diferentes sistemas. }\end{array}$ \\
\hline
\end{tabular}

\subsubsection{Avaliação do Duolingo}

Para ilustrar a utilização do método foi selecionada a avaliação de qualidade executada no aplicativo Duolingo. Inicialmente, foi aplicado o checklist que consistia em

5 Duolingo: https://play.google.com/store/apps/details?id=com.duolingo

6 Wlingua: https://play.google.com/store/apps/details?id=com.wlingua.curso

7 Rosetta: https://play.google.com/store/apps/details?id=air.com.rosettastone.mobile.CoursePlayer 
um total de 80 questões (na última versão este número passou para 85), as quais foram respondidas por um especialista. Apesar de existirem oito critérios de qualidade, para exemplificar a avaliação de uma deles, o critério Usabilidade será considerado. A Tabela 35 apresenta a pontuação das respostas fornecidas no checklist e a pontuação total obtida.

Tabela 35 - Pontuações Obtidas na Avaliação de Usabilidade do Duolingo

\begin{tabular}{l|l|l|l}
\hline Questão & Pontuação & Questão & Pontuação \\
\hline 1 & 10 & 6 & 10 \\
\hline 2 & 0 & 7 & 10 \\
\hline 3 & 10 & 8 & 10 \\
\hline 4 & 10 & 9 & 10 \\
\hline 5 & 10 & $10 \quad 9$ & 10 \\
\hline Total & \multicolumn{2}{|c}{90} \\
\hline
\end{tabular}

Nota-se que apenas uma questão não obteve a pontuação máxima. O objetivo da questão que não obteve pontuação era verificar se o aplicativo possuía demonstrações do uso de suas funcionalidades. Por não possuir este tipo de ajuda para o aluno, a questão não obteve pontos. Já as outras questões, obtiveram pontuação máxima. Uma delas era referente à padronização do aplicativo, ou seja, seus botões, menus, fotos, letras, entre outros seguiam um padrão satisfatório para o avaliador.

A partir dos resultados obtidos, pode-se concluir que o Duolingo possui um nível de qualidade superior para a característica Usabilidade, totalizando 90 pontos. Além da característica apresentada, a Figura 16 apresenta a sumarização dos resultados obtidos com a avaliação do Duolingo.

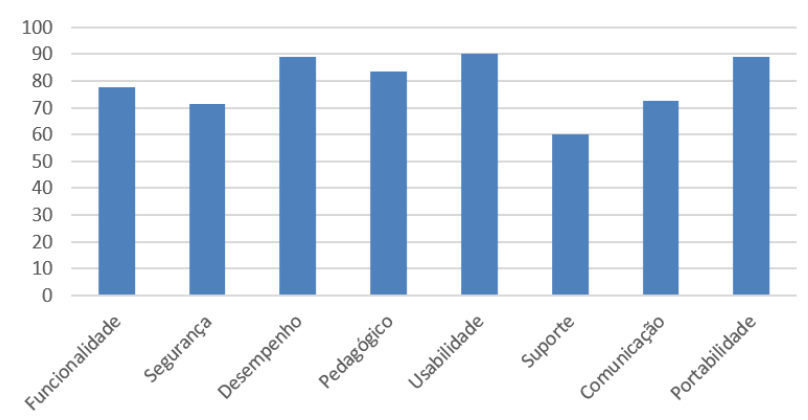

Figura 16 - Resultado da Avaliação do Duolingo

A utilização do método MoLEva viabilizou a obtenção das informações necessárias para que fosse realizada a análise dos pontos positivos e negativos do aplicativo apresentados na Tabela 36, que sumariza os pontos positivos e negativos de cada critério de qualidade avaliado.

Por meio dos critérios de julgamento definidos, pode-se observar que o Duolingo não possui nenhum critério de qualidade com nível baixo, embora a avaliação da característica Suporte tenha ficado próxima de 50\%. As características classificadas com um nível superior foram Usabilidade, Pedagógica e Portabilidade. 
Tabela 36 - Pontos Positivos e Negativos Identificados para o Aplicativo Duolingo

\begin{tabular}{|c|c|c|}
\hline Critério & Pontos Negativos & Pontos Positivos \\
\hline Funcionalidade & $\begin{array}{l}\text { Falta de um sistema de buscas para } \\
\text { encontrar funcionalidades específi- } \\
\text { cas no aplicativo e a não adaptação } \\
\text { do conteúdo de acordo com os re- } \\
\text { cursos disponíveis. }\end{array}$ & $\begin{array}{l}\text { Utilização de diferentes recursos de } \\
\text { mídia (ex. vídeo, áudio, imagens, } \\
\text { entre outros) e apresentação de da- } \\
\text { dos sobre o uso do aplicativo (ex. } \\
\text { desempenho nas aulas) }\end{array}$ \\
\hline Segurança & $\begin{array}{l}\text { O aplicativo não faz bloqueio em re- } \\
\text { lação a quantidade de vezes que o } \\
\text { usuário errou a senha ao entrar no } \\
\text { aplicativo e no cadastro de senha } \\
\text { o usuário não é informado sobre o } \\
\text { quão segura ela é. }\end{array}$ & $\begin{array}{l}\text { O aplicativo esteve disponível du- } \\
\text { rante todo o processo de avaliação, } \\
\text { não apresentando nenhuma intermi- } \\
\text { tência e ao simular falhas na cone- } \\
\text { xão as informações inseridas no apli- } \\
\text { cativo não foram perdidas. }\end{array}$ \\
\hline Desempenho & $\begin{array}{l}\text { O aplicativo não apresenta meca- } \\
\text { nismos de medição de conexão, avi- } \\
\text { sando o usuário caso a conexão não } \\
\text { suporte o aplicativo. }\end{array}$ & $\begin{array}{l}\text { O aplicativo apresentou um tempo } \\
\text { de resposta satisfatório durante } \\
\text { todo o processo de avaliação, inclu- } \\
\text { sive durante a sua comunicação com } \\
\text { o servidor. }\end{array}$ \\
\hline Pedagógico & $\begin{array}{l}\text { O aplicativo não consegue detec- } \\
\text { tar automaticamente informações } \\
\text { contextuais ligada ao contexto dos } \\
\text { usuários, possuindo assim um mate- } \\
\text { rial de aprendizagem genérico. }\end{array}$ & $\begin{array}{l}\text { Organização do conteúdo de apren- } \\
\text { dizagem, possibilita uma maior inte- } \\
\text { ratividade utilizando assim o dispo- } \\
\text { sitivo móvel como um agente inte- } \\
\text { rativo e fornece diferentes tipos de } \\
\text { atividades de aprendizagem. }\end{array}$ \\
\hline Usabilidade & $\begin{array}{l}\text { Não apresenta demonstrações sobre } \\
\text { suas funcionalidades. }\end{array}$ & $\begin{array}{l}\text { Possui uma interface amigável, pa- } \\
\text { dronização do aplicativo e funciona- } \\
\text { lidades intuitivas. }\end{array}$ \\
\hline Suporte & $\begin{array}{l}\text { Durante o processo de avaliação ao } \\
\text { simular um erro grave o aplicativo } \\
\text { não se comporta de maneira satis- } \\
\text { fatória, não permitindo reportar o } \\
\text { erro e nem gravar o trabalho atual } \\
\text { e não é exibida a versão atual do } \\
\text { aplicativo. }\end{array}$ & $\begin{array}{l}\text { O aplicativo pode ser modificado de } \\
\text { acordo com as necessidades do usuá- } \\
\text { rio. }\end{array}$ \\
\hline Comunicação & $\begin{array}{l}\text { O aplicativo não possui ferramen- } \\
\text { tas de colaboração para a resolução } \\
\text { de tarefas e não possui mecanismos } \\
\text { para denuncias de mensagens com } \\
\text { conteúdo ofensivo. }\end{array}$ & $\begin{array}{l}\text { Possui funcionalidade para feed- } \\
\text { back de desempenho dos aprendizes, } \\
\text { exibe notificações de eventos para o } \\
\text { usuário e a ativação e desativação } \\
\text { de notificações pelo próprio aplica- } \\
\text { tivo. }\end{array}$ \\
\hline Portabilidade & $\begin{array}{l}\text { Não permite navegação offline, ou } \\
\text { seja, o aplicativo ficou inutilizável } \\
\text { na ausência de conexão com a In- } \\
\text { ternet. }\end{array}$ & $\begin{array}{l}\text { O aplicativo é atualizado constan- } \\
\text { temente e as configurações da nova } \\
\text { versão são feitas automaticamente, } \\
\text { além de ser compatível com diferen- } \\
\text { tes sistemas operacionais. }\end{array}$ \\
\hline
\end{tabular}

\subsubsection{Resultados da Avaliação de Qualidade dos Aplicativos}

O método MoLEva foi aplicado aos demais aplicativos selecionados, avaliando assim a qualidade de acordo com as características definidas. A Figura 17a sumariza os resultados de cada característica de qualidade para cada aplicativo, permitindo a comparação entre eles. A Figura 17b apresenta o resultado final da avaliação de qualidade dos aplicativos.

Observa-se que os aplicativos Duolingo, Wlingua e Rosetta Stone permaneceram em um faixa de pontuação de qualidade média, porém o aplicativo Rosetta Stone apresentou uma pontuação inferior aos demais. Esse resultado deve-se ao fato da identificação de uma maior quantidade de problemas para esse aplicativo. As principais vantagens e desvantagens dos aplicativos, observadas a partir da utilização do método MoLEva, são 


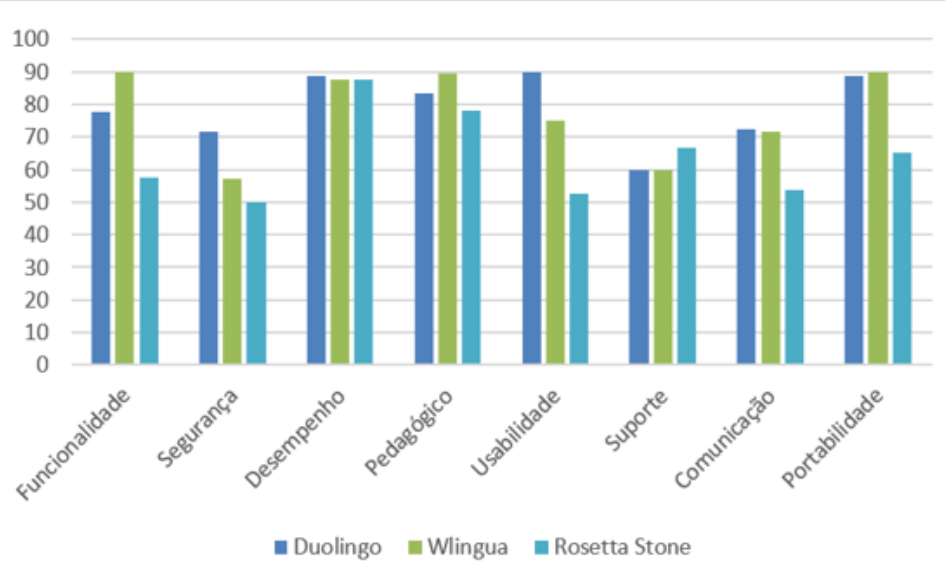

(a) Resultado da avaliação dos aplicativos

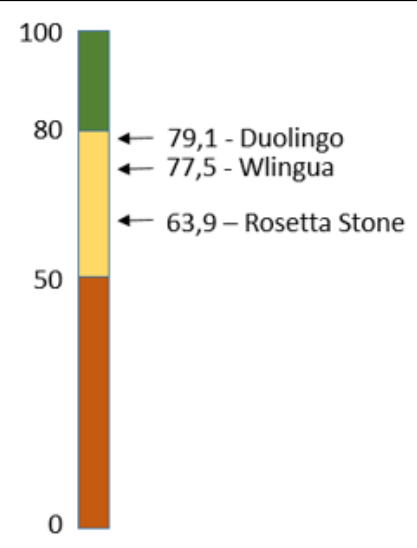

b) Avaliação final dos aplicativos

Figura 17 - Resultado Final da Avaliação dos Aplicativos

apresentadas na Tabela 37.

Tabela 37 - Principais Vantagens e Desvantagens dos Aplicativos Avaliadas

\begin{tabular}{|c|c|c|c|}
\hline & Duolingo & Wlingua & Rosetta Stone \\
\hline Vantagens & $\begin{array}{l}\text { (i) utilização gratuita; (ii) in- } \\
\text { terface agradável, intuitiva } \\
\text { com componentes padroni- } \\
\text { zados; e (iii) permite maior } \\
\text { interatividade utilizando di- } \\
\text { versos tipos de atividades. }\end{array}$ & $\begin{array}{l}\text { (i) versão gratuita restrita, } \\
\text { porém permite utilização de } \\
\text { todos os recursos durante } \\
\text { um mês; (ii) em caso de } \\
\text { instabilidade na conexão, o } \\
\text { aplicativo se adapta para } \\
\text { manter sua utilização; (iii) } \\
\text { armazenamento das informa- } \\
\text { ções evitando perda de da- } \\
\text { dos. }\end{array}$ & $\begin{array}{l}\text { (i) suporte técnico; (ii) vá- } \\
\text { rios recursos que permitem } \\
\text { maior interatividade; e (iii) } \\
\text { ótimo desempenho na comu- } \\
\text { nicação com recursos exter- } \\
\text { nos. }\end{array}$ \\
\hline Desvantagens & $\begin{array}{l}\text { (i) ao cadastrar a senha } \\
\text { de acesso não é informado } \\
\text { o nível de segurança da } \\
\text { mesma; (ii) ausência de me- } \\
\text { canismo para reportar men- } \\
\text { sagens ofensivas; e (iii) fun- } \\
\text { cionalidades sem demonstra- } \\
\text { ção de uso. }\end{array}$ & $\begin{array}{l}\text { (i) após um mês, os recursos } \\
\text { de aprendizagem ficam res- } \\
\text { tritos a versão gratuita; (ii) } \\
\text { ao cadastrar a senha, não é } \\
\text { indicado o seu nível de se- } \\
\text { gurança; e (iii) o aplicativo } \\
\text { não pode ser modificado de } \\
\text { acordo com as necessidades } \\
\text { do usuário. }\end{array}$ & $\begin{array}{l}\text { (i) botões com funcionalida- } \\
\text { des confusas; (ii) não tem su- } \\
\text { porte para utilizar o aplica- } \\
\text { tivo no modo retrato; e (iii) } \\
\text { o teclado não é adaptado de } \\
\text { acordo com o contexto do } \\
\text { conteúdo (por exemplo, ao } \\
\text { digitar um e-mail o teclado } \\
\text { não exibe o símbolo "@"). }\end{array}$ \\
\hline
\end{tabular}

Além das desvantagens citadas, alguns problemas comuns a todos os aplicativos avaliados também foram observados: (i) não é possível utilizar o aplicativo em modo offline; (ii) a colaboração não é incentivada e não são disponibilizados recursos para tal; (iii) não há bloqueio ao tentar realizar a autenticação várias vezes com senha incorreta; e (iv) mecanismos de ajuda e manuais não são fornecidos ou são de difícil acesso.

Ao final da utilização do método MoLEva, observou-se que ele conseguiu identificar diversos problemas de qualidade relacionados aos aplicativos avaliados. O método também identifica oportunidades de melhorias, auxiliando os responsáveis pelos aplicativos em sua evolução.

Apesar dos resultados favoráveis observados, também foram identificadas melho- 
rias para serem feitas no método. Dentre as melhorias, a divisão do critério de qualidade Pedagógico em mais critérios poderia permitir um melhor detalhamento desse critério. Essa melhoria foi realizada e atualmente o método possui três critérios de qualidade relacionados à categoria Pedagógica (Aprendizagem, Conteúdo e Interatividade). Além disso, os critérios Socioeconômicos e Socioculturais não estavam em evidência no método. Na versão atual do método estes critérios podem ser analisados individualmente.

\subsection{Considerações Finais}

Neste capítulo foram apresentadas as etapas de desenvolvimento do método de avaliação de qualidade para aplicativos educacionais móveis, denominado MoLEva. Além disso, também foram descritos seus principais componentes: modelo de qualidade, métricas e critérios de julgamento.

Por fim, foi apresentada uma validação preliminar do método MoLEva, que foi realizada durante o seu desenvolvimento. Tal validação foi importante no desenvolvimento do método, já que a partir dos seus resultados foi possível evoluir o método, deixando-o mais abrangente e atendendo as necessidades identificadas durante a validação.

No próximo capítulo, é apresentada a aplicação do método por meio de dois estudos de caso, conduzidos com o objetivo de avaliar a versão atual do método MoLEva. 



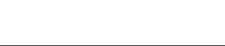

\section{AVALIAÇÃO DO MÉTODO MOLEVA}

\subsection{Considerações Iniciais}

De acordo com Yin (2009), o estudo de caso é uma estratégia de investigação adequada para pesquisas em que é necessário investigar um fenômeno em seu ambiente natural. Além disso, Yin (2009) também sugere que em um estudo de caso algumas etapas devem ser seguidas. Primeiramente a definição do objetivo do estudo deve ser clara. Em seguida, deve ser definida a coleta de dados para o estudo, determinando dessa maneira os instrumentos necessários para isso. Além disso, é importante que a análise dos dados seja feita contendo analogias e comparações. Por fim, as conclusões devem conter possíveis inferências não estatísticas e explicações sobre os acontecimentos.

Nessa perspectiva, optou-se por utilizar o estudo de caso para avaliar o método MoLEva. Para isso, dois estudos de caso foram conduzidos. O primeiro refere-se à aplicação do método com um avaliador e o aplicativo ENEM (Exame Nacional do Ensino Médio); este estudo de caso é apresentado na Seção 5.2. Já o segundo estudo de caso está relacionado com a aplicação do método considerando oito avaliadores e dois aplicativos no domínio do ensino de idiomas (Duolingo e Wlingua). Este estudo de caso é apresentado na Seção 5.3. Por fim, na Seção 5.4 são apresentadas as considerações finais.

\subsection{Estudo de Caso 1: Aplicativo ENEM}

A primeira avaliação do método MoLEva na sua última versão consistiu em sua utilização para avaliar a qualidade do aplicativo ENEM (Figura 18). Sua seleção ocorreu primeiramente por ser um aplicativo relacionado ao ENEM, que atualmente é um tema muito procurado pelos estudantes, utilizado como mecanismo de seleção para grande parte dos cursos superiores no Brasil. 

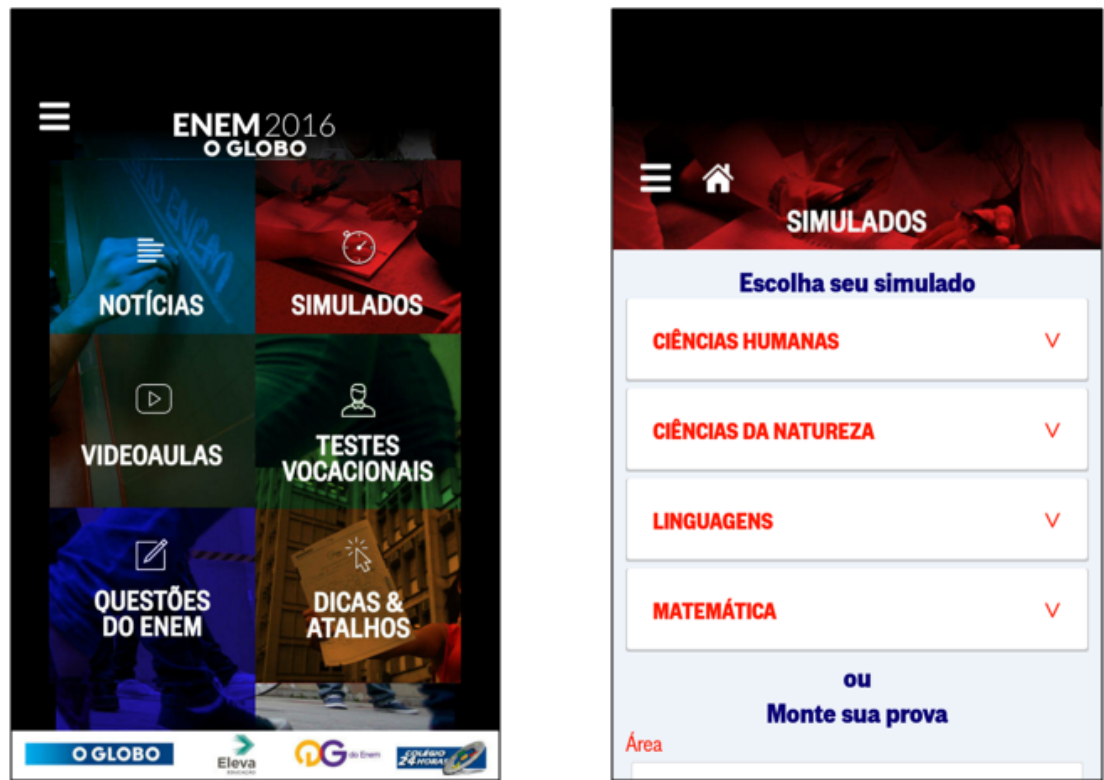

Figura 18 - Aplicativo ENEM

Como segundo critério para seleção do aplicativo, foi considerada a sua avaliação nas lojas de aplicativos, além de seu número de instalações. Os critérios definidos foram: possuir uma nota de avaliação maior que quatro e possuir um número maior que 10.000 instalações. Além destes critérios, também foi considerado como critério o aplicativo estar disponível para pelo menos duas plataformas diferentes, no caso, o aplicativo do ENEM encontra-se disponível para Android e iOS.

De modo geral, o aplicativo selecionado tem como objetivo consolidar todas as informações necessárias sobre o ENEM, permitindo que o aluno além de estudar para o exame, também possa receber notícias sobre o ENEM, além de informações sobre a educação e outros exames.

O aluno pode, por meio do aplicativo, estudar para o exame com videoaulas que estão disponíveis cobrindo os temas abordados pelo exame. Além de possibilitar os estudos, o aplicativo também permite que o aluno faça simulados e responda questões oficiais do ENEM. Ao realizar os testes propostos pelo aplicativo, o aluno recebe os resultados que obteve, podendo comparar o seu desempenho com testes anteriores, além de possibilitar a comparação com outros alunos que utilizam também o aplicativo.

Para a execução do estudo de caso foi utilizada a ferramenta web MoLEva, apresentada no Capítulo 4. Por meio dessa ferramenta, o avaliador foi capaz de responder às perguntas da avaliação e ao final receber o resultado do nível de qualidade do aplicativo avaliado. Além disso, o estudo de caso foi conduzido considerando como avaliador o autor do trabalho.

No total, foram respondidas 85 questões do checklist e o aplicativo foi avaliado em dois sistemas operacionais distintos (Android e iOS). Além disso, a avaliação foi feita 
utilizando dois smartphones e um tablet, permitindo que o aplicativo fosse utilizado em diferentes dispositivos. Os resultados obtidos são analisados a seguir.

\subsubsection{Análise dos Resultados}

A Figura 19 ilustra os resultados obtidos na avaliação de qualidade do aplicativo ENEM, de acordo com cada um dos 12 critérios de qualidade estabelecidos pelo MoLEva. Os critérios que apresentaram pontuações mais baixas foram: Sociocultural, Adequação Funcional, Segurança, Confiabilidade e Interatividade.

Ao final da avaliação obteve-se os resultados referentes aos critérios de qualidade, apresentados na Figura 19. Nota-se pelos resultados que o método MoLEva identificou critérios de qualidade com pontuações baixas, indicando assim possíveis oportunidades de melhoria para o aplicativo.

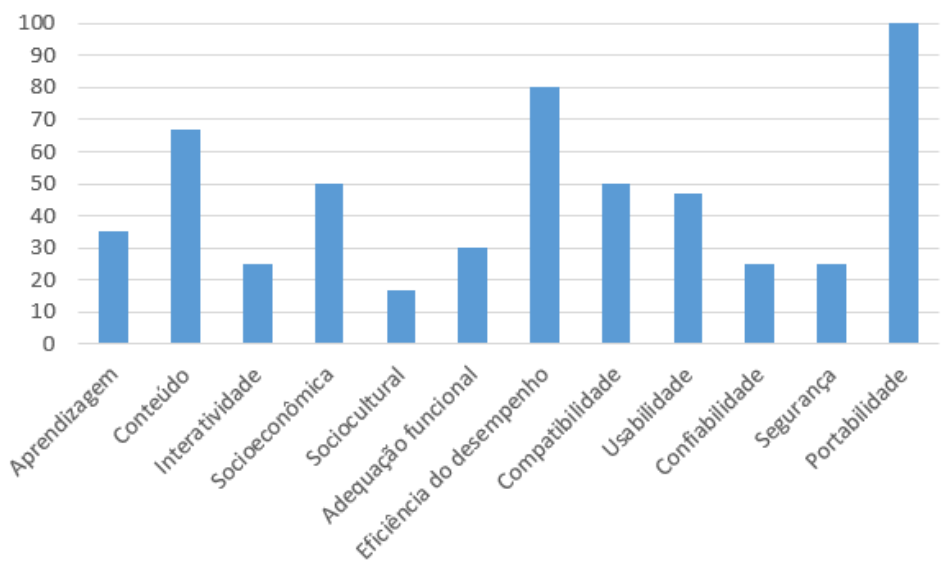

Figura 19 - Aplicativo ENEM: Resultado por Critério de Qualidade

O critério Sociocultural apresentou baixa pontuação, indicando que o aplicativo possui limitações ao considerar os aspectos socioculturais de seus usuários. Por exemplo, o aplicativo não possui mecanismos para reportar conteúdos considerados ofensivos pelo usuário, o que indica uma oportunidade de melhoria.

O critério Adequação Funcional também teve baixa pontuação, indicando que o aplicativo não disponibiliza as funções que satisfazem as necessidades dos alunos. Por exemplo, o aplicativo não faz o uso de diferentes tipos de mídias, fazendo com que grande parte dos recursos do aplicativo explorem apenas vídeos. Outro critério com baixa pontuação foi Segurança; dentre os problemas identificados, destaca-se que o aplicativo não inibe a criação de usuários falsos, possibilitando que usuários mal intencionados utilizem o aplicativo.

O último critério dentre aqueles com pontuação mais baixa foi Interatividade. Sua baixa pontuação ocorreu pois o aplicativo possui limitações ao disponibilizar funcio- 
nalidades que permitem aos usuários interagirem entre si. Por exemplo, o aplicativo não incentiva a cooperação entre os alunos.

É importante destacar que, além da análise dos critérios com pontuações baixas, também é necessário verificar os motivos que fizeram alguns critérios receberem pontuações maiores, indicando um nível de qualidade superior. Dentre os critérios com maiores pontuações, destaca-se a Portabilidade, que indica que apesar do aplicativo ter sido submetido a testes em diferentes dispositivos e sistemas operacionais não apresentou problemas. Além disso, o aplicativo está disponível para os principais sistemas operacionais, facilitando assim a sua utilização.

O critério Eficiência do Desempenho também foi classificado com o nível de qualidade superior. Isso indica que o aplicativo apresentou um bom desempenho durante a avaliação, utilizando de maneira otimizada os recursos dos dispositivos. Dessa maneira, o aplicativo foi utilizado sem apresentar lentidões e travamentos.

Por fim, dentre as pontuações mais altas também foi relacionado o critério Conteúdo. A isenção de erros no conteúdo durante a avaliação e o fornecimento de conteúdo atualizado para os alunos contribuiu para que esse critério obtivesse uma pontuação razoável. Apesar desse critério estar entre as maiores pontuações, ele obteve $66,67 \%$, de acordo com o padrão estabelecido no método MoLEva, sendo classificado com o nível médio de qualidade. Para melhorar a avaliação desse critério, é necessário efetuar melhorias como, por exemplo, a organização dos materiais por nível de conhecimento, propiciando estudos do nível básico ao avançado.

Além do resultado por critérios de qualidade, também foram obtidas as pontuações referentes ao nível de qualidade do aplicativo com relação às categorias, conforme ilustrado na Figura 20a. Por meio do resultado obtido, é possível identificar que a categoria Técnica obteve uma pontuação maior que 50\%, enquanto as demais categorias tiveram pontuações abaixo de 50\%. Dessa maneira, as categorias Pedagógica e Social obtiveram os respectivos níveis de qualidade classificados como baixo, sendo apenas a categoria Técnica classificada com o nível de qualidade médio.

O resultado obtido por categoria utilizando o método MoLEva é importante, já que a partir deste resultado é possível identificar as categorias que necessitam de melhorias para aumentar o seu nível de qualidade. No caso do aplicativo ENEM, nota-se que a categoria Social recebeu a menor avaliação. Devido ao contexto do aplicativo que se refere a um exame feito por diferentes perfis de alunos, a categoria Social é uma oportunidade de melhoria importante que foi revelada pelo MoLEva e deve ser analisada. A análise desse problema deve ser feita para os critérios de qualidade Socioeconômico e Sociocultural, já que estes critérios estão relacionados à categoria Social.

A partir do resultado obtido, gerou-se o valor final da qualidade do aplicativo 


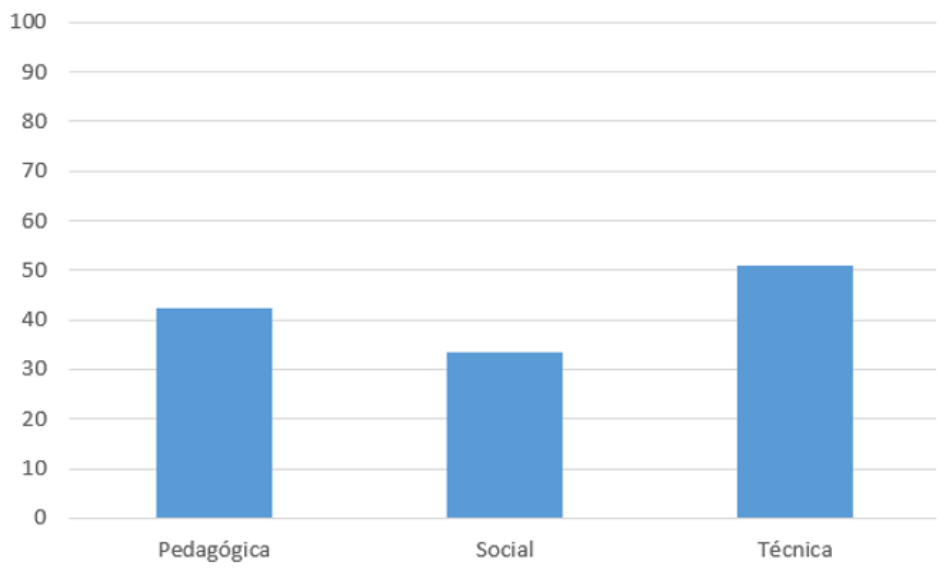

(a) Resultado da avaliação da aplicação por categoria

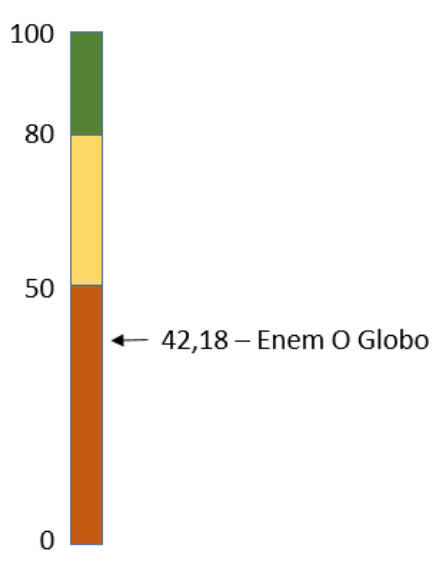

(b) Nível de qualidade da aplicação

Figura 20 - Resultado Final da Avaliação de Qualidade do Aplicativo ENEM

(Figura 20b). Com base nesse resultado, é possível identificar que o aplicativo avaliado possui muitos pontos de melhoria, já que seu nível de qualidade obteve 42,18\% de pontuação. Aplicando os critérios de julgamento definidos no método, o resultado final é que o aplicativo possui um nível baixo de qualidade.

De modo geral, a aplicação do método MoLEva na avaliação de qualidade do aplicativo ENEM foi bem sucedida, sendo possível identificar oportunidades de melhoria para o aplicativo, além de destacar os critérios de qualidade que obtiveram maior nível de qualidade. Devido ao avaliador ser o autor do método MoLEva, não foi possível identificar dificuldades na aplicação do método, porém um ponto importante que deve ser considerado é que o método MoLEva exige tempo do seu avaliador. De fato, o tempo exigido para a aplicação do MoLEva é uma limitação, a qual deve ser tratada em pesquisas futuras envolvendo a evolução do método.

\subsection{Estudo de Caso 2: Aplicativos Duolingo e Wlingua}

O segundo estudo de caso envolvendo a aplicação do método MoLEva foi conduzido no contexto de aplicativos para o ensino de idiomas. Além de disponibilizarem várias opções de aplicativos em diferentes sistemas operacionais, esse tipo de aplicativo possui um objetivo bem definido, que é o ensino de idiomas. Para este estudo de caso foram selecionados dois aplicativos educacionais móveis: (i) Duolingo; e (ii) Wlingua.

Tais aplicativos foram escolhidos pois, além de possuírem uma boa avaliação nas lojas de aplicativos, eles também satisfazem a premissa de que os aplicativos devem estar disponíveis para os três principais sistemas operacionais existentes atualmente (Android, iOS e Windows). O motivo dessa premissa foi mitigar a possibilidade de um avaliador não possuir o sistema adequado para a instalação e avaliação do aplicativo. 
Além disso, a escolha desses aplicativos possibilitou a comparação entre o resultado final obtido neste estudo de caso com o apresentado na avaliação do método feita durante o seu desenvolvimento, apresentada na Seção 4.4.1.

O aplicativo Duolingo utilizado no estudo de caso disponibiliza recursos que permitem o exercício da leitura, escrita e dicção. Além disso, também são aplicados conceitos de gamificação, incentivando o usuário a atingir metas diárias.

Já o aplicativo Wlingua também disponibiliza recursos que permitem o exercício da leitura, escrita e dicção, porém fornece a opção de seleção do sotaque que deseja utilizar no aprendizado. Além disso, o aplicativo fornece relatórios detalhados de progresso e também permite o download de aulas, possibilitando ao usuário o aprendizado offline.

O estudo de caso em questão envolveu a comparação do método MoLEva com o método TUP, apresentado na Seção 2.3.1.4. O objetivo da comparação foi investigar se o método MoLEva identifica uma quantidade maior de problemas que o método TUP. Além disso, também se pretendeu analisar se o método TUP seria capaz de identificar algum problema não detectado pelo MoLEva, indicando dessa maneira uma possível melhoria para o método.

A escolha do método TUP também se justifica devido à falta de métodos específicos para a avaliação de qualidade de aplicativos educacionais móveis. Por este motivo, optou-se pelo TUP (BEDNARIK et al., 2004; BEDNARIK, 2002; GERDT; MIRAFTABI; TUKIAINEN, 2002), desenvolvido para a avaliação de qualidade de softwares educacionais em geral. Basicamente, o TUP avalia a qualidade do software por meio de um checklist que considera a qualidade de um software em três aspectos: (i) Usabilidade; (ii) Tecnologia; e (iii) Pedagogia.

A fim de avaliar o método MoLEva com uma quantidade maior de avaliadores, este estudo de caso foi conduzido com oito avaliadores. Dessa forma, foi possível avaliar o método com avaliadores que não possuíam conhecimento sobre o método proposto.

\subsubsection{Planejamento do Estudo de Caso}

Antes da execução do estudo de caso foi necessário fazer o seu planejamento. Para isso foi necessária a definição dos seus objetivos. Além disso, também são definidos os perfis dos participantes do estudo. Por fim, são definidos os instrumentos utilizados durante o estudo de caso.

\section{Objetivos}

Os objetivos do estudo de caso envolvendo os aplicativos Duolingo e Wlingua foram:

- Comparação entre os métodos MoLEva e TUP: a ideia é comparar a quantidade 
de problemas identificados pelos métodos TUP e MoLEva, fazendo uma análise dos problemas identificados pelo TUP que não foram identificados pelo MoLEva. Além disso, também é feita uma análise sobre a percepção dos avaliadores com relação à utilização de ambos os métodos;

- Análise do resultado da avaliação de qualidade dos aplicativos pelo MoLEva: pretendese conduzir uma análise sobre os resultados fornecidos pelo MoLEva após a sua execução;

\section{Participantes}

Para o presente estudo de caso, foram selecionados oito alunos de pós-graduação do ICMC-USP na área Engenharia de Software, sendo um doutor, seis doutorandos e um mestre. Dentre os alunos participantes, dois já atuavam como professor.

\section{Instrumentação}

Como citado anteriormente, a coleta de dados é uma etapa importante para o estudo de caso, já que são esses dados que servirão como base para as análises e conclusão do estudo. Assim, no que se refere à instrumentação utilizada no estudo de caso, os seguintes documentos foram apresentados aos participantes: (i) termo de adesão ao estudo experimental; (ii) formulário de caracterização do participante; (iii) documento com a orientação das atividades que o participante deveria realizar; (iv) formulário para a aplicação do método TUP; (v) ferramenta web utilizada para a aplicação do método MoLEva; e (vi) formulário de pós-avaliação, utilizado para recuperar informações após a execução dos métodos.

\subsubsection{Execução do Estudo de Caso}

Para a execução do estudo de caso os participantes selecionados foram divididos em dois grupos. Essa divisão foi feita a partir das respostas de cada um deles no formulário de caracterização do participante. Esse documento foi submetido aos participantes objetivando coletar as informações necessárias para a divisão dos grupos. Para que esta divisão fosse feita de forma balanceada, as seguintes características foram consideradas por ordem de prioridade:

1. Conhecimento sobre qualidade de software;

2. Experiência em avaliação de qualidade de aplicativos;

3. Utilização dos aplicativos educacionais móveis contidas no estudo de caso;

4. Nível de conhecimento no idioma inglês. 
Após a divisão dos grupos, foi definido que cada grupo executaria ambos os métodos em aplicativos diferentes, como mostra a Figura 21. Esse tipo de execução caracteriza a abordagem Within-Group, definida por Lazar, Feng e Hochheiser (2010), que se caracteriza por ser mais adequado para amostras menores e evita ruídos por diferenças individuais. Apesar das vantagens, essa abordagem também apresenta desvantagens como: (i) efeito aprendizagem, que ocorre devido ao participante possuir um conhecimento maior na segunda execução do estudo, podendo influenciar nos resultados; e (ii) fadiga devido às múltiplas condições do estudo de caso.

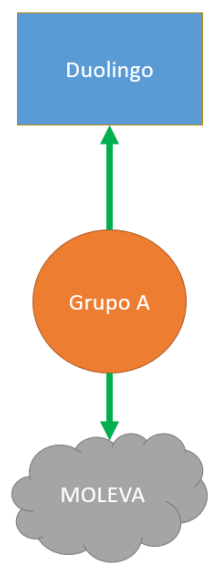

(a) Primeira etapa

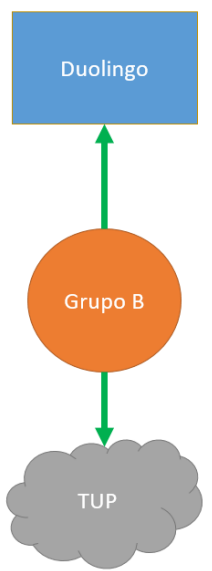

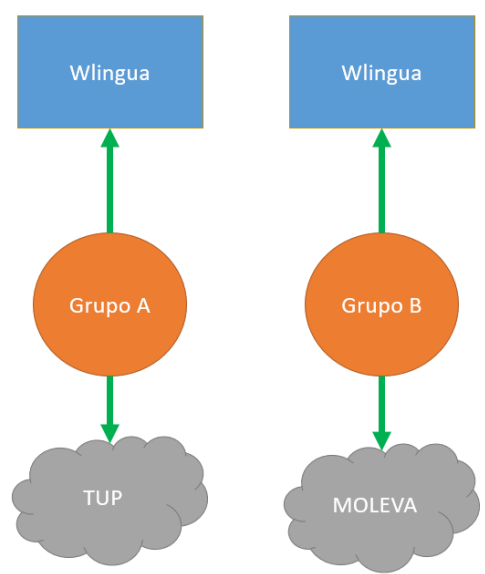

(b) Segunda etapa

Figura 21 - Etapas de Execução do Estudo de Caso 2

Para evitar o fator aprendizagem, ambos os grupos foram submetidos aos dois métodos em momentos diferentes. A fadiga, entretanto, não pode ser reduzida devido ao tamanho do estudo de caso. Dessa maneira, todos os participantes tiveram contato com os dois métodos e os dois aplicativos selecionadas.

A execução das atividades do estudo de caso ocorreu na seguinte sequência:

1. Os participantes receberam, leram e aceitaram o termo de adesão ao estudo;

2. Os participantes receberam um guia da avaliação. Esse guia continha as informações necessárias para que o participante pudesse executar a avaliação;

3. Foi informado aos participantes como proceder na utilização do sistema criado para a execução do método MoLEva. Para a execução do método TUP, foi disponibilizado o checklist online e as orientações para sua execução;

4. Os participantes foram informados sobre o prazo de um mês para a execução das avaliações;

5. Após a finalização da avaliação, os participantes preencheram um formulário de pós-avaliação. 
Após a finalização do estudo de caso, os dados foram coletados, analisados e sintetizados a fim de avaliar o método de acordo com os objetivos definidos no planejamento do estudo.

\subsubsection{Análise dos Resultados}

O estudo de caso foi executado por oito participantes, sendo que os dispositivos utilizados durante o estudo de caso foram exclusivamente smartphones. Já os sistemas operacionais utilizados foram variados. Embora a maioria tenha sido Android (5 avaliações), também foram utilizados o iOS (2 avaliações) e Windows (1 avaliação).

Ao final da aplicação dos métodos, todas as respostas foram analisadas e agrupadas pelos aspectos de qualidade definidos no método TUP. O agrupamento foi necessário para permitir a comparação dos problemas identificados de acordo com cada aspecto. Por esse motivo, os critérios de qualidade do MoLEva foram relacionados com os aspectos de qualidade do TUP, como é apresentado na Figura 22.

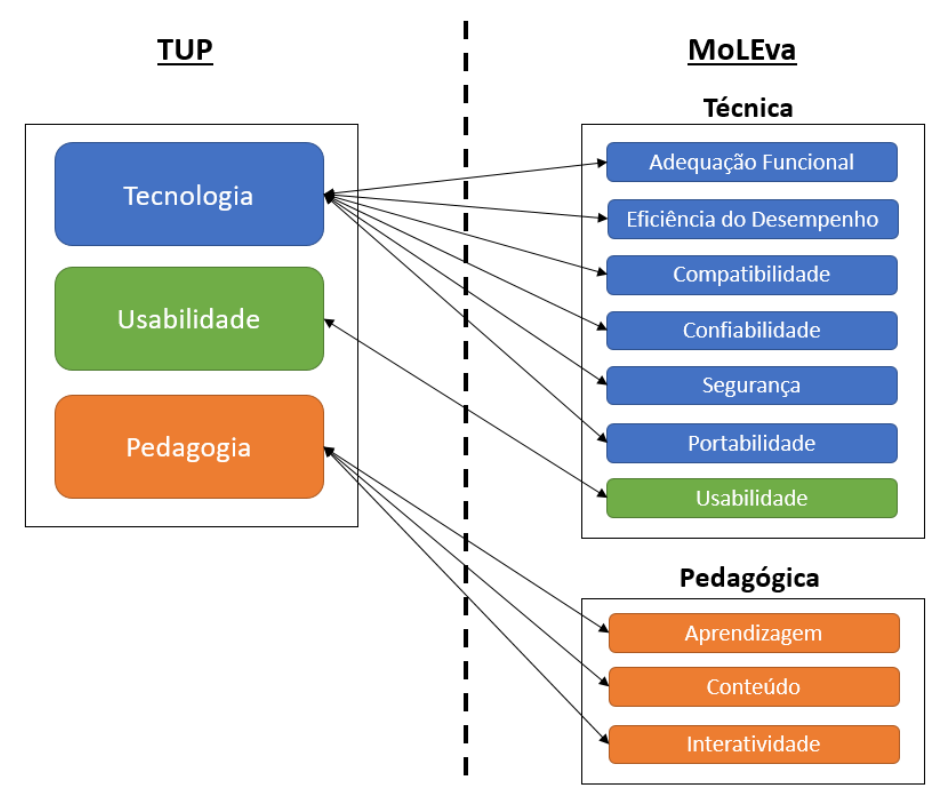

Figura 22 - Relacionamento entre os Aspectos de Qualidade do TUP com o MoLEva

Devido ao método TUP não abordar a categoria Social existente no MoLEva, a sua associação não foi feita. Dessa maneira, os pontos obtidos nessa categoria são exclusivos do MoLEva e são contabilizados como problemas, já que sua existência demonstra que o método MoLEva é mais abrangente considerando tal aspecto.

\section{Comparação entre os métodos MoLEva e TUP}

O primeiro resultado apresentado refere-se ao aspecto Tecnologia. Os quatro tipos de problemas identificados pelo TUP são apresentados na Tabela 38. 
Tabela 38 - Problemas Relacionados à Tecnologia, Resultantes da Aplicação do Método TUP

\begin{tabular}{l|c|c}
\hline Problema & Duolingo & Wlingua \\
\hline O aplicativo não fornece apoio à importação ou exportação de recursos externos. & $\mathrm{X}$ & $\mathrm{X}$ \\
\hline O aplicativo não é adaptável às necessidades das pessoas com deficiência. & $\mathrm{X}$ & $\mathrm{X}$ \\
\hline O aplicativo não permite adaptação para os diferentes grupos etários de usuários. & $\mathrm{X}$ & \\
\hline Não é possível alterar o idioma do aplicativo. & $\mathrm{X}$ & \\
\hline Total & $\mathbf{4}$ & $\mathbf{2}$ \\
\hline
\end{tabular}

Tabela 39 - Problemas Relacionados à Tecnologia, Resultantes da Aplicação do Método MoLEva

\begin{tabular}{|c|c|c|}
\hline Problema & Duolingo & Wlingua \\
\hline $\begin{array}{l}\text { As necessidades dos alunos e professores em relação às funções presentes no aplicativo } \\
\text { não são totalmente atendidas. }\end{array}$ & $\mathrm{X}$ & $\mathrm{X}$ \\
\hline $\begin{array}{l}\text { Quando ocorre variação na rede as funcionalidades não se adaptam de acordo com os } \\
\text { recursos disponíveis. }\end{array}$ & $\mathrm{X}$ & \\
\hline $\begin{array}{l}\text { As notificações enviadas pelo aplicativo não podem ser configuradas no próprio apli- } \\
\text { cativo. }\end{array}$ & & $\mathrm{X}$ \\
\hline $\begin{array}{l}\text { O aplicativo não distingue os diferentes perfis dos usuários durante o processo de } \\
\text { aprendizagem. }\end{array}$ & $\mathrm{X}$ & $\mathrm{X}$ \\
\hline $\begin{array}{l}\text { O aplicativo não apresenta mecanismos de medição de banda larga, verificando se } \\
\text { a banda larga utilizada pelos usuários está de acordo com a mínima exigida pelo } \\
\text { aplicativo. }\end{array}$ & $\mathrm{X}$ & $\mathrm{X}$ \\
\hline O aplicativo não possui um consumo de energia satisfatório. & $\mathrm{X}$ & $\mathrm{X}$ \\
\hline O aplicativo não possui um desempenho de tempo e resposta satisfatório. & & $\mathrm{X}$ \\
\hline O aplicativo não possui capacidade de se comunicar com outros aplicativos. & $\mathrm{X}$ & $\mathrm{X}$ \\
\hline $\begin{array}{l}\text { O aplicativo não se comporta de maneira satisfatória na navegação e utilização em } \\
\text { modo offline. }\end{array}$ & & $\mathrm{X}$ \\
\hline $\begin{array}{l}\text { O aplicativo não permite salvar pontos de backup ou faz isso automaticamente, evi- } \\
\text { tando que dados sejam perdidos. }\end{array}$ & & $\mathrm{X}$ \\
\hline $\begin{array}{l}\text { Em caso de falha, o aplicativo não permaneceu em funcionamento evitando sua fina- } \\
\text { lização ou bloqueio. }\end{array}$ & & $\mathrm{X}$ \\
\hline As contas dos usuários não apresentam privilégios bem definidos. & $\mathrm{X}$ & $\mathrm{X}$ \\
\hline $\begin{array}{l}\text { O aplicativo não faz uma contagem e bloqueio em relação à quantidade de vezes que } \\
\text { o usuário tentou se logar e não conseguiu. }\end{array}$ & $\mathrm{X}$ & $\mathrm{X}$ \\
\hline Ao cadastrar uma senha, o usuário não é informado sobre o quão segura ela é. & $\mathrm{X}$ & $\mathrm{X}$ \\
\hline O aplicativo não possui mecanismos para inibir a criação de usuários falsos. & $\mathrm{X}$ & $\mathrm{X}$ \\
\hline $\begin{array}{l}\text { A proteção dos usuários contra ameaças como vírus, malwares, trojans, entre outros, } \\
\text { quando ocorre a troca de informações ou arquivos entre os usuários não é satisfatória. }\end{array}$ & $\mathrm{X}$ & $\mathrm{X}$ \\
\hline Total & 11 & 15 \\
\hline
\end{tabular}

Já na execução do método MoLEva, obteve-se o total de 16 tipos de problemas, como mostra a Tabela 39. Nota-se que o método MoLEva, nesse aspecto, identificou uma quantidade maior de problemas que o TUP. A diferença obtida pode ser justificada pelo fato do método MoLEva ser mais abrangente, possuindo um conjunto maior de questões que abordam as características tecnológicas. Além disso, o MoLEva foi desenvolvido objetivando avaliar aplicativos educacionais móveis, de modo que suas questões possuem o foco na inspeção de aplicativos com características específicas. Já o TUP, apesar de avaliar softwares educacionais, não considera as características móveis.

Embora o MoLEva tenha identificado uma quantidade maior de problemas, a diferença entre os métodos demonstra que, enquanto algumas características são consideradas como tecnologia no TUP, no MoLEva tais características estão localizadas em outras categorias. Por exemplo, o problema identificado como o aplicativo não ser adaptável a pessoas com deficiência é avaliado no método MoLEva pelo critério de qualidade Usabilidade. Já os problemas referentes à adaptação para diferentes grupos etários e a possibilidade 
Tabela 40 - Problemas Relacionados à Usabilidade, Resultantes da Aplicação do Método TUP

\begin{tabular}{l|c|c}
\hline Problema & Duolingo & Wlingua \\
\hline $\begin{array}{l}\text { Não é possível selecionar os modos avançados de controle de acordo com a experiência } \\
\text { do usuário. }\end{array}$ & $\mathrm{X}$ & $\mathrm{X}$ \\
\hline O nível de interação com o aplicativo não corresponde às características dos usuários. & $\mathrm{X}$ & \\
\hline O aplicativo não oferece atalhos para a maioria dos comandos ou tarefas disponíveis. & $\mathrm{X}$ & $\mathrm{X}$ \\
\hline Total & $\mathbf{3}$ & $\mathbf{2}$ \\
\hline
\end{tabular}

de alterar o idioma do aplicativo, são considerados pelo MoLEva na categoria Social.

Por outro lado, o MoLEva não identifica explicitamente a importação e exportação de recursos externos que foi identificada pelo TUP. Apesar disso, o MoLEva avalia no critério de qualidade Adequação Funcional, se as funções presentes no aplicativo satisfazem o usuário. Dessa maneira, caso esta seja uma funcionalidade essencial para o usuário este critério pode não ser atendido, revelando assim a necessidade dessa função.

Embora o problema citado anteriormente possa ser identificado em uma pergunta geral, a inclusão de uma pergunta específica para analisar o problema será considerada, porém é preciso cautela para não deixar a avaliação extensa, causando fadiga nos avaliadores.

O segundo aspecto avaliado foi a Usabilidade, sendo que na execução do método TUP foram identificados três tipos de problemas, como mostra a Tabela 40. Já o método MoLEva identificou 14 tipos de problemas que são apresentados na Tabela 41. Devido ao método MoLEva ser específico para aplicativos móveis e considerando o uso desse tipo de aplicativo por meio de dispositivos móveis, pode-se concluir que o MoLEva converge para uma taxa maior de identificação de problemas em comparação ao método TUP.

Com relação aos problemas identificados pelo TUP, pode-se concluir que para o contexto móvel, considerando os dispositivos atuais que possuem suas funcionalidades acessíveis pelo toque e o tamanho de suas telas, a utilização de atalhos para a maioria dos comandos poderia ocasionar em uma interface carregada, prejudicando assim a Usabilidade. Apesar da justificativa, os aspectos relacionados aos atalhos e funcionalidades avançadas devem ser analisados em uma próxima atualização do MoLEva.

Por fim, a última comparação entre os métodos é feita com relação ao aspecto Pedagógico. Para este aspecto, o método TUP identificou 10 tipos de problemas, apresentados na Tabela 42. Já o método MoLEva foi capaz de identificar 12 tipos de problemas como mostra a Tabela 43. Pode-se observar que, neste aspecto, os resultados de ambos os métodos ficaram bastante próximos.

Apesar do resultado ser semelhante, observou-se dois tipos de problemas diferentes identificados pelos métodos. Dentre os problemas identificados pelo TUP, alguns não são considerados no MoLEva, como, por exemplo, a criação de notas e marcadores. Este problema, apesar de poder ser identificado pela satisfação do usuário com relação às 
Tabela 41 - Problemas Relacionados à Usabilidade, Resultantes da Aplicação do Método MoLEva

\begin{tabular}{l|c|c}
\hline Problema & Duolingo & Wlingua \\
\hline $\begin{array}{l}\text { Caso existam funcionalidades que não são autoexplicativas, o aplicativo não informa } \\
\text { ao usuário sobre a funcionalidade de seus componentes por meio de "balões" explica- } \\
\text { tivos, botões de ajuda ou similares. }\end{array}$ & $\mathrm{X}$ \\
\hline $\begin{array}{l}\text { As facilidades que o aplicativo oferece no envio de mensagens para outros usuários } \\
\text { não são satisfatórias. }\end{array}$ & & $\mathrm{X}$ \\
\hline O grau de aprendizado que os usuários têm em relação ao aplicativo não é satisfatório. & $\mathrm{X}$ \\
\hline $\begin{array}{l}\text { A ajuda que o aplicativo oferece para os usuário não é classificada de maneira satis- } \\
\text { fatória. }\end{array}$ & $\mathrm{X}$ \\
\hline $\begin{array}{l}\text { A separação dos componentes de ação do aplicativo (ex. botões, checkbox, radio } \\
\text { buttons, menu, entre outros) não são posicionados de maneira satisfatória. }\end{array}$ & $\mathrm{X}$ \\
\hline $\begin{array}{l}\text { O aplicativo não foi avaliado de maneira satisfatória com relação à sua interface ser } \\
\text { "amigável". }\end{array}$ & $\mathrm{X}$ \\
\hline $\begin{array}{l}\text { As mensagens de erros geradas pelo aplicativo não foram avaliadas de maneira satis- } \\
\text { fatória. }\end{array}$ & $\mathrm{X}$ \\
\hline O aplicativo não exibe dicas ou sugestões para auxiliar o usuário na sua utilização. & \\
\hline $\begin{array}{l}\text { A quantidade de elementos exibidos nas telas do aplicativo não foi avaliada de maneira } \\
\text { satisfatória. }\end{array}$ & $\mathrm{X}$ \\
\hline $\begin{array}{l}\text { A facilidade no preenchimento de dados no aplicativo não foi avaliada de maneira } \\
\text { satisfatória. }\end{array}$ & $\mathrm{X}$ \\
\hline A apresentação dos dados no aplicativo não foi avaliada de maneira satisfatória. & $\mathrm{X}$ \\
\hline $\begin{array}{l}\text { O aplicativo não evita que o usuário chegue a um ponto em que não consiga mais } \\
\text { avançar ou retornar. }\end{array}$ & $\mathrm{X}$ \\
\hline $\begin{array}{l}\text { A utilização de mecanismos contra erros voluntários/involuntários dos usuários não } \\
\text { foi classificada de maneira satisfatória. }\end{array}$ & $\mathrm{X}$ \\
\hline $\begin{array}{l}\text { O aplicativo não se adapta à pessoas com necessidades especiais de maneira satisfa- } \\
\text { tória. }\end{array}$ & $\mathrm{X}$ & $\mathrm{X}$ \\
\hline Total & $\mathbf{7}$ & $\mathbf{1 1}$ \\
\hline
\end{tabular}

Tabela 42 - Problemas Relacionados à Pedagogia, Resultantes da Aplicação do Método TUP

\begin{tabular}{|c|c|c|}
\hline Problema & Duolingo & Wlingua \\
\hline $\begin{array}{l}\text { O aplicativo não faz distinção entre os papéis dos usuários no processo de aprendiza- } \\
\text { gem. }\end{array}$ & & $\mathrm{X}$ \\
\hline Não é possível modificar as metas de aprendizagem. & $\mathrm{X}$ & \\
\hline $\begin{array}{l}\text { O professor não pode preparar e modificar materiais de aprendizagem usando o apli- } \\
\text { cativo. }\end{array}$ & $\mathrm{X}$ & \\
\hline $\begin{array}{l}\text { Os professores não podem compartilhar materiais de aprendizagem usando o aplica- } \\
\text { tivo. }\end{array}$ & $\mathrm{X}$ & \\
\hline O aplicativo não permite ao usuário preparar uma apresentação. & $\mathrm{X}$ & \\
\hline Não é possível criar testes, exames ou trabalhos por meio do aplicativo. & $\mathrm{X}$ & \\
\hline $\mathrm{O}$ aplicativo não facilita o trabalho em grupo. & $\mathrm{X}$ & $\mathrm{X}$ \\
\hline Não é possível criar notas ou marcadores dentro do aplicativo. & $\mathrm{X}$ & $\mathrm{X}$ \\
\hline O aplicativo não permite a criação e compartilhamento de artefados de aprendizagem. & & $\mathrm{X}$ \\
\hline $\begin{array}{l}\text { Não é possível personalizar a interface de acordo com as necessidades individuais dos } \\
\text { alunos. }\end{array}$ & $\mathrm{X}$ & $\mathrm{X}$ \\
\hline Total & 8 & 5 \\
\hline
\end{tabular}


Tabela 43 - Problemas Relacionados à Pedagogia, Resultantes da Aplicação do Método MoLEva

\begin{tabular}{|c|c|c|}
\hline Problema & Duolingo & Wlingua \\
\hline O aplicativo não se adapta ao contexto físico de maneira satisfatória. & $\mathrm{X}$ & $\mathrm{X}$ \\
\hline $\begin{array}{l}\text { O aplicativo não disponibiliza uma área em sua interface para divulgar eventos rela- } \\
\text { cionados ao seu contexto. }\end{array}$ & & $\mathrm{X}$ \\
\hline $\begin{array}{l}\text { O aplicativo não é capaz de detectar automaticamente a informação contextual ligada } \\
\text { ao contexto dos usuários e tutores. }\end{array}$ & $\mathrm{X}$ & $\mathrm{X}$ \\
\hline A adaptação ao conhecimento dos usuários não é feita de maneira satisfatória. & $\mathrm{X}$ & $\mathrm{X}$ \\
\hline $\begin{array}{l}\text { O nível de simulação do ambiente real que o aplicativo oferece no aprendizado do } \\
\text { aluno sobre determinando tema não é satisfatório. }\end{array}$ & $\mathrm{X}$ & $\mathrm{X}$ \\
\hline $\begin{array}{l}\text { Os diferentes tipos de atividades educacionais que o aplicativo oferece para auxiliar } \\
\text { na aquisição de conhecimento não são classificados de maneira satisfatória. }\end{array}$ & $\mathrm{X}$ & \\
\hline A organização do conteúdo de aprendizagem não é classificada de maneira satisfatória. & $\mathrm{X}$ & $\mathrm{X}$ \\
\hline $\begin{array}{l}\text { A criação e modificação do conteúdo de aprendizagem oferecido pelo aplicativo não } \\
\text { são classificadas de maneira satisfatória. }\end{array}$ & $\mathrm{X}$ & $\mathrm{X}$ \\
\hline O aplicativo não permite a reutilização do conteúdo de aprendizagem. & $\mathrm{X}$ & $\mathrm{X}$ \\
\hline $\begin{array}{l}\text { A integração do conteúdo oferecido pelo aplicativo não é classificada de maneira } \\
\text { satisfatória. }\end{array}$ & $\mathrm{X}$ & \\
\hline $\begin{array}{l}\text { O aplicativo não possui ferramentas específicas para colaboração de tarefas, sendo } \\
\text { feitos através de wikis, jogos, micro blogs e fóruns. }\end{array}$ & & $\mathrm{X}$ \\
\hline $\begin{array}{l}\text { O aplicativo não oferece atividades educacionais que incentivam a cooperação entre } \\
\text { os usuários do aplicativo. }\end{array}$ & $\mathrm{X}$ & $\mathrm{X}$ \\
\hline Total & 10 & 10 \\
\hline
\end{tabular}

funcionalidades disponibilizadas pelo aplicativo, deverá ser analisado, definindo se deve ou não ser criada uma pergunta específica para ele no método MoLEva.

Além disso, o MoLEva também não considera em suas perguntas específicas a capacidade do aplicativo em permitir a criação de testes, exames e trabalhos. Este problema precisa ser analisado antes de ser incluído na avaliação do MoLEva, pois considerando as restrições relacionadas aos aplicativos móveis, funcionalidades que demandam muita entrada de dados podem prejudicar a Usabilidade. Dessa maneira, é preciso analisar se este tipo de funcionalidade deve ser incluído em um sistema web, no qual seriam disponibilizadas as funcionalidades gerenciais do aplicativo e que necessitem de uma quantidade maior de dados de entradas.

Embora a quantidade de tipos de problemas seja similar entre o TUP e o MoLEva, nota-se que alguns problemas identificados podem não representar um problema quando estão no contexto de aplicativos educacionais móveis.

De acordo com o resultados, observa-se que alguns problemas identificados pelo TUP também são identificados pelo MoLEva, demonstrando que apesar da aplicação do método TUP em um contexto móvel, ele conseguiu identificar problemas que podem ser considerados genéricos no contexto de aplicativos educacionais, independentemente se são móveis ou não. Por exemplo, ambos os métodos avaliam a presença de mecanismos que incentivam a colaboração entre os alunos.

Apesar da associação dos aspectos de qualidade do método TUP com os critérios de qualidade do MoLEva ter colaborado para a comparação dos métodos, não foi possível associar os critérios sociais que o MoLEva possui. Portanto, para esse critério apenas o método MoLEva foi considerado e sua execução identificou quatro tipos de problemas, 
Tabela 44 - Problemas Relacionados ao Contexto Social, Resultantes da Aplicação do Método MoLEva

\begin{tabular}{l|c|c}
\hline Problema & Duolingo & Wlingua \\
\hline O aplicativo não possui opção para reportar incidentes ocorridos durante o seu uso. & $\mathrm{X}$ & \\
\hline $\begin{array}{l}\text { O aplicativo não indica claramente qual é a sua versão atual, juntamente com as } \\
\text { últimas atualizações/modificações realizadas. }\end{array}$ & $\mathrm{X}$ & $\mathrm{X}$ \\
\hline O usuário não recebe feedback sobre os erros ou problemas reportados. & $\mathrm{X}$ & \\
\hline $\begin{array}{l}\text { O aplicativo não possui mecanismos para denunciar mensagens com conteúdo ofen- } \\
\text { sivo. }\end{array}$ & $\mathrm{X}$ & $\mathrm{X}$ \\
\hline Total & $\mathbf{4}$ & $\mathbf{2}$ \\
\hline
\end{tabular}

como mostra a Tabela 44.

Observa-se que os problemas identificados pelo MoLEva na categoria Social representam problemas importantes a serem considerados pelos aplicativos. De fato, considerar o contexto social de um aplicativo é importante na análise de qualidade e, nesse sentido, o MoLEva foi capaz de identificar oportunidades de melhoria para o aplicativo que não foram identificadas pelo método TUP.

A partir dos resultados obtidos, pode-se concluir que o método MoLEva identifica uma quantidade maior de problemas em relação ao TUP. Essa diferença pode ser visualizada na Figura 23, que apresenta a síntese da comparação dos resultados obtidos entre os dois métodos. Observa-se que o método MoLEva identificou 46 tipos de problemas e o TUP 17.

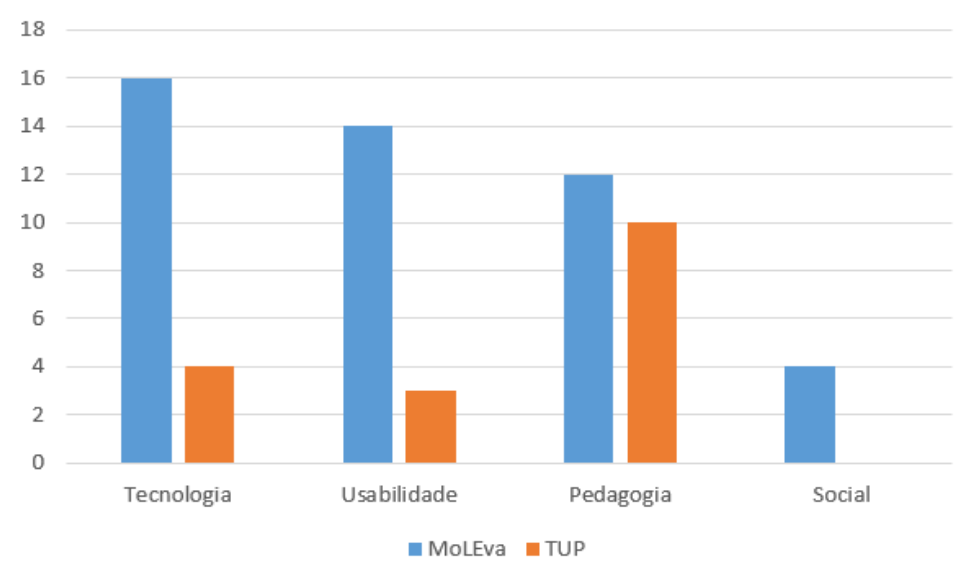

Figura 23 - Comparação dos Problemas Encontrados nos Métodos MoLEva e TUP

De acordo com as informações apresentadas anteriormente, é possível concluir que o método MoLEva apresentou um melhor desempenho que o TUP, já que identificou uma quantidade maior de problemas. No entanto, embora o resultado tenha sido favorável para o MoLEva, o TUP identificou problemas que o MoLEva não encontrou. Estes problemas deverão ser analisados e a viabilidade de serem representados como novas perguntas no MoLEva deve ser verificada como parte dos trabalhos futuros associados à evolução do método.

Além dos resultados obtidos com a aplicação dos métodos, também foram coleta- 
Tabela 45 - Pontos Positivos e Negativos Identificados na Aplicação do Método TUP

\begin{tabular}{l|l}
\hline Positivos & Negativos \\
\hline $\begin{array}{l}\text { A apresentação do progresso da avaliação deixou } \\
\text { o participante confortável. }\end{array}$ & As questões pedagógicas são um pouco confusas. \\
\hline $\begin{array}{l}\text { As questões são mais curtas que as apresentadas } \\
\text { no método MoLEva. }\end{array}$ & $\begin{array}{l}\text { O método não abrange os aspectos sociais que são } \\
\text { abrangidos no método MoLEva. }\end{array}$ \\
\hline $\begin{array}{l}\text { O método é abrangente e direciona o avaliador a } \\
\text { considerar muitos aspectos do aplicativo que está } \\
\text { sendo avaliado. }\end{array}$ & $\begin{array}{l}\text { Algumas questões são confusas e possuem vários } \\
\text { sentidos. }\end{array}$ \\
\hline & $\begin{array}{l}\text { O método é confuso em alguns momentos, pois } \\
\text { não foi possível entender o objetivo de algumas } \\
\text { perguntas. }\end{array}$ \\
\hline & $\begin{array}{l}\text { Muitas perguntas não pareciam ser adequadas aos } \\
\text { aplicativos móveis. }\end{array}$ \\
\hline & $\begin{array}{l}\text { O método é extenso, o que o torna cansativo para } \\
\text { os avaliadores. }\end{array}$ \\
\hline
\end{tabular}

Tabela 46 - Pontos Positivos e Negativos Identificados na Aplicação do Método MoLEva

\begin{tabular}{l|l}
\hline Positivos & Negativos \\
\hline $\begin{array}{l}\text { Os exemplos nas questões ajudam a entender o } \\
\text { objetivo da avaliação. }\end{array}$ & $\begin{array}{l}\text { O método é extenso, o que o torna cansativo para } \\
\text { os avaliadores. }\end{array}$ \\
\hline $\begin{array}{l}\text { Método bastante abrangente, avaliando diversas } \\
\text { características de um aplicativo educacional mó- } \\
\text { vel. }\end{array}$ & $\begin{array}{l}\text { Algumas questões são difíceis de serem avaliadas, } \\
\text { exigindo conhecimentos mais aprofundados sobre } \\
\text { como testar o aplicativo. }\end{array}$ \\
\hline $\begin{array}{l}\text { As perguntas são mais fáceis de entender que as } \\
\text { do método TUP. }\end{array}$ & \\
\hline
\end{tabular}

das informações a respeito de sua execução. Para obter essas informações, foi utilizado um formulário de pós-inspeção aplicado ao final da execução de cada método. Uma das questões avaliadas foi referente aos pontos positivos e negativos identificados pelos participantes. A Tabela 45, apresenta os pontos positivos e negativos do método TUP.

A partir dos aspectos citados pelos participantes sobre o TUP, é possível concluir que a falta de exemplos nas questões pode prejudicar seu entendimento. Além disso, a falta de perguntas específicas para os aplicativos educacionais móveis fez com que poucos problemas fossem identificados. Outro ponto negativo é que o método é extenso, fazendo com que seja morosa a sua execução. Porém, sua extensão faz com que o método seja considerado abrangente (apesar de não considerar o contexto móvel) desconsiderando o contexto móvel e direciona o avaliador a inspecionar diversos aspectos de qualidade do aplicativo.

Já os pontos positivos e negativos identificados pelos participantes sobre o método MoLEva são apresentados na Tabela 46. Dentre os pontos negativos é citado que o método exige muito tempo dos avaliadores, problema este que ocorre também no TUP devido à extensão de ambos os métodos. Além disso, algumas questões exigem um conhecimento aprofundado do avaliador para que sejam respondidas, acarretando um tempo maior para seu entendimento e conclusão da avaliação.

Com relação aos pontos positivos do MoLEva, destaca-se que a inclusão de exemplos nas questões do checklist colaborou para o entendimento das perguntas. Além disso, o método foi considerado abrangente, possibilitando a avaliação de diversas característi- 
cas relacionadas aos aplicativos educacionais móveis. Entretanto, como trabalhos futuros relacionados com a evolução do método MoLEva, todos os pontos negativos deverão ser considerados, adequando o método às necessidades dos avaliadores.

Ao final das avaliações também foram feitas algumas perguntas sobre a aplicação dos métodos. A primeira pergunta questiona se o participante se sentiu confortável durante a aplicação do método. A Figura 24 apresenta o resultado obtido. Pode-se observar que o método MoLEva possui um bom nível de concordância para essa pergunta. No entanto, dois participantes indicaram discordância. Isso pode ser justificado pelo fato de que o sistema utilizado para a aplicação do método não exibia a porcentagem de conclusão da avaliação, deixando o participante sem ter uma perspectiva de término da avaliação.

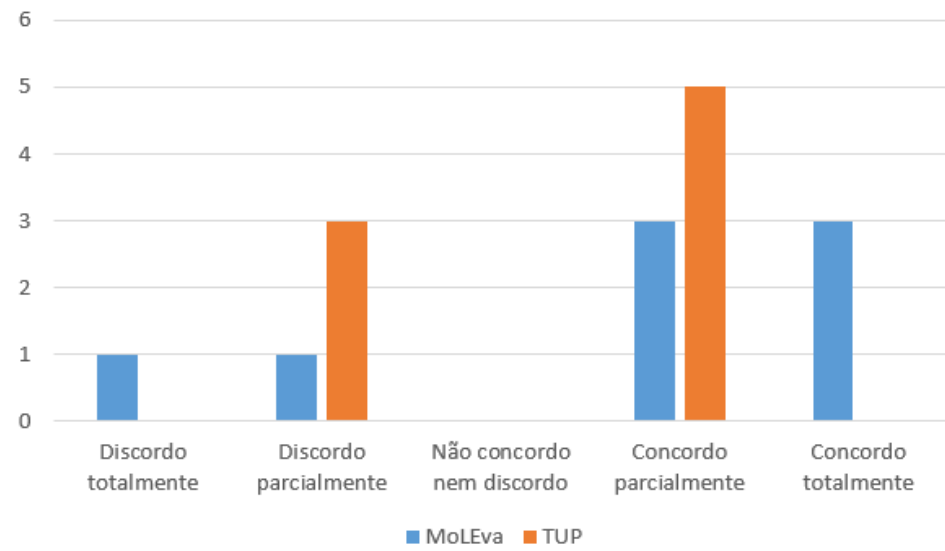

Figura 24 - Respostas sobre "O Quão Confortável" o Avaliador sentiu-se ao Aplicar o Método

Em seguida, foi perguntado aos participantes se o método utilizado era adequado para avaliar aplicativos educacionais móveis. As respostas para essa pergunta estão sumarizadas na Figura 25. Com o resultado obtido é possível concluir que a maioria dos participantes consideram o método MoLEva adequado para a avaliação de aplicativos educacionais móveis. Já o método TUP teve opiniões divididas. Esse comportamento pode ser devido ao fato do método não ter sido criado para o contexto móvel, fazendo com que o MoLEva obtivesse um nível de concordância maior para essa pergunta.

Outra pergunta feita aos participantes foi se o método utilizado era abrangente e contemplava as principais características relacionadas aos aplicativos educacionais móveis. O resultado obtido é apresentado na Figura 26. Nota-se que todos os participantes consideram o método MoLEva abrangente e que ele contempla as principais características do contexto para o qual foi criado. Já o método TUP, por não considerar o contexto móvel, não obteve o mesmo nível de concordância.

Além das perguntas anteriores, também foi questionado aos participantes se eles compreenderam facilmente as perguntas contidas no checklist de avaliação. A Figura 27 mostra os resultados obtidos. Observa-se que a maior parte dos participantes concordam que as perguntas contidas no checklist do MoLEva são de fácil compreensão. Já no método 


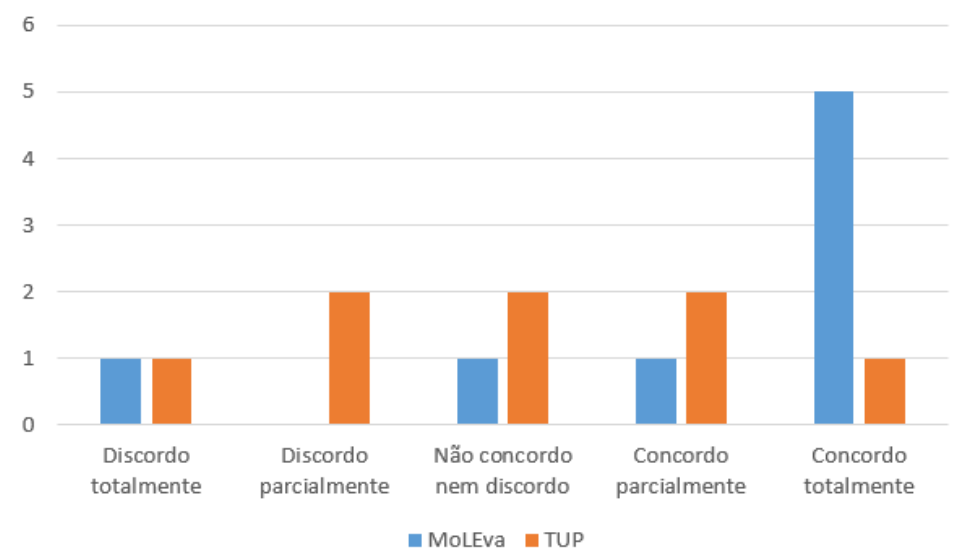

Figura 25 - Respostas sobre o Método ser Adequado ou não para o Contexto de Aplicativos Educacionais Móveis

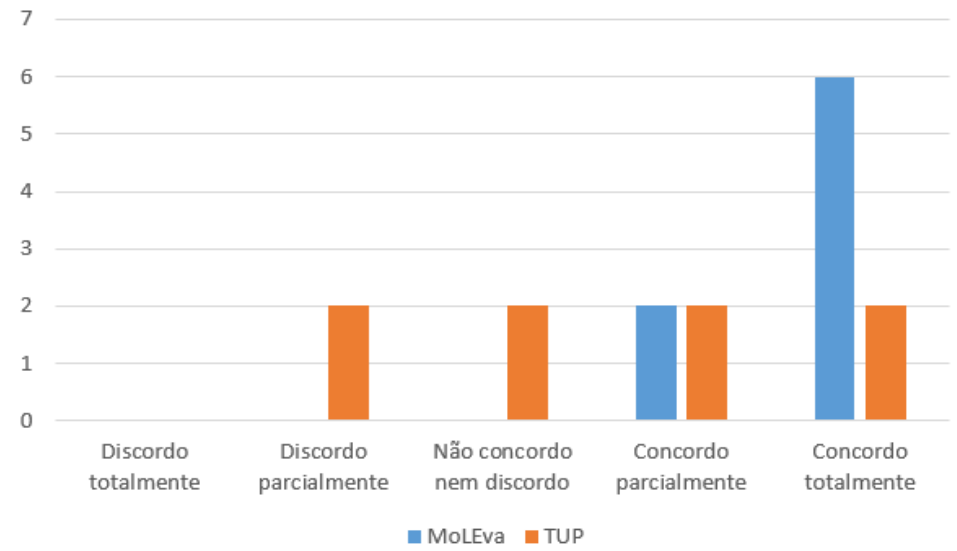

Figura 26 - Respostas sobre o Método ser Abrangente e Contemplar as Principais Características Relacionadas aos Aplicativos Educacionais Móveis

TUP os participantes tiveram opiniões divididas. Esse comportamento pode ser explicado pelo fato do método MoLEva possuir exemplos para suas perguntas, fazendo com que elas obtivessem um nível de compreensão maior que o TUP, que não possuía exemplos.

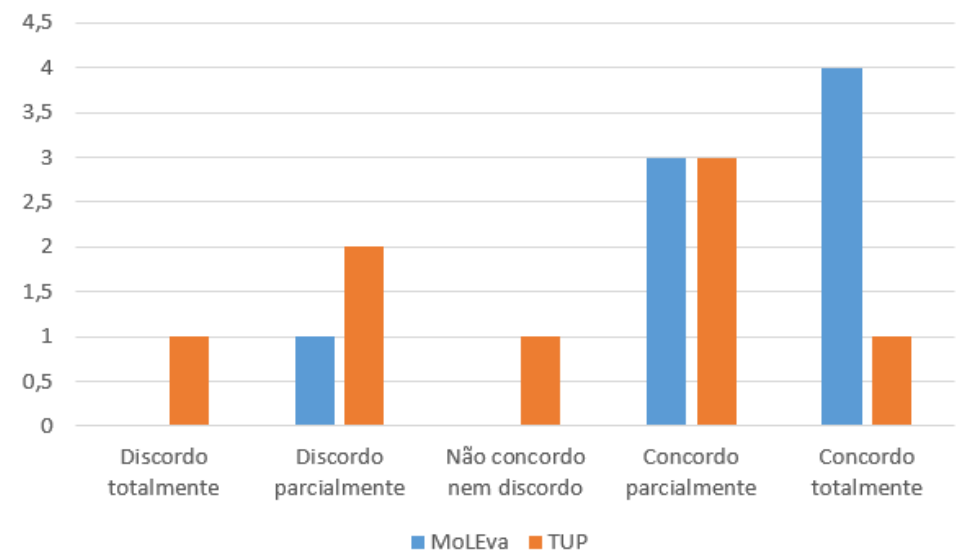

Figura 27 - Respostas sobre a Compreensão das Perguntas Contidas no Checklist

Por fim, os participantes foram questionados sobre o quão adequadas eram as res- 
postas disponibilizadas para as perguntas do checklist. A Figura 28, apresenta o resultado obtido para essa pergunta.

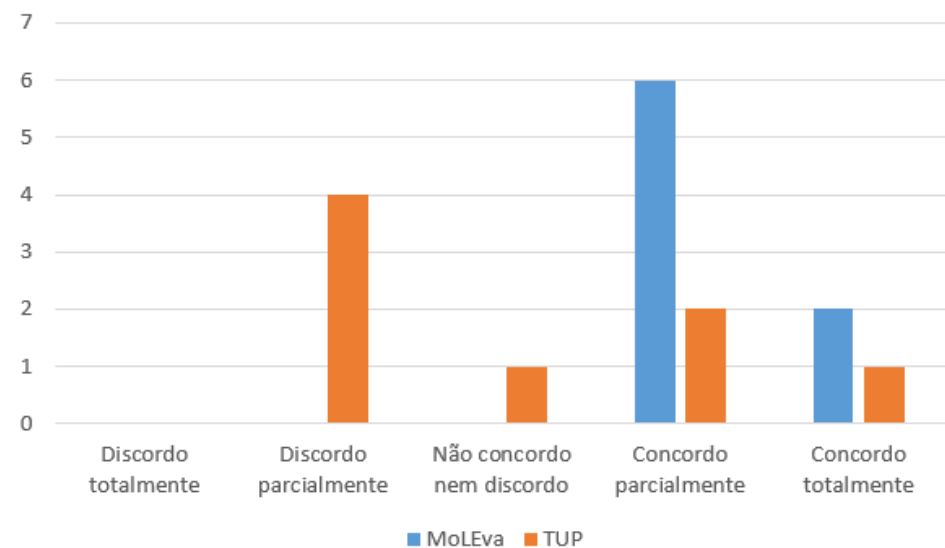

Figura 28 - Respostas sobre a Adequação das Perguntas Contidas no Checklist

O resultado obtido para essa questão mostra que o MoLEva, por utilizar a escala de Likert na maioria de suas perguntas, deixa o participante com maior liberdade para decidir a resposta sobre sua avaliação. Já o método TUP, possui em sua maioria, respostas mais assertivas do tipo "Sim" ou "Não". Embora o método MoLEva também utilize esse tipo de resposta, não o faz exaustivamente.

\section{Análise do Resultado da Avaliação de Qualidade dos Aplicativos pelo MoLEva}

A análise dos resultados da avaliação de qualidade dos aplicativos é importante para a avaliação do método MoLEva, já que por meio dos resultados é possível identificar se a partir da aplicação do método conseguiu-se definir um nível de qualidade para o aplicativo, além de revelar suas deficiências.

Para este estudo de caso, os valores dos critérios de julgamento mantiveram-se com o padrão definido pelo método MoLEva que são:

- Superior: pontuação igual ou maior que 80\%;

- Médio: pontuação igual ou maior que $50 \%$ e menor que $80 \%$;

- Baixo: pontuação menor que $50 \%$.

Com o objetivo de analisar duas avaliações de qualidade individualmente (uma do Duolingo e outra do Wlingua), foram selecionadas as avaliações que foram realizadas pelos avaliadores mais experientes (de acordo com o formulário de caracterização do participante) de cada aplicação que utilizou o MoLEva como método de avaliação. A Figura 29, apresenta a avaliação de qualidade dos aplicativos Duolingo e Wlingua sob a perspectiva dos critérios de qualidade estabelecidos pelo método. 


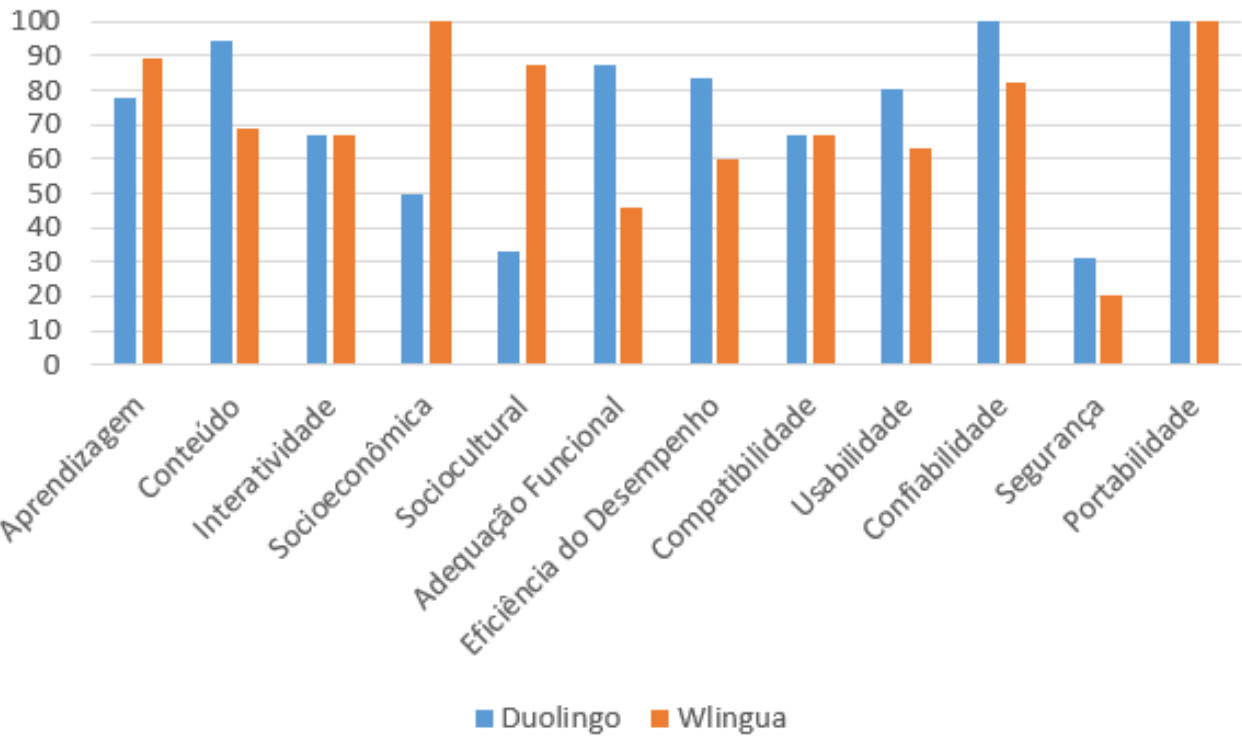

Figura 29 - Resultado da Avaliação de Qualidade dos Aplicativos por Critério de Qualidade: Avaliadores Experientes

O resultado por critérios de qualidade indica que o método MoLEva conseguiu identificar alguns critérios que chamam a atenção para melhoria nos aplicativos. Um desses critérios é Segurança, identificado nos dois aplicativos como sendo o critério com menor pontuação. Este resultado mostra que uma análise relacionada à segurança desses aplicativos deve ser realizada, pois aspectos de segurança podem acarretar riscos para os aplicativos e seus usuários.

Além disso, o aplicativo Duolingo possui outros dois critérios com o nível de qualidade mais baixo. Um deles é o critério Sociocultural, que sugere que o aplicativo pode ter problemas ao fornecer funcionalidades e se adaptar ao contexto cultural de seus usuários. Por exemplo, o aplicativo não possui mecanismos para denunciar mensagens ou conteúdos considerados ofensivos. O outro critério avaliado com o nível baixo é o Socioeconômico, indicando que o aplicativo deve dar maior atenção aos fatores sociais e econômicos que permeiam o aplicativo. Por exemplo, foi identificado que não é possível reportar um problema pelo aplicativo, caso um problema ocorra.

Já o aplicativo Wlingua obteve melhores pontuações relacionadas a estes critérios. Por outro lado, o critério Adequação Funcional não foi bem pontuado, o que sugere que o aplicativo pode ter deficiências em suas funcionalidades, além de possíveis funcionalidades que deveriam existir no aplicativo, mas que não estão presentes.

Embora alguns critérios não tenham sido bem avaliados, é importante ressaltar que para ambos aplicativos o critério Portabilidade resultou em 100\% da pontuação, indicando que os aplicativos podem ser utilizados em diversos tipos de dispositivos sem que ocorra problemas.

Além disso, é importante ressaltar que o aplicativo Duolingo obteve 100\% para 
o critério Confiabilidade, indicando que o aplicativo possui um comportamento consistente. Já o aplicativo Wlingua também obteve $100 \%$ de pontuação em outro critério que foi o Socioeconômico, indicando que o aplicativo é viável e possui uma boa relação custo-benefício.

Para os dois avaliadores citados, também foram analisadas as informações obtidas por categoria, apresentadas na Figura 30. Observa-se que o Duolingo apresenta um baixo nível de qualidade para as questões relacionadas à categoria Social, embora apresente uma pontuação consistente para os critérios Pedagógicos e Técnicos. Por este motivo, é possível concluir que o aplicativo deveria ter atenção à categoria Social. Já o aplicativo Wlingua possui todos os critérios entre o nível médido e superior, demonstrando assim que todos as categorias estão com um bom nível de qualidade. Embora o resultado seja satisfatório para o aplicativo Wlingua, é importante que as deficiências identificadas sejam melhoradas, removendo assim as lacunas existentes no aplicativo.

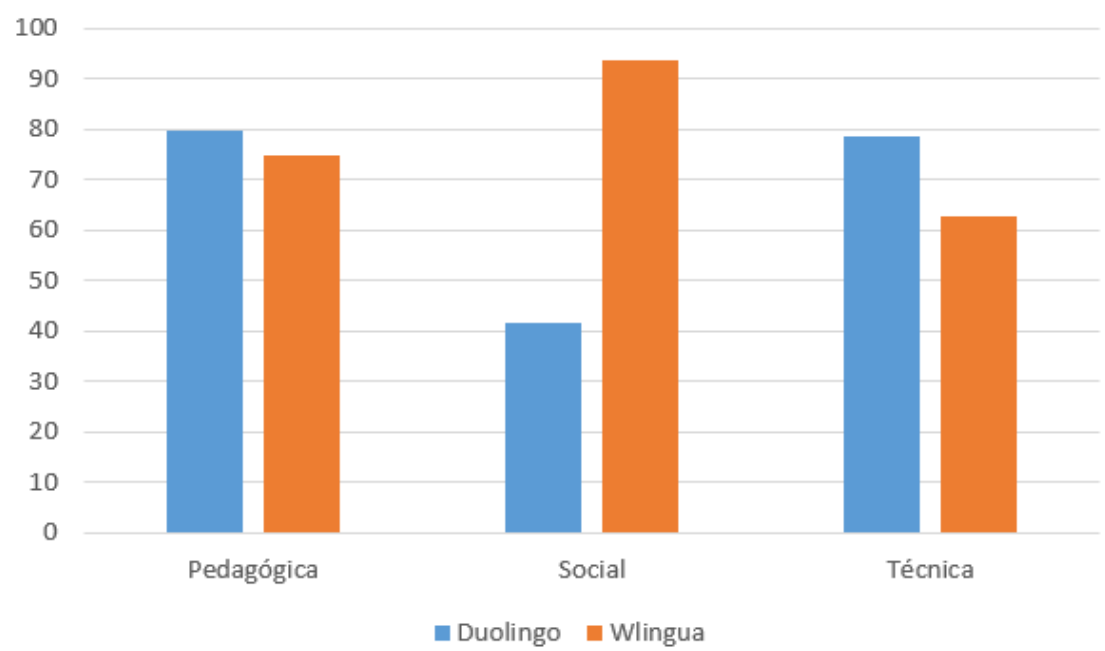

Figura 30 - Resultado da Avaliação de Qualidade dos Aplicativos por Categoria - Avaliadores Experientes

Após a avaliação individual feita com os avaliadores mais experientes, também foram obtidos os dados relacionados à consolidação de todas as avaliações desse estudo de caso. A Figura 31, apresenta o resultado por critério de qualidade considerando a média de todas as avaliações. Observa-se que para o Duolingo houve uma melhora nas avaliações que estavam com pontuações menores na avaliação individual, porém a característica Socioeconômica continua com pontuação baixa. Este resultado é importante, pois caso a pontuação seja um consenso entre os avaliadores, isso pode representar uma maior assertividade na análise do nível de qualidade.

Já as pontuações mais altas relacionadas ao Duolingo continuaram as mesmas, indicando que o resultado obtido com as avaliações está consistente com relação aos critérios mais bem avaliados. Com relação ao aplicativo Wlingua, suas pontuações também se mantiveram consistentes, porém nota-se que quase todos os critérios apresentaram 
quedas ao considerar todas as avaliações realizadas.

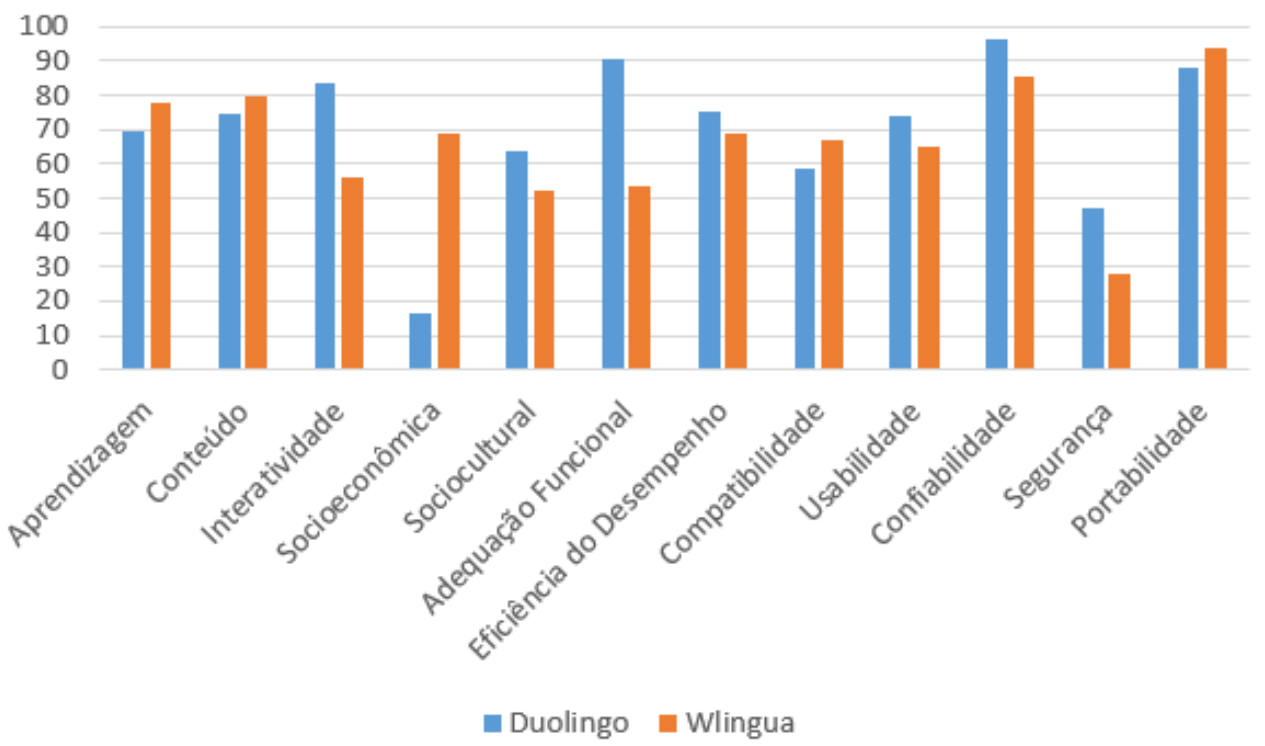

Figura 31 - Resultado da Avaliação de Qualidade dos Aplicativos por Critério de Qualidade

Com relação ao resultado por categoria, apresentado na Figura 32, observa-se que os níveis de qualidade obtiveram poucas alterações. Entretanto, para o aplicativo Wlingua, é possível identificar uma considerável alteração da avaliação individual para a geral. Na avaliação individual a categoria Social obteve 93,75 pontos, já na geral resultou em 60,42 pontos. Este resultado mostra uma diferença considerável entre as avaliações. Dessa maneira, é importante que seja considerado nos trabalhos futuros a investigação de divergências no entendimento das perguntas relacionadas à esta categoria.

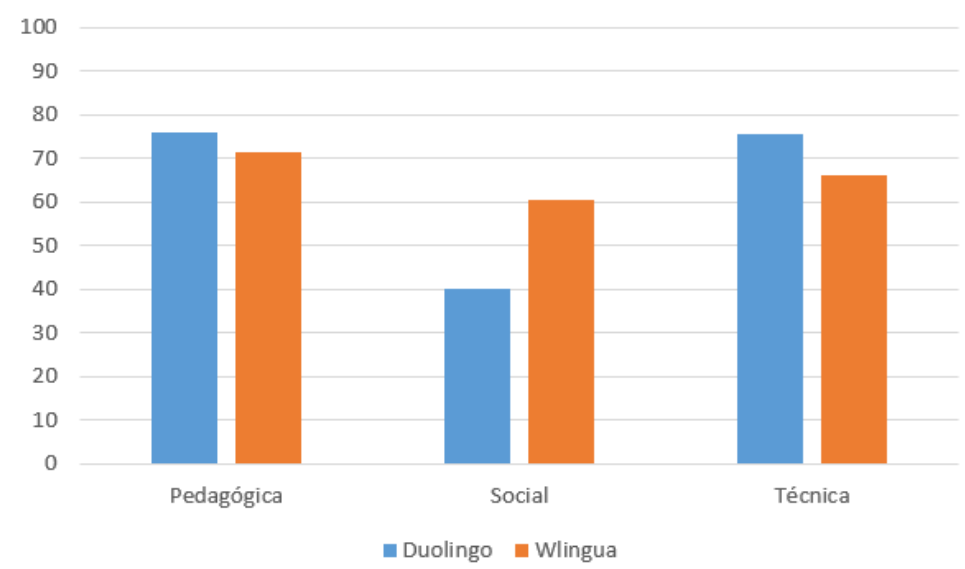

Figura 32 - Resultado da Avaliação de Qualidade dos Aplicativos por Categoria

Por fim, a Figura 33 apresenta o resultado geral da avaliação de qualidade, comparando o resultado do estudo de caso, com a primeira aplicação do método apresentada no Capítulo 4. Nota-se que no novo estudo o nível de qualidade de ambos os aplicativos sofreram queda, apesar de continuarem sendo classificadas com o nível de qualidade médio. 
Além disso, as suas posições foram invertidas, representando um queda maior no nível de qualidade do aplicativo Duolingo. Este resultado, indica que a nova versão do MoLEva é mais abrangente, identificando um maior número de problemas. Além disso, o segundo estudo teve participação de mais avaliadores, podendo ocasionar também em uma maior identificação de problemas.

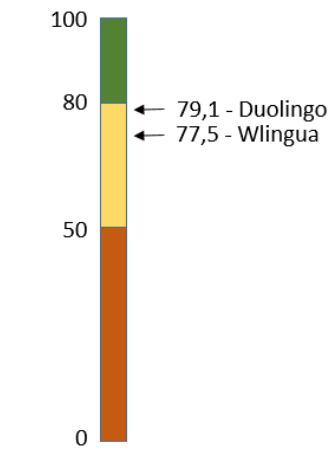

MoLEva - Versão 1

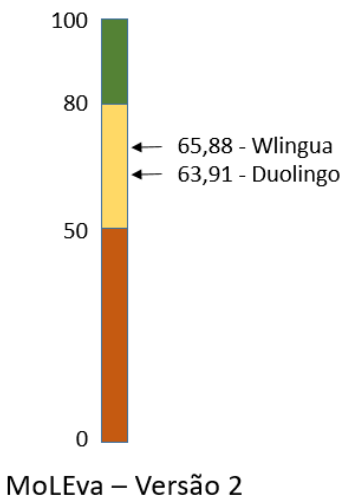

MoLEva - Versão 2

Figura 33 - Níveis de Qualidade dos Aplicativos Duolingo e Wlingua

Apesar das análises apresentadas fornecerem indícios de que o método MoLEva pode ser utilizado nas avaliações de qualidade de aplicativos educacionais móveis, é fundamental que mais estudos e experimentos formais sejam planejados e conduzidos, em diferentes domínios de aplicação.

\subsubsection{Ameaças à Validade}

Nesta seção são discutidas as principais ameaças à validade do estudo conduzido. O primeiro aspecto a ser considerado é que a condução do estudo ocorreu de maneira remota, não sendo executada em um ambiente controlado. Dessa maneira, todos os avaliadores receberam as orientações por meio de documentos. Além disso, não houve nenhum treinamento relacionado ao método MoLEva, visto que as informações sobre o método estavam contidas apenas nos documentos.

Outro ponto importante está relacionado com a interpretação dos itens avaliados. Apesar de existir um exemplo para cada questão do checklist, uma interpretação incorreta pode ocasionar em uma avaliação incorreta.

Além disso, os participantes selecionados são todos do meio acadêmico e da mesma universidade. Seria interessante a participação de uma quantidade maior de participantes

e de uma maneira mais abrangente, considerando outras universidades. É importante observar, ainda, que dentre os participantes nenhum é da indústria.

Por fim, o estudo de caso conduzido demandou muito esforço dos avaliadores, visto que os dois métodos utilizados possuem muitas perguntas. Além disso, antes da avaliação é necessário conhecer o aplicativo para que seja possível avaliá-lo. Por este motivo, o 
estudo ocasionou a fadiga dos participantes, podendo influenciar nos resultados finais do estudo.

Ressalta-se que novos experimentos vêm sendo planejados de modo a considerar as ameaças identificadas. A execução de novos experimentos faz parte das atividades futuras associadas à continuidade da pesquisa, devendo ser realizada em curto prazo.

\subsection{Considerações Finais}

A partir dos resultados obtidos com os estudos de caso realizados foi possível concluir que o método MoLEva é factível de ser aplicado na avaliação de qualidade de aplicativos educacionais móveis. Este resultado é favorável para o método MoLEva, pois ele foi capaz de indicar pontos relevantes de melhoria para os aplicativos avaliados. Ressalta-se, também, que sua avaliação possibilita a comparação entre aplicativos, permitindo que o usuário escolha o aplicativo que possui os pontos positivos mais relevantes para sua necessidade, auxiliando assim na tomada de decisão. Os resultados obtidos na avaliação dos aplicativos foram publicados em Soad e Barbosa (2017).

Além dos resultados favoráveis à sua aplicação, a comparação com o método TUP indicou que a preocupação com as características de um aplicativo móvel contribui para uma identificação maior de problemas. Dessa maneira, o método MoLEva demonstrou-se mais abrangente que o TUP, apesar de possuir uma quantidade menor de questões em seu checklist.

Por fim, novos estudos de caso devem ser conduzidos, além de novas pesquisas baseadas nos resultados obtidos com o MoLEva, buscando desenvolver uma versão que possa ser executada mais rapidamente e automatizando alguns pontos da avaliação.

No próximo capítulo é apresentada um visão geral sobre o trabalho realizado; também são sintetizadas as principais contribuições da pesquisa, limitações e trabalho futuros. 

CAPÍTULO

\section{6}

.

\section{CONCLUSÕES}

\subsection{Visão Geral}

Com o advento da tecnologia móvel, os aplicativos educacionais proporcionaram uma nova modalidade de ensino, conhecida como aprendizagem móvel (mobile learning ou simplesmente m-learning) (KINSHUK; SUTINEN; GOH, 2003; NAH; WHITE; SUSSEX, 2008; GUY, 2009; WEXLER et al., 2008). A aprendizagem móvel possui como característica a capacidade de fornecer uma forte interação entre os aprendizes, professores e tutores, permitindo que eles possam contribuir, participar e acessar o ambiente de ensino utilizando dispositivos móveis (celulares, tablets, laptops, rádio, tv, entre outros), a qualquer momento e em qualquer lugar.

Embora essa nova modalidade de ensino proporcione benefícios, ela também apresenta problemas e desafios organizacionais, culturais, econômicos, pedagógicos e tecnológicos, entre outros. A avaliação de qualidade de aplicativos educacionais móveis está entre os problemas, sobretudo devido à carência de métodos que contemplem os aspectos específicos de um aplicativo educacional móvel. Embora existam métodos de avaliação de qualidade, estes são muito genéricos, o que dificulta a avaliação de aplicativos para m-learning.

Nesse cenário, este trabalho visou o desenvolvimento de um método para avaliação da qualidade de aplicativos educacionais móveis, denominado MoLEva. O método é composto por três componentes principais: (i) modelo de qualidade; (ii) métricas; e (iii) critérios de julgamento. A concepção do modelo utilizou como base os modelos já existentes, como o modelo de McCall (CAVANO; MCCALL, 1978), modelo de Boehm (BOEHM; BROWN; LIPOW, 1976) e as normas ISO/IEC 9126 e ISO/IEC 25010. Além disso, o modelo de qualidade definido para o método MoLEva foi fundamentado nas pesquisas sobre características de qualidade para aplicativos educacionais móveis definidos 
em Soad, Duarte-Filho e Barbosa (2015) e Duarte-Filho e Barbosa (2013b).

Com o objetivo de avaliar o método MoLEva, foram conduzidos dois estudos de caso. Os resultados obtidos forneceram indícios de que o método proposto é capaz de identificar problemas nos aplicativos, indicando oportunidades de melhoria de qualidade para os mesmos. Além disso, o método também fornece para os avaliadores pontuações que permitem a comparação entre diferentes aplicativos. A possibilidade de comparação entre aplicativos permite ao MoLEva auxiliar na tomada de decisão a respeito da escolha de um aplicativo, já que ele fornece o nível de qualidade dos aplicativos avaliados.

A seguir são apresentadas as principais contribuições deste trabalho, bem como suas limitações e trabalhos futuros.

\subsection{Contribuições}

Como principais contribuições da pesquisa realizada destacam-se:

- Proposição de um método de avaliação de qualidade para aplicativos educacionais móveis, composto por: (i) modelo de qualidade; (ii) métricas; e (iii) critérios de julgamento.

- Estabelecimento de um modelo de qualidade para aplicativos educacionais móveis, organizado em categorias e critérios de qualidade. Ressalta-se que o modelo definido também pode servir como base para outras pesquisas relacionadas a aplicativos educacionais móveis.

- Concepção de um checklist para avaliações da qualidade de aplicativos educacionais móveis.

- Desenvolvimento de uma ferramenta web, possibilitando a automatização das avaliações de qualidade do método MoLEva.

\subsubsection{Produção Científica}

O presente trabalho resultou a publicação de cinco artigos completos em conferências relevantes na área.

- SOAD, G.; DUARTE FILHO, N. F.; BARBOSA, E. F. Uma Contribuição ao Estabelecimento de Características de Qualidade para Aplicações Educacionais Móveis. In: XIV Simpósio Brasileiro de Qualidade de Software (SBQS), Manaus, AM, 2015, p. 165-179; 
- SOAD, G.; DUARTE FILHO, N. F.; BARBOSA, E. F. Quality Evaluation of Mobile Learning Applications. In: 2016 IEEE Frontiers in Education Conference (FIE), Erie, PA, 2016, p. 1-9;

- SOAD, G.; ESTECA, A. M. N.; FIORAVANTI, M.L. ; BARBOSA, E. F. Towards a CSCL Systems Evaluation Catalog. In: 31st International Conference on Computers and Their Applications (CATA 2016), Las Vegas, NV, 2016, p. 1-6.

- SOAD, G.; FIORAVANTI, M. L.; MARCOLINO, A. S.; FALVO JUNIOR, V.; DUARTE FILHO, N. F.; BARBOSA, E. F. ReqML-Catalog: The Road to a Requirements Catalog for Mobile Learning Applications. In: 2017 IEEE Frontiers in Education Conference (FIE), Indianapolis, IN, 2017.

- SOAD, G.; BARBOSA, E. F. MoLEva: Um Método de Avaliação de Qualidade para Aplicativos Educacionais Móveis. In: XVI Simpósio Brasileiro de Qualidade de Software (SBQS), Rio de Janeiro, RJ, 2017;

Além disso, um artigo completo envolvendo a proposição e aplicação do método MoLEva encontra-se em elaboração, devendo ser submetido em periódico relevante da área.

\subsection{Dificuldades e Limitações}

Dente as principais dificuldades e limitações encontradas durante a realização deste trabalho, destacam-se:

- Poucos trabalhos relacionados à avaliação de qualidade de aplicativos educacionais móveis;

- Dificuldades para tornar o método ágil, sem interferir na sua abrangência (a criação da ferramenta web contribuiu para a amenização desta dificuldade);

- Muito tempo requerido dos avaliadores durante a validação do método. Por ser um método abrangente, seu tempo de aplicação é alto;

- Validação do método por meio de avaliações remotas, sem que houvesse treinamento presencial sobre o método.

\subsection{Trabalhos Futuros}

Como discutido durante a apresentação do trabalho, as contribuições do método MoLEva e as possibilidades de melhorias identificadas com base nos resultados apresenta- 
dos fornecem várias perspectivas para realização de trabalhos futuros e continuidade da pesquisa. Dentre tais possibilidades, destacam-se:

- O modelo de qualidade utilizado no método MoLEva fornece uma base de características relacionadas aos aplicativos educacionais móveis, permitindo que outros trabalhos neste contexto possam se beneficiar do modelo.

- A avaliação de aplicativos pelo método MoLEva ocasionou fadiga nos avaliadores. Por este motivo, é necessário evoluir o método para que sua execução seja mais rápida. Para isso sugere-se como trabalho futuro a revisão das questões, analisando a possibilidade de unificação de algumas perguntas.

- Desenvolvimento de trabalhos que objetivam a automatização da avaliação de algumas características. Dessa maneira, para cada característica de qualidade existente no modelo, deve-se desenvolver técnicas que automatizam a sua avaliação. Esta iniciativa, além de prover agilidade para o método, também pode contribuir para diminuição da subjetividade da avaliação.

- Evolução da ferramenta web MoLEva. A evolução da ferramenta permite a inclusão de novas funcionalidades como, por exemplo, permitir a comparação entre diferentes avaliações e compartilhamento dos resultados da avaliação. Além disso, também se pretende evoluir a ferramenta para que ela possa disponibilizar para consulta, todas as avaliações efetuadas por meio dela. Dessa maneira, a ferramenta atuaria como um repositório de avaliações de qualidade, podendo auxiliar os desenvolvedores na evolução dos aplicativos, além de ajudar os usuários na tomada de decisão sobre a utilização ou não de um aplicativo.

- Condução de novas avaliações do método MoLEva, aplicando o estudo em um ambiente controlado e com novos participantes. Além disso, também devem ser conduzidas novas avaliações com outros domínios de aplicativos educacionais móveis. 


\section{REFERÊNCIAS}

ABACHI, H. R.; MUHAMMAD, G. The impact of m-learning technology on students and educators. Computers in Human Behavior, v. 30, n. 0, p. 491 - 496, 2014. ISSN 0747-5632. Citado nas páginas 34 e 35.

ABDURRAHMAN, J.; BEER, M.; CROWTHER, P. Pedagogical requirements for mobile learning : a review on mobilearn task model. Journal of Interactive Media in Education, Ubiqity Press, v. 2015, n. 1, p. 1-17, August 2015. Citado nas páginas 20 e 25 .

ACHARYA, A.; SINHA, D. Assessing the quality of m-learning systems using ISO/IEC 25010. International Journal of Advanced Computer Research, v. 3, n. 3, 2013. Citado nas páginas 20, 23, 27, 28, 61, 63, 64, 65, 66, 67, 68, 70, 73 e 74.

AL-ANI, M. F.; HAMEED, S. M.; FAISAL, L. Students' perspectives in adopting mobile learning at university of bahrain. In: 2013 Fourth International Conference on e-Learning "Best Practices in Management, Design and Development of e-Courses: Standards of Excellence and Creativity". [S.l.: s.n.], 2013. p. 86-89. Citado nas páginas 19, 34 e 35.

ALI, A.; OUDA, A.; CAPRETZ, L. F. A conceptual framework for measuring the quality aspects of mobile learning. Bulletin of the IEEE Technical Committee on Learning Technology, v. 14, n. 4, p. 31, 2012. Citado nas páginas 61 e 65.

AVELLIS, G. Mobile learning and multimedia educational software requirements' evaluation. International Journal of Education and Information Technologies, v. 8, p. 83-92, 2014. Citado nas páginas 61, 65, 69 e 70.

AVELLIS, G.; SCARAMUZZI, A.; FINKELSTEIN, A. Evaluating non functional requirements in mobile learning contents and multimedia educational software. MLearn Annual Conference, 2003. Citado nas páginas 61, 65, 69 e 70.

BARBOSA, E. F. Uma contribuição ao processo de desenvolvimento e modelagem de módulos educacionais. Tese (Doutorado) — Universidade de São Paulo, 2004. Citado na página 19.

BEDNARIK, R. Evaluation of Education Environments: The TUP Model. Dissertação (Mestrado) - Department of Computer Science, University of Joensuu, Finland, 2002. Citado nas páginas 13, 20, 50, 51 e 100.

BEDNARIK, R.; GERDT, P.; MIRAFTABI, R.; TUKIAINEN, M. Development of the tup model - evaluating educational software. In: IEEE International Conference on Advanced Learning Technologies, 2004. Proceedings. [S.l.: s.n.], 2004. p. 699-701. Citado nas páginas 20, 50 e 100.

BEVAN, N. Quality in use: Meeting user needs for quality. Journal of Systems and Software, Elsevier, v. 49, n. 1, p. 89-96, 1999. Citado na página 40. 
BOEHM, B. W.; BROWN, J. R.; LIPOW, M. Quantitative evaluation of software quality. In: IEEE COMPUTER SOCIETY PRESS. Proceedings of the 2nd international conference on Software engineering. [S.1.], 1976. p. 592-605. Citado nas páginas 20, $41,42,43$ e 119 .

BOJA, C.; BATAGAN, L. Analysis of m-learning applications quality. World Scientific and Engineering Academy and Society (WSEAS) Transactions on Computers, Stevens Point, Wisconsin, USA, v. 8, n. 5, p. 767-777, 2009. Citado nas páginas 27, 28, 61, 63, 64, 65, 66, 69 e 70 .

BOJA, C.; BaTaGAN, L.; VIsOIU, A. Validation of a multi-criteria model used to evaluate m-learning applications quality. In: Proceedings of the 12th International Conference on Computer Systems and Technologies. New York, NY, USA: ACM, 2011. (CompSysTech '11), p. 590-595. Citado nas páginas 61, 64 e 65.

CAVANO, J. P.; MCCALL, J. A. A framework for the measurement of software quality. ACM SIGSOFT Software Engineering Notes, ACM, v. 3, n. 5, p. 133-139, 1978. Citado nas páginas 13, 20, 41, 42 e 119.

CORRAL, L.; SILLITTI, A.; SUCCI, G. Mobile multiplatform development: An experiment for performance analysis. Procedia Computer Science, v. 10, n. 0, p. 736 - 743, 2012. Citado na página 26.

CRAIG, A.; COLDWELL-NEILSON, J.; GOOLD, A.; BEEKHUYZEN, J. P. A review of e-learning technologies - opportunities for teaching and learning. In: CSEDU. [S.l.: s.n.], 2012. p. 29-41. Citado na página 19.

CROMPTON, H. A historical overview of mobile learning: Toward learner-centered education. Handbook of mobile learning, p. 3-14, 2013. Citado na página 24.

DUARTE-FILHO, N. F. Uma contribuição ao estabelecimento de uma arquitetura de referência para ambientes de aprendizagem móvel. Tese (Doutorado) Universidade de São Paulo, 2016. Citado nas páginas 75 e 83.

DUARTE-FILHO, N. F.; BARBOSA, E. F. Estudo e definição de um conjunto de características e requisitos para ambientes de aprendizagem móvel. In: XXIII Simpósio Brasileiro de Informática na Educação (SBIE 2012) - Congresso Brasileiro de Informática na Educação (CBIE 2012). [S.l.: s.n.], 2012. Citado nas páginas 25 e 61 .

A contribution to the quality evaluation of mobile learning environments. In: Frontiers in Education Conference, 2013 IEEE. [S.l.: s.n.], 2013. p. 379-382. ISSN 0190-5848. Citado nas páginas 13, 61, 74, 75, 84 e 85.

A requirements catalog for mobile learning environments. In: Proceedings of the 28th Annual ACM Symposium on Applied Computing. New York, NY, USA: ACM, 2013. (SAC '13), p. 1266-1271. Citado nas páginas 27, 28, 61, 63, 64, 65, 66, 69, $70,71,76$ e 120 .

ECONOMIDES, A. A. Requirements of mobile learning applications. International Journal of Innovation and Learning, v. 5, n. 5, 2008. Citado nas páginas 20, 25, 28, $32,55,57,61,63,64,65,66,69,70$ e 71 . 
ESCUDEIRO, P.; ESCUDEIRO, N. Evaluation of serious games in mobile platforms with qef: Qef (quantitative evaluation framework). In: IEEE Seventh International Conference on Wireless, Mobile and Ubiquitous Technology in Education (WMUTE). [S.l.: s.n.], 2012. p. 268-271. Citado nas páginas 61, 65, 69 e 70.

FAZLINA, S.; MANAP, A.; RIAS, R. Mobile learning awareness among students at higher learning institutes: A case study. In: International Conference on Informatics and Creative Multimedia (ICICM). [S.l.: s.n.], 2013. p. 226-229. Citado nas páginas 19, 34 e 35 .

GAFNI, R. Quality metrics for pda-based m-learning information systems. Interdisciplinary Journal of E-Learning and Learning Objects, INFORM, v. 5, n. 1, p. 359-378, 2009. Citado nas páginas 27, 28, 61, 63, 64, 66 e 68.

GARTNER. Gartner Says Worldwide Sales of Smartphones Grew 7 Percent in the Fourth Quarter of 2016. 2017. < http://www.gartner.com/newsroom/id/ 3609817> . Acessado em: 25/03/2017. Citado nas páginas 15 e 26.

GERDT, P.; MIRAFTABI, R.; TUKIAINEN, M. Evaluating educational software environments. In: International Conference on Computers in Education, 2002. Proceedings. [S.l.: s.n.], 2002. p. 675-676 vol.1. Citado na página 100.

GUY, R. The Evolution of Mobile Teaching and Learning. [S.l.]: Informing Science Press, 2009. Citado nas páginas 19, 24 e 119.

HUANG, Y.-M.; LIN, Y.-T.; CHENG, S.-C. Effectiveness of a mobile plant learning system in a science curriculum in taiwanese elementary education. Computers \& Education, Elsevier, v. 54, n. 1, p. 47-58, 2010. Citado nas páginas 19, 34 e 35.

HUJAINAH, F.; DAHLAN, H.; AL-HAIMI, B. Usability guidelines of mobile learning application. Journal of Information Systems Research and Innovation, 2013. Citado nas páginas $61,63,65,66,69$ e 71 .

ISO/IEC 14598. ISO/IEC 14598: Information Technology - Evaluation of Software Products. [S.l.]: ISO/IEC, 1998. Citado nas páginas 39, 44, 74, 76 e 82.

ISO/IEC 25000. International Organization for Standardization/ International Electrotechnical Comission ISO/IEC 25000: Systems and software Quality Requirements and Evaluation (SQuaRE). [S.1.]: ISO/IEC, 2005. Citado nas páginas $13,21,43$ e 44 .

ISO/IEC 25010. ISO/IEC 25010 - Systems and software engineering - Systems and software Quality Requirements and Evaluation (SQuaRE) - System and software quality models. [S.1.], 2010. Citado nas páginas 20, 45, 46, 55, 62 e 77.

ISO/IEC 8402. ISO 8402: Quality Management and Quality Assurance : Vocabulary. [S.l.]: ISO/IEC, 1994. Citado na página 38.

ISO/IEC 9126. ISO/IEC 9126. Software engineering - Product quality. [S.l.]: ISO/IEC, 2001. Citado nas páginas 20, 28, 39, 41, 43 e 45.

KEARNEY, M.; SCHUCK, S.; BURDEN, K.; AUBUSSON, P. Viewing mobile learning from a pedagogical perspective. Research in Learning Technology, v. 20, n. 0, 2012. ISSN 2156-7077. Citado nas páginas 19, 20 e 25. 
KEEGAN, D. The incorporation of mobile learning into mainstream education and training. In: World Conference on Mobile Learning. [S.1.: s.n.], 2005. p. 11. Citado na página 25.

KINSHUK, S. J.; SUTINEN, E.; GOH, T. Mobile technologies in support of distance learning. Asian Journal of Distance Education, v. 1, n. 1, p. 60-68, 2003. Citado nas páginas 19, 24 e 119.

KITCHENHAM, B.; CHARTERS, S. Guidelines for performing Systematic Literature Reviews in Software Engineering. [S.l.], 2007. Citado nas páginas 55 e 56.

KOSCIANSKI, A.; SOARES, M. S. Qualidade de Software - $2^{\mathbf{a}}$ Edição: Aprenda as metodologias e técnicas mais modernas para o desenvolvimento de software. [S.1.]: Novatec, 2007. Citado na página 39.

LANE, N.; MILUZZO, E.; LU, H.; PEEBLES, D.; CHOUDHURY, T.; CAMPBELL, A. A survey of mobile phone sensing. Communications Magazine, IEEE, v. 48, n. 9, p. 140-150, 2010. Citado nas páginas 19, 27 e 28.

LAZAR, J.; FENG, J.; HOCHHEISER, H. Research Methods in Human-Computer Interaction. Indianapolis, IN: Wiley, 2010. Citado na página 102.

LIKERT, R. A Technique for the Measurement of Attitudes. [S.l.: s.n.], 1932. (A Technique for the Measurement of Attitudes, № 136-165). Citado nas páginas 51 e 83.

LOOI, C.-K.; SUN, D.; WU, L.; SEOW, P.; CHIA, G.; WONG, L.-H.; SOLOWAY, E.; NORRIS, C. Implementing mobile learning curricula in a grade level: Empirical study of learning effectiveness at scale. Computers \& Education, v. 77, n. 0, p. 101 - 115, 2014. ISSN 0360-1315. Citado na página 34.

MARTINEZ, M.; AZEVEDO, G.; LOPES, S.; PAGLIUSO, P.; COLOMBO, R.; RODRIGUES, M.; JINO, M. The software product evaluation database-supporting mede-pros. In: Software Engineering Standards, 1999. Proceedings. Fourth IEEE International Symposium and Forum on. [S.l.: s.n.], 1999. p. 182-191. ISSN 1082-3670. Citado na página 85.

MISHRA, N.; CHAVHAN, R. Effectiveness of mobile learning on awareness about learning disability among student teachers. In: Technology Enhanced Education (ICTEE), 2012 IEEE International Conference on. [S.l.: s.n.], 2012. p. 1-6. Citado nas páginas 19,34 e 35.

MOSTAKHDEMIN-HOSSEINI, A. Analysis of pedagogical considerations of m-learning in smart devices. International Journal of Interactive Mobile Technologies (iJIM), v. 3, n. 4, p. 33-34, 2009. Citado nas páginas 61, 69 e 70.

NAH, K. C.; WHITE, P.; SUSSEX, R. The potential of using a mobile phone to access the internet for learning efl listening skills within a korean context. ReCALL, Cambridge Univ Press, v. 20, n. 03, p. 331-347, 2008. Citado nas páginas 19, 24 e 119.

OSGOOD, C. E. Semantic differential technique in the comparative study of cultures. American Anthropologist, American Anthropological Association, Wiley, v. 66, n. 3, p. 171-200, 1964. Citado na página 83. 
OYELERE, S. S.; SUHONEN, J. Design and implementation of mobileedu m-learning application for computing education in nigeria: A design research approach. In: 2016 International Conference on Learning and Teaching in Computing and Engineering (LaTICE). [S.1.: s.n.], 2016. p. 27-31. Citado na página 24.

PARSONS, D.; RYU, H. A framework for assessing the quality of mobile learning. In: International Conference for Process Improvement, Research and Education. [S.l.: s.n.], 2006. p. 17-27. Citado nas páginas 20, 27, 28, 61, 67, 69 e 70.

PETTICREW, M.; ROBERTS, H. Systematic Reviews in the Social Sciences: A Practical Guide. [S.l.]: Wiley, 2008. Citado na página 56.

PICEK, R.; GRCIC, M. Evaluation of the potential use of m-learning in higher education. In: Information Technology Interfaces (ITI), Proceedings of the ITI 2013 35th International Conference on. [S.l.: s.n.], 2013. p. 63-68. ISSN 1334-2762. Citado nas páginas 19, 34 e 35.

POCATILU, P.; BOJA, C. Quality Characteristics and Metrics related to M-Learning Process. The Amfiteatru Economic journal, v. 11, n. 26, p. 346-354, June 2009. Citado nas páginas 61, 63, 64, 65, 67, 68, 69, 70 e 71.

POCATILU, P.; DOINEA, M.; CIUREA, C. Development of distributed mobile learning systems. In: Proceedings of the 9th WSEAS International Conference on Circuits, Systems, Electronics, Control \& Signal Processing. Stevens Point, Wisconsin, USA: World Scientific and Engineering Academy and Society (WSEAS), 2010. (CSECS '10), p. 196-201. Citado nas páginas 61 e 66.

PRESSMAN, R. Software Engineering: A Practitioner's Approach. Seventh edition. [S.l.]: McGraw-Hill Education, 2010. (McGraw-Hill higher education). Citado na página 38.

REIS, R.; ESCUDEIRO, P.; ESCUDEIRO, N. Educational resources for mobile wireless devices: A case study. In: Wireless, Mobile and Ubiquitous Technology in Education (WMUTE), 2012 IEEE Seventh International Conference on. [S.l.: s.n.], 2012. p. 264-267. Citado nas páginas 61, 65, 69 e 70.

ROCHA, A. da; MALDONADO, J.; WEBER, K. Qualidade de software: teoria e prática. [S.l.]: Prentice Hall, 2001. Citado nas páginas 13 e 40.

RUBENS, N.; KAPLAN, D.; OKAMOTO, T. E-learning 3.0: Anyone, anywhere, anytime, and ai. In: New Horizons in Web Based Learning. [S.l.]: Springer, 2014. p. 171-180. Citado na página 19.

SARRAB, M.; AL-SHIHI, H.; REHMAN, O. Exploring major challenges and benefits of m-learning adoption. British Journal of Applied Science \& Technology, v. 3, n. 4, p. 826 - 839, 2013. Citado na página 20.

SARRAB, M.; ELBASIR, M.; ALNAELI, S. Towards a quality model of technical aspects for mobile learning services: An empirical investigation. Computers in Human Behavior, v. 55, Part A, p. 100 - 112, 2016. Citado na página 55.

SCHEPMAN, A.; RODWAY, P.; BEATTIE, C.; LAMBERT, J. An observational study of undergraduate students' adoption of (mobile) note-taking software. Computers in Human Behavior, v. 28, n. 2, p. 308 - 317, 2012. Citado na página 25. 
SHARPLES, M. Mobile learning: research, practice and challenges. Distance Education in China, v. 3, n. 5, p. 5-11, 2013. Citado na página 20.

SHIPLEY, G. Learning OpenShift. [S.l.]: Packt Publishing, 2014. (Community experience distilled). Citado na página 87.

SOAD, G.; BARBOSA, E. F. Moleva: Um método de avaliação de qualidade para aplicativos educacionais móveis. In: XVI Simpósio Brasileiro de Qualidade de Software (SBQS). [S.l.: s.n.], 2017. Citado na página 117.

SOAD, G.; DUARTE-FILHO, N. F.; BARBOSA, E. F. Uma contribuição ao estabelecimento de características de qualidade para aplicações educacionais móveis. In: XIV Simpósio Brasileiro de Qualidade de Software (SBQS). [S.l.: s.n.], 2015. p. 165179. Citado nas páginas 75, 76 e 120.

Quality evaluation of mobile learning applications. In: 2016 IEEE Frontiers in Education Conference (FIE). [S.l.: s.n.], 2016. p. 1-8. Citado na página 88.

SOAD, G.; FIORAVANTI, M. L.; MARCOLINO, A. S.; FALVO-JUNIOR, V.; DUARTEFILHO, N. F.; BARBOSA, E. F. Reqml-catalog: The road to a requirements catalog for mobile learning applications. In: 2017 IEEE Frontiers in Education Conference (FIE). [S.l.: s.n.], 2017. Citado na página 76.

SPRIESTERSBACH, A.; SPRINGER, T. Quality attributes in mobile web application development. In: Product Focused Software Process Improvement: 5th International Conference (PROFES). [S.l.: s.n.], 2004. p. 120-130. Citado nas páginas 27, $28,61,63,64,65$ e 66 .

SU, C.-H.; CHENG, C.-H. A mobile game-based insect learning system for improving the learning achievements. Procedia - Social and Behavioral Sciences, v. 103, n. 0, p. 42 - 50, 2013. 13th International Educational Technology Conference. Citado na página 35 .

SVETLANA, K. et al. Adaptation e-learning contents in mobile environment. In: ACM. Proceedings of the 2nd International Conference on Interaction Sciences: Information Technology, Culture and Human. [S.l.], 2009. p. 474-479. Citado na página 19.

TAYLOR, J. A task-centred approach to evaluating a mobile learning environment for pedagogical soundness. In: Learning with mobile devices, research and development. [S.l.]: Learning and Skills Development Agency, 2004. p. 167-171. Citado nas páginas 27 e 61.

TRAXLER, J.; LEACH, J. Innovative and sustainable mobile learning in africa. In: IEEE. Wireless, Mobile and Ubiquitous Technology in Education, 2006. WMUTE'06. Fourth IEEE International Workshop on. [S.1.], 2006. p. 98-102. Citado na página 24.

VISOIU, A.; BATAGAN, L.; BOJA, C. Quality model for m-learning applications. In: Proceedings of the 8th WSEAS International Conference on Data Networks, Communications, Computers. Stevens Point, Wisconsin, USA: World Scientific and Engineering Academy and Society (WSEAS), 2009. (DNCOCO'09), p. 60-66. Citado nas páginas 23, 61, 64, 65, 68 e 73 . 
WAZLAWICK, R. Engenharia de Software - Conceitos e Práticas. Primeira edição. [S.l.]: Elsevier Brasil, 2013. Citado nas páginas 46 e 49.

WEXLER, S.; BROWN, J.; METCALF, D.; ROGERS, D.; WAGNER, E. Mobile learning: What it is, why it matters, and how to incorporate it into your learning strategy. Guild Research, 2008. Citado nas páginas 19, 24 e 119.

YIN, R. Case Study Research: Design and Methods. [S.1.]: SAGE Publications, 2009. (Applied Social Research Methods). Citado na página 95.

ZAMFIROIU, A. Quality metrics for evaluation process in m-learning environment. European Scientific Journal, v. 1, September 2014. Citado na página 61.

ZORAN, K.; ARSOVSKI, S.; ARSOVSKI, Z.; RANKOVIC, V.; MILANOVIC, I.; REJMAN-PETROVIC, D. Quality aspects and metrics in m-learning information systems. In: 6th International Quality Conference. [S.l.: s.n.], 2012. p. 663-672. Citado nas páginas 61, 65, 68, 69, 70 e 71 . 

APÊNDICE

\section{A}

LISTA DE VERIFICAÇÃO DO MÉTODO

MOLEVA

Este checklist tem por finalidade a avaliação de qualidade de aplicativos educacionais móveis. O checklist possui perguntas que contemplam todos os critérios de qualidade definidos no modelo MoLEva. Abaixo são apresentadas as perguntas que estão contidas no checklist.

1 - [Aprendizagem]: O aplicativo apresenta dados sobre seu uso? (ex. desempenho nas aulas, porcentagem de conclusão do curso, horas de utilização, pontuações, entre outros).
( ) $\operatorname{Sim}$
( ) Não
( ) Não se aplica
( ) Avaliação prejudicada

2 - [Aprendizagem]: Como pode ser classificada a maneira em que o aplicativo se adapta ao contexto físico?

Ineficiente ( ) ( ) ( ) ( ) ( ) Eficiente

$\begin{array}{lllll}1 & 2 & 3 & 4 & 5\end{array}$

( ) Não se aplica

( ) Avaliação prejudicada

3 - [Aprendizagem]: O aplicativo exibe notificações de avisos e eventos para os usuários?
( ) $\operatorname{Sim}$
( ) Não
( ) Não se aplica 
( ) Avaliação prejudicada

4 - [Aprendizagem]: O aplicativo disponibiliza uma área em sua interface para divulgar eventos relacionados ao seu contexto?

( ) Sim

( ) Não

( ) Não se aplica

( ) Avaliação prejudicada

5 - [Aprendizagem]: O aplicativo é capaz de detectar automaticamente a informação contextual ligada ao contexto dos usuários e tutores.

( ) $\mathrm{Sim}$

( ) Não

( ) Não se aplica

( ) Avaliação prejudicada

6 - [Aprendizagem]: Como pode ser classificada a adaptação ao conhecimento dos usuários? Ineficiente ( ) ( ) ( ) ( ) ( ) Eficiente $\begin{array}{lllll}1 & 2 & 3 & 4 & 5\end{array}$

( ) Não se aplica

( ) Avaliação prejudicada

7 - [Aprendizagem]: Como pode ser classificado o nível de simulação do ambiente real que o aplicativo oferece no aprendizado do aluno sobre determinando tema?

Ineficiente ( ) ( ) ( ) ( ) ( ) Eficiente $\begin{array}{lllll}1 & 2 & 3 & 4 & 5\end{array}$

( ) Não se aplica

( ) Avaliação prejudicada

8 - [Aprendizagem]: O aplicativo fornece dados estatísticos sobre o desempenho dos alunos/turmas para o professor?

( ) Sim

( ) Não

( ) Não se aplica

( ) Avaliação prejudicada 
9 - [Aprendizagem]: Como podem ser classificados os diferentes tipos de atividades educacionais que o aplicativo oferece para auxiliar na aquisição de conhecimento?

Ineficiente ( ) ( ) ( ) ( ) ( ) Eficiente

$\begin{array}{lllll}1 & 2 & 3 & 4 & 5\end{array}$

( ) Não se aplica

( ) Avaliação prejudicada

10 - [Aprendizagem]: Em caso de um conteúdo avançado, o aplicativo verifica se o aprendiz possui o conhecimento base necessário para o aprendizado?

( ) Sim

( ) Não

( ) Não se aplica

( ) Avaliação prejudicada

11 - [Conteúdo]: Como pode ser classificada a interação entre os objetos de aprendizagem do aplicativo e seus usuários?

Ineficiente ( ) ( ) ( ) ( ) ( ) Eficiente

$\begin{array}{lllll}1 & 2 & 3 & 4 & 5\end{array}$

( ) Não se aplica

( ) Avaliação prejudicada

12 - [Conteúdo]: Como pode ser classificada a organização do conteúdo de aprendizagem? Ineficiente ( ) ( ) ( ) ( ) ( ) Eficiente

$$
\begin{array}{lllll}
1 & 2 & 3 & 4 & 5
\end{array}
$$

( ) Não se aplica

( ) Avaliação prejudicada

13 - [Conteúdo]: Como podem ser classificadas as atividades e materiais educacionais utilizados no aplicativo?

Ineficiente ( ) ( ) ( ) ( ) ( ) Eficiente

$$
\begin{array}{lllll}
1 & 2 & 3 & 4 & 5
\end{array}
$$

( ) Não se aplica

( ) Avaliação prejudicada

14 - [Conteúdo]: Os conteúdos de aprendizagem são divididos em vários níveis de conhecimento? 
( ) $\mathrm{Sim}$

( ) Não

( ) Não se aplica

( ) Avaliação prejudicada

15 - [Conteúdo]: Durante a avaliação todo o conteúdo de aprendizagem esteve isento de erros?
( ) Sim
( ) Não
( ) Não se aplica
( ) Avaliação prejudicada

16 - [Conteúdo]: Como pode ser classificada a credibilidade do material disponibilizado pelo aplicativo?

Ineficiente ( ) ( ) ( ) ( ) ( ) Eficiente

$\begin{array}{lllll}1 & 2 & 3 & 4 & 5\end{array}$

( ) Não se aplica

( ) Avaliação prejudicada

17 - [Conteúdo]: Como pode ser classificado o nível de atualização do conteúdo de aprendizagem disponibilizado pelo aplicativo?

Ineficiente ( ) ( ) ( ) ( ) ( ) Eficiente

$\begin{array}{lllll}1 & 2 & 3 & 4 & 5\end{array}$

( ) Não se aplica

( ) Avaliação prejudicada

18 - [Conteúdo]: Como pode ser classificada a criação e modificação do conteúdo de aprendizagem oferecido pelo aplicativo?

Ineficiente ( ) ( ) ( ) ( ) ( ) Eficiente

$$
\begin{array}{lllll}
1 & 2 & 3 & 4 & 5
\end{array}
$$

( ) Não se aplica

( ) Avaliação prejudicada

19 - [Conteúdo]: O aplicativo permite a reutilização do conteúdo de aprendizagem?

( ) $\mathrm{Sim}$

( ) Não 
( ) Não se aplica

( ) Avaliação prejudicada

20 - [Conteúdo]: O aplicativo evita o uso de muitos elementos multimídia em uma tela, evitando assim que o usuário tenha pontos de distração?

( ) $\operatorname{Sim}$

( ) Não

( ) Não se aplica

( ) Avaliação prejudicada

21 - [Conteúdo]: Como pode ser classificada a integração do conteúdo oferecido pelo aplicativo?

Ineficiente ( ) ( ) ( ) ( ) ( ) Eficiente

$\begin{array}{lllll}1 & 2 & 3 & 4 & 5\end{array}$

( ) Não se aplica

( ) Avaliação prejudicada

22 - [Interatividade]: O aplicativo possui funcionalidades de feedback de desempenho dos alunos de forma instantânea?

( ) $\operatorname{Sim}$

( ) Não

( ) Não se aplica

( ) Avaliação prejudicada

23 - [Interatividade]: Como pode ser classificada a forma de comunicação/feedback entre professores e alunos?

Ineficiente ( ) ( ) ( ) ( ) ( ) Eficiente

$\begin{array}{lllll}1 & 2 & 3 & 4 & 5\end{array}$

( ) Não se aplica

( ) Avaliação prejudicada

24 - [Interatividade]: O aplicativo possui ferramentas específicas para colaboração de tarefas, sendo feitos através de wikis, jogos, microblogs e fóruns?
( ) $\operatorname{Sim}$
( ) Não
( ) Não se aplica 
( ) Avaliação prejudicada

25 - [Interatividade]: O aplicativo oferece atividades educacionais que incentivam a cooperação entre os usuários do aplicativo?

( ) Sim

( ) Não

( ) Não se aplica

( ) Avaliação prejudicada

26 - [Socioeconômica]: O aplicativo oferece uma versão gratuita por um período limitado ou com funcionalidades limitadas para que os usuários possam testá-lo?

( ) Sim

( ) Não

( ) Não se aplica

( ) Avaliação prejudicada

27 - [Socioeconômica]: O aplicativo possui opção para reportar incidentes ocorridos durante o seu uso?

( ) Sim

( ) Não

( ) Não se aplica

( ) Avaliação prejudicada

28 - [Socioeconômica]: O custo do suporte técnico está incluído na assinatura de uso do produto?

( ) $\mathrm{Sim}$

( ) Não

( ) Não se aplica

( ) Avaliação prejudicada

29 - [Socioeconômica]: O aplicativo indica claramente qual é a sua versão atual, juntamente com as últimas atualizações/modificações realizadas?
( ) Sim
( ) Não
( ) Não se aplica
( ) Avaliação prejudicada 
30 - [Socioeconômica]: Como pode ser classificado o processo de resolução de problemas/incidentes (em relação ao tempo médio que a empresa contratante se prontifica em resolver um erro no aplicativo)?

Ineficiente ( ) ( ) ( ) ( ) ( ) Eficiente

$\begin{array}{lllll}1 & 2 & 3 & 4 & 5\end{array}$

( ) Não se aplica

( ) Avaliação prejudicada

31 - [Socioeconômica]: O usuário recebe feedback sobre os erros ou problemas reportados?

( ) $\operatorname{Sim}$

( ) Não

( ) Não se aplica

( ) Avaliação prejudicada

32 - [Sociocultural]: O aplicativo pode ser modificado de acordo com as necessidades dos usuários?

( ) $\mathrm{Sim}$

( ) Não

( ) Não se aplica

( ) Avaliação prejudicada

33 - [Sociocultural]: O aplicativo possui mecanismos para denunciar mensagens com conteúdo ofensivo?

( ) Sim

( ) Não

( ) Não se aplica

( ) Avaliação prejudicada

34 - [Sociocultural]: Como pode ser classificado o aplicativo de acordo com o seu nível de recomendação?

Ineficiente ( ) ( ) ( ) ( ) ( ) Eficiente

$\begin{array}{lllll}1 & 2 & 3 & 4 & 5\end{array}$

( ) Não se aplica

( ) Avaliação prejudicada 
35 - [Adequação funcional]: Como pode ser classificado o nível de satisfação das necessidades específicas de alunos e professores em relação às funções presentes no aplicativo?

Ineficiente ( ) ( ) ( ) ( ) ( ) Eficiente

$$
\begin{array}{lllll}
1 & 2 & 3 & 4 & 5
\end{array}
$$

( ) Não se aplica

( ) Avaliação prejudicada

36 - [Adequação funcional]: O aplicativo faz uso de diferentes tipos de mídia? (ex. vídeo, texto, áudio, imagens, entre outros).

( ) $\mathrm{Sim}$

( ) Não

( ) Não se aplica

( ) Avaliação prejudicada

37 - [Adequação funcional]: Quando ocorre variação na rede as funcionalidades conseguem se adaptar de acordo com os recursos disponíveis?

( ) $\mathrm{Sim}$

( ) Não

( ) Não se aplica

( ) Avaliação prejudicada

38 - [Adequação funcional]: É possível realizar sincronização e a coordenação de dados entre os meios de comunicação, dispositivos e redes (intranet e internet)?
( ) Sim
( ) Não
( ) Não se aplica
( ) Avaliação prejudicada

39 - [Adequação funcional]: As notificações enviadas pelo aplicativo podem ser configuradas por meio dele?

( ) Sim

( ) Não

( ) Não se aplica

( ) Avaliação prejudicada

40 - [Adequação funcional]: O aplicativo distingue os diferentes perfis dos usuários no 
processo de aprendizagem?

( ) Sim

( ) Não

( ) Não se aplica

( ) Avaliação prejudicada

41 - [Eficiência do desempenho]: O aplicativo mantêm na memória apenas arquivos necessários, evitando o acúmulo de arquivos temporários ou sem uso?

( ) $\operatorname{Sim}$

( ) Não

( ) Não se aplica

( ) Avaliação prejudicada

42 - [Eficiência do desempenho]: O aplicativo apresenta mecanismos de medição de banda larga, verificando se a banda larga utilizada pelos usuários está de acordo com a mínima exigida pelo sistema?

( ) $\operatorname{Sim}$

( ) Não

( ) Não se aplica

( ) Avaliação prejudicada

43 - [Eficiência do desempenho]: Como pode ser classificado o consumo de energia do dispositivo? O consumo de energia deve ser coerente com o seu uso, ou seja, um aplicativo pode executar ações mesmo não sendo utilizado.

Ineficiente ( ) ( ) ( ) ( ) ( ) Eficiente

$\begin{array}{lllll}1 & 2 & 3 & 4 & 5\end{array}$

( ) Não se aplica

( ) Avaliação prejudicada

44 - [Eficiência do desempenho]: Como pode ser classificado o tempo de carregamento do aplicativo?

Ineficiente ( ) ( ) ( ) ( ) ( ) Eficiente

$\begin{array}{lllll}1 & 2 & 3 & 4 & 5\end{array}$

( ) Não se aplica

( ) Avaliação prejudicada 
45 - [Eficiência do desempenho]: Como o aplicativo pode ser classificado em relação ao desempenho de tempo de resposta?

Ineficiente ( ) ( ) ( ) ( ) ( ) Eficiente $\begin{array}{lllll}1 & 2 & 3 & 4 & 5\end{array}$

( ) Não se aplica

( ) Avaliação prejudicada

46 - [Eficiência do desempenho]: Os requisitos mínimos exigidos pelo aplicativo são respeitados?

( ) Sim

( ) Não

( ) Não se aplica

( ) Avaliação prejudicada

47 - [Compatibilidade]: Caso o aplicativo execute funções em segundo plano, essas funções são executadas sem interferirem no desempenho do dispositivo?
( ) $\mathrm{Sim}$
( ) Não
( ) Não se aplica
( ) Avaliação prejudicada

48 - [Compatibilidade]: O aplicativo pode ser utilizado juntamente com outros sistemas em execução, sem causar impactos negativos?
( ) $\operatorname{Sim}$
( ) Não
( ) Não se aplica
( ) Avaliação prejudicada

49 - [Compatibilidade]: O aplicativo possui a capacidade de se comunicar com outros aplicativos?

( ) Sim

( ) Não

( ) Não se aplica

( ) Avaliação prejudicada

50 - [Usabilidade]: Caso existam funcionalidades que não são autoexplicativas, o aplicativo 
informa ao usuário sobre a funcionalidade de seus componentes por meio de "balões" explicativos, botões de ajuda ou similares?
( ) Sim
( ) Não
( ) Não se aplica
( ) Avaliação prejudicada

51 - [Usabilidade]: Como podem ser classificadas as facilidades que o aplicativo oferece no envio de mensagens para outros usuários?
Ineficiente ( ) ( ) ( ) ( ) ( ) Eficiente
$\begin{array}{lllll}1 & 2 & 3 & 4 & 5\end{array}$

( ) Não se aplica

( ) Avaliação prejudicada

52 - [Usabilidade]: Como pode ser avaliada a padronização do aplicativo (fotos, letras, cores, menus, entre outros)?

Ineficiente ( ) ( ) ( ) ( ) ( ) Eficiente

$\begin{array}{lllll}1 & 2 & 3 & 4 & 5\end{array}$

( ) Não se aplica

( ) Avaliação prejudicada

53 - [Usabilidade]: Os aprendizes com diferentes tipos de experiências/idades têm iguais possibilidades de obter sucesso com as funcionalidades estabelecidas?
( ) $\operatorname{Sim}$
( ) Não
( ) Não se aplica
( ) Avaliação prejudicada

54 - [Usabilidade]: Como podem ser classificadas as denominações de títulos, menus, textos e botões com relação ao que estes estão representando no contexto do aplicativo?

Ineficiente ( ) ( ) ( ) ( ) ( ) Eficiente
$\begin{array}{lllllll}1 & 2 & 3 & 4 & 5\end{array}$

( ) Não se aplica

( ) Avaliação prejudicada

55 - [Usabilidade]: Como pode ser classificado o grau de aprendizado que os usuários têm 
em relação ao aplicativo?

Ineficiente ( ) ( ) ( ) ( ) ( ) Eficiente

$\begin{array}{lllll}1 & 2 & 3 & 4 & 5\end{array}$

( ) Não se aplica

( ) Avaliação prejudicada

56 - [Usabilidade]: Como pode ser classificada a ajuda que o aplicativo oferece para os usuários, por meio de tutoriais ou manuais? Caso as funcionalidades sejam intuitivas, permitindo o descarte desse tipo de ajuda, a classificação deverá ser eficiente.

Ineficiente ( ) ( ) ( ) ( ) ( ) Eficiente

$\begin{array}{lllll}1 & 2 & 3 & 4 & 5\end{array}$

( ) Não se aplica

( ) Avaliação prejudicada

57 - [Usabilidade]: Como pode ser classificada a separação dos componentes de ação do aplicativo (ex. botões, checkbox, radio buttons, menu, entre outros)? Os componentes devem ser posicionados evitando que possam ser acionados acidentalmente.

Ineficiente ( ) ( ) ( ) ( ) ( ) Eficiente

$\begin{array}{lllll}1 & 2 & 3 & 4 & 5\end{array}$

( ) Não se aplica

( ) Avaliação prejudicada

58 - [Usabilidade]: Qual a avaliação em relação à interface "amigável" do aplicativo?

Ineficiente ( ) ( ) ( ) ( ) ( ) Eficiente

$\begin{array}{lllll}1 & 2 & 3 & 4 & 5\end{array}$

( ) Não se aplica

( ) Avaliação prejudicada

59 - [Usabilidade]: Como são avaliadas as mensagens de erros geradas pelo aplicativo?

Ineficiente ( ) ( ) ( ) ( ) ( ) Eficiente

$\begin{array}{lllll}1 & 2 & 3 & 4 & 5\end{array}$

( ) Não se aplica

( ) Avaliação prejudicada

60 - [Usabilidade]: O aplicativo exibe dicas ou sugestões para auxiliar o usuário em sua utilização? 

( ) $\mathrm{Sim}$
( ) Não
( ) Não se aplica
( ) Avaliação prejudicada

61 - [Usabilidade]: Como pode ser classificada a quantidade de elementos exibidos nas telas do aplicativo?

Ineficiente ( ) ( ) ( ) ( ) ( ) Eficiente

$$
\begin{array}{lllll}
1 & 2 & 3 & 4 & 5
\end{array}
$$

( ) Não se aplica

( ) Avaliação prejudicada

62 - [Usabilidade]: Como pode ser classificada a facilidade no preenchimento de dados no aplicativo?

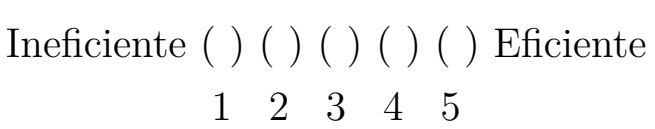

( ) Não se aplica

( ) Avaliação prejudicada

63 - [Usabilidade]: Como pode ser classificada a apresentação dos dados no aplicativo?

Ineficiente ( ) ( ) ( ) ( ) ( ) Eficiente

$\begin{array}{lllll}1 & 2 & 3 & 4 & 5\end{array}$

( ) Não se aplica

( ) Avaliação prejudicada

64 - [Usabilidade]: O aplicativo evita que o usuário chegue a um ponto em que não consiga mais avançar ou retornar?
( ) $\mathrm{Sim}$
( ) Não
( ) Não se aplica
( ) Avaliação prejudicada

65 - [Usabilidade]: Como pode ser classificada a utilização de mecanismos contra erros voluntários/involuntários dos usuários?

Ineficiente ( ) ( ) ( ) ( ) ( ) Eficiente 
( ) Não se aplica

( ) Avaliação prejudicada

66 - [Usabilidade]: Como pode ser classificada a capacidade do aplicativo em se adaptar a pessoas com necessidades especiais?

Ineficiente ( ) ( ) ( ) ( ) ( ) Eficiente $\begin{array}{lllll}1 & 2 & 3 & 4 & 5\end{array}$

( ) Não se aplica

( ) Avaliação prejudicada

67 - [Usabilidade]: Como pode ser classificada a navegação pelo aplicativo?

Ineficiente ( ) ( ) ( ) ( ) ( ) Eficiente $\begin{array}{lllll}1 & 2 & 3 & 4 & 5\end{array}$

( ) Não se aplica

( ) Avaliação prejudicada

68 - [Confiabilidade]: Os resultados obtidos são exatos e livres de erros?

( ) Sim

( ) Não

( ) Não se aplica

( ) Avaliação prejudicada

69 - [Confiabilidade]: Como pode ser classificada a maneira que o aplicativo permite navegação e utilização offline (através da sincronização de dados)?

Ineficiente ( ) ( ) ( ) ( ) ( ) Eficiente $\begin{array}{lllll}1 & 2 & 3 & 4 & 5\end{array}$

( ) Não se aplica

( ) Avaliação prejudicada

70 - [Confiabilidade]: As opções oferecidas pelo aplicativo estão todas funcionando corretamente? Em que nível você as classificaria?

( ) Sim

( ) Não

( ) Não se aplica

( ) Avaliação prejudicada 
71 - [Confiabilidade]: O aplicativo esteve disponível (ininterruptamente) durante a avaliação?
( ) Sim
( ) Não
( ) Não se aplica
( ) Avaliação prejudicada

72 - [Confiabilidade]: O aplicativo permite salvar pontos de backup ou faz isso automaticamente, evitando assim a perda de dados?
( ) $\operatorname{Sim}$
( ) Não
( ) Não se aplica
( ) Avaliação prejudicada

73 - [Confiabilidade]: Ao realizar a transferência de dados o aplicativo é tolerante a falhas?
( ) $\operatorname{Sim}$
( ) Não
( ) Não se aplica
( ) Avaliação prejudicada

74 - [Confiabilidade]: Em caso de falha, o aplicativo permaneceu em funcionamento evitando sua finalização ou bloqueio?
( ) $\operatorname{Sim}$
( ) Não
( ) Não se aplica
( ) Avaliação prejudicada

75 - [Segurança]: O acesso às informações e serviços é concedido somente a usuários credenciados?
( ) Sim
( ) Não
( ) Não se aplica
( ) Avaliação prejudicada

76 - [Segurança]: As contas dos usuários apresentam privilégios bem definidos, com vários níveis de acesso (administrador, usuários, convidados, entre outros)? 
( ) $\mathrm{Sim}$

( ) Não

( ) Não se aplica

( ) Avaliação prejudicada

77 - [Segurança]: O aplicativo faz uma contagem e bloqueio em relação à quantidade de vezes que o usuário tentou se logar e não conseguiu? O bloqueio pode ser feito, por exemplo, por meio de travamento da seção com liberação mediante a um administrador, permissão de nova tentativa depois de um determinado período, entre outros.

( ) $\mathrm{Sim}$

( ) Não

( ) Não se aplica

( ) Avaliação prejudicada

78 - [Segurança]: Ao cadastrar uma senha, o usuário é informado sobre o quão segura ela é?

( ) Sim

( ) Não

( ) Não se aplica

( ) Avaliação prejudicada

79 - [Segurança]: O aplicativo possui mecanismos para inibir a criação de usuários falsos?

( ) $\operatorname{Sim}$

( ) Não

( ) Não se aplica

( ) Avaliação prejudicada

80 - [Segurança]: Como pode ser classificada a proteção dos usuários contra ameaças como vírus, malwares, trojans, entre outros, quando ocorre a troca de informações ou arquivos entre os usuários?

Ineficiente ( ) ( ) ( ) ( ) ( ) Eficiente

$\begin{array}{lllll}1 & 2 & 3 & 4 & 5\end{array}$

( ) Não se aplica

( ) Avaliação prejudicada

81 - [Segurança]: O aplicativo registra as ações do usuário durante a sua utilização, per- 
mitindo assim a rastreabilidade?

( ) Sim

( ) Não

( ) Não se aplica

( ) Avaliação prejudicada

82 - [Portabilidade]: Como o aplicativo se comporta sendo executado e acessado em diferentes tipos de dispositivos móveis?

Ineficiente ( ) ( ) ( ) ( ) ( ) Eficiente

$\begin{array}{lllll}1 & 2 & 3 & 4 & 5\end{array}$

( ) Não se aplica

( ) Avaliação prejudicada

83 - [Portabilidade]: Como pode ser classificada a utilização do aplicativo em diferentes sistemas operacionais?

Ineficiente ( ) ( ) ( ) ( ) ( ) Eficiente

$\begin{array}{lllll}1 & 2 & 3 & 4 & 5\end{array}$

( ) Não se aplica

( ) Avaliação prejudicada

84 - [Portabilidade]: Como pode ser classificada a facilidade de instalação do aplicativo em todos os dispositivos especificados?

Ineficiente ( ) ( ) ( ) ( ) ( ) Eficiente

$\begin{array}{lllll}1 & 2 & 3 & 4 & 5\end{array}$

( ) Não se aplica

( ) Avaliação prejudicada

85 - [Portabilidade]: Quando o aplicativo é instalado ou atualizado sua configuração é feita automaticamente?
( ) Sim
( ) Não
( ) Não se aplica
( ) Avaliação prejudicada 